\section{Serial verb constructions and covert coordinations in Edo - an analysis in Type Logical Grammar}

\author{
Ralf Naumann and Thomas Gamerschlag \\ Heinrich-Heine-Universität Düsseldorf
}

\begin{abstract}
Based on both syntactic and semantic criteria, Stewart (2001) and, following him, Baker and Stewart (1999), distinguish two types of serial verb constructions (SVC) and one type of covert coordination (CC) in Edo. In this article, we present an analysis of these constructions, using Type Logical Grammar (TLG) with an event-based semantic component. We choose as base logic the non-associative Lambek calculus augmented with two unary multiplicative connectives $(\mathrm{NL}(\diamond, \square))$. SVCs and CCs are interpreted as complex event structures. The complex predicates underlying these structures are derived from simple verbs by means of a constructor. SVCs and CCs differ in terms of which part of the complex event structure is denoted. For SVCs, this is the sum of all events in the structure whereas for a CC this is only the first event in the sequence. The two verbs in an SVC and a $\mathrm{CC}$ are treated asymmetrically by assuming that the first verb has an extended subcategorization frame. The additional argument is of type vp (possibly modally decorated). Constraints on word order and the realization of arguments are accounted for using structural rules like permutation and contraction. The application of these rules is enforced by making use of the unary connectives.
\end{abstract} Keywords: Type Logical Grammar, Edo, serial verb constructions, covert coordinations 


\section{SERIAL VERB GONSTRUGTIONS AND GOVERT GOORDINATIONS IN EDO}

A standard characterization of serial verb constructions (SVCs) is (1) (Aikhenvald 2006).

(1) An SVC is a sequence of two or more verbs with one subject and one value for tense and aspect in which the verbs are combined without overt coordination or subordination. Serial verb constructions describe what is conceptualized as a single event.

This criterion is necessary only because it is also satisfied by a similar yet distinct construction, the so-called covert coordination (CC). A common strategy to distinguish the two constructions is to use the criterion of argument sharing. For SVCs but not for CCs one has (2).

(2) In an SVC an internal argument is shared.

SVCs occur in every language belonging to the Kwa family (NigerCongo) like Edo, Yoruba or Igbo. They are also found in many creole languages which have a Kwa substrate, such as Haitian.

For Edo, Stewart (2001) and, following him, Baker and Stewart (1999) distinguish two types of SVCs and one type of CC. ${ }^{1}$ In (3) each construction is illustrated by an example and the name given to the construction by Stewart (2001). ${ }^{2}$ The examples below are taken from Baker and Stewart (1999:3).

(3) a. Òzó ghá gbè è̀é wù.

Ozo FUT hit goat die

'Ozo will strike the goat dead.'

RSVC

b. Òzó ghá gbè ẹ̀wé khiẹ̀n.

Ozo FUT hit goat sell

'Ozo will kill the goat and sell it.'

CSVC

\footnotetext{
${ }^{1}$ Baker and Stewart (2001) distinguish also a third type, a purposive SVC which will not be discussed in this article.

${ }^{2}$ In writing the Edo examples we follow Stewart (2001) and Baker and Stewart (1999) who use the standard Edo orthography (see e.g. Agheyisi 1986), adding markings of high tone (á), low tone (à) and downstep (!).
} 
c. Òzó ghá gbè èwé khiẹ̀n ùhùnmwùn érẹ̀n.

Ozo FUT hit goat sell head its

'Ozo will kill the goat and sell its head.'

CC

This classification is based both on syntactic and semantic criteria, such as the type of the verbs, the distributional and interpretatory patterns of adverbs and the argument identifications between the verbs.

\section{Patterns of argument identifications}

In a 'resultative serial verb construction' (RSVC), $\mathrm{V}_{1}$ is either transitive or intransitive whereas $\mathrm{V}_{2}$ is either a stative, unaccusative or transitive verb with an unaccusative variant like 'lala' (enter). ${ }^{3}$ If $\mathrm{V}_{2}$ is stative, $\mathrm{V}_{1}$ is transitive. The examples below are taken from Stewart (2001).

(4) a. Òzó kòkó Àdésúwà mòsé.

Ozo raise Adesuwa be-beautiful

'Ozo raised Adesuwa to be beautiful.' tr. + stative

Stewart (2001:12)

b. Òzó sùá Úyi dé.

Ozo push Uyi fall

'Ozo pushed Uyi down.' tr. + unacc.

Stewart (2001:8)

c. Òzó dé wú.

Ozo fall die

'Ozo fell to death.'

unacc. + unacc.

Stewart (2001:15)

d. Òzó sàán kpàá.

Ozo jump leave

'Ozo jumped out.'

unerg. + unacc.

Stewart (2001:15)

e. Òzó gbé ẹ̀khù làá òwá.

Ozo hit door enter house

'Ozo hit the door into the house.' tr. + tr.

Stewart (2001:145)

\footnotetext{
${ }^{3}$ Thus, combinations of a transitive/intransitive $V_{1}$ with an unergative $V_{2}$ are excluded.
} 
In an RSVC with a transitive $\mathrm{V}_{1}$ and an intransitive $\mathrm{V}_{2}$, the only argument of $\mathrm{V}_{2}$ is identified with the object argument of $\mathrm{V}_{1}$. (4a) can only mean that Adesuwa is beautiful as a result of the raising. The interpretation that Ozo became beautiful as a consequence of his raising Adesuwa is not possible. In intransitive-unaccusative pairs, both arguments are identified with each other and in the rare pattern of two transitive verbs, the direct object of $V_{1}$ is identified with the subject of $\mathrm{V}_{2}$.

In a 'consequential serial verb construction' (CSVC), the verbs are either transitive or ditransitive. The subjects and direct objects are always identified with each other. By contrast, the indirect object of a ditransitive verb is never identified with any argument of the other verb. In particular, the indirect objects are not identified if both verbs are ditransitive.

a. Òzó lé èvbàré ré.

Ozo cook food eat

'Ozo cooked food and ate it.'

Stewart (2001:60)

b. Òzó rhié íghó hàé Úyi

Ozo take money pay Uyi

'Ozo took some money and paid Uyi it.'

Baker and Stewart (2001:27)

c. Úyi hàe İsộkẹ̀n íghó dó-rhié

Uyi pay Isoken money steal

'Uyi paid Isoken the money and stole it.'

Stewart (2001:137)

d. Òzó vbọ́ ọ̀khọ́khọ̀ ìgàn rhié nè Úyi.

Ozo pluck chicken feather give to Uyi

'Ozo plucked the chicken of its feathers and gave them to Uyi.'

Baker and Stewart (1999:35)

The possible argument patterns for the two types of SVCs are summarized in (6).

(6)

$$
\begin{array}{ll}
\text { RSVC } & \text { CSVC } \\
\mathrm{V}_{1}(\mathrm{x})+\mathrm{V}_{2}(\mathrm{x}) & \mathrm{V}_{1}(\mathrm{x}, \mathrm{y})+\mathrm{V}_{2}(\mathrm{x}, \mathrm{y}) \\
\mathrm{V}_{1}(\mathrm{x}, \mathrm{y})+\mathrm{V}_{2}(\mathrm{y}) & \mathrm{V}_{1}(\mathrm{x}, \mathrm{y})+\mathrm{V}_{2}(\mathrm{x}, \mathrm{y}, \mathrm{z}) ; \mathrm{V}_{1}(\mathrm{x}, \mathrm{y}, \mathrm{z})+\mathrm{V}_{2}(\mathrm{x}, \mathrm{y}) \\
\mathrm{V}_{1}(\mathrm{x}, \mathrm{y})+\mathrm{V}_{2}(\mathrm{y}, \mathrm{z}) & \mathrm{V}_{1}\left(\mathrm{x}, \mathrm{y}, \mathrm{z}_{1}\right)+\mathrm{V}_{2}\left(\mathrm{x}, \mathrm{y}, \mathrm{z}_{2}\right)
\end{array}
$$


In a CC only the subject arguments are identified whereas the object arguments do not have to be coreferential.

a. Àbiẹ́!yúwà hî́n èrhán kpàán àlìmó.

Abieyuwa climb tree pluck orange

'Abieyuwa climbed the tree and plucked an orange.'

Stewart (2001:4)

b. Òzó gbé èkhù lá òwá.

Ozo hit door enter house

'Ozo hit the door and [he] entered the house.'

Stewart (2001:89)

Despite the fact that the subjects are always identified, it is not possible to have a subject pronoun before $\mathrm{V}_{2}$ in a CSVC, see the example in (8a). Similarly, a subject pronoun before $V_{2}$ in an RSVC is not admissible although the subject of $\mathrm{V}_{2}$ is identified with the object argument of $\mathrm{V}_{1}$ (8b) (examples from Stewart 2001:64)
a. "Òzó ${ }_{k}$ mú èmà Ọ $_{k}$ kpèé.
Ozo carry drum he beat
b. Òzó kòkó Àdésúwà ${ }_{k}$ Ọ $_{k}$ mòsé.
Ozo raise Adesuwa she be_beautiful

This restriction does not hold for a CC. It is possible to have a subject pronoun before $\mathrm{V}_{2}$, provided it is coreferential with $\mathrm{NP}_{1}$.
Òzó $k$ gbọoọ́ ívìn
Ó $k$ bóló ộkà.

Ozo plant coconut he peel corn

'Ozo planted coconut and [he] peeled the corn.'

Stewart (2001:65)

If in a CC the object arguments are coreferential, there is a pronoun after $\mathrm{V}_{2}$ that is anaphoric to $\mathrm{NP}_{2}$.

$$
\begin{aligned}
& \text { Òzó }_{k} \text { lé ízè̀ } \text { Q̣́ }_{k} \text { rrí ọ́è̀ } \\
& \text { Ozo cook rice he eat it } \\
& \text { 'Ozo cooked rice and he ate it.' } \\
& \text { Stewart (2001:64) }
\end{aligned}
$$

Though the object arguments are always identified with each other in a CSVC, it is not possible to have either an NP or a pronoun coreferential with $\mathrm{NP}_{2}$ after $\mathrm{V}_{2}$. (11) cannot be interpreted as a CSVC but only as a CC. 
*Òzó lé ízẹ̀ rrí ợrè

Ozo cook rice eat it

if interpreted as a CSVC, possible as a CC

Stewart (2001:61)

From what has been said one arrives at the syntactic patterns of RSVCs and CSVCs in (12).

$\begin{array}{ll}\text { RSVC } & \\ \text { tr. + unacc./stat. } & \mathrm{NP}_{1} \mathrm{~V}_{1} \mathrm{NP}_{2} \mathrm{~V}_{2} \\ \text { intr. + unacc. } & \mathrm{NP}_{1} \mathrm{~V}_{1} \mathrm{~V}_{2} \\ \text { tr. + tr. } & \mathrm{NP}_{1} \mathrm{~V}_{1} \mathrm{NP}_{2} \mathrm{~V}_{2} \mathrm{NP}_{3} \\ \text { CSVC } & \\ \text { tr. + tr. } & \mathrm{NP}_{1} \mathrm{~V}_{1} \mathrm{NP}_{2} \mathrm{~V}_{2} \\ \text { tr. + ditr. } & \mathrm{NP}_{1} \mathrm{~V}_{1} \mathrm{NP}_{2} \mathrm{~V}_{2} \mathrm{NP}_{3} \\ \text { ditr. + tr. } & \mathrm{NP}_{1} \mathrm{~V}_{1} \mathrm{NP}_{2} \mathrm{NP}_{3} \mathrm{~V}_{2} \\ \text { ditr. + ditr. } & \mathrm{NP}_{1} \mathrm{~V}_{1} \mathrm{NP}_{2} \mathrm{NP}_{3} \mathrm{~V}_{2} \mathrm{NP}_{4}\end{array}$

A last criterion that is relevant for an analysis of SVCs and CCs is the distribution of manner adverbs. Adverbs like 'giegie' (quickly) occur to the left of the verb and to the right of the subject and possible tense/aspect markers. They cannot occur in sentence-final position, i.e. either after the verb (intransitive verb) or the direct object (transitive verb). ${ }^{4,5}$

$$
\begin{aligned}
& \text { Òzó ghá giẹ́!giẹ́ kó!kó ọ̀gọ́ ('giẹ́!giẹ́). } \\
& \text { Ozo FUT quickly gather bottle (“quickly) } \\
& \text { 'Ozo will quickly gather the bottles.' } \\
& \text { Stewart (2001:21) }
\end{aligned}
$$

\footnotetext{
${ }^{4}$ Stewart (2001) as well as Baker and Stewart (1999) discuss a second type of manner adverbs the distribution of which differs from that of the adverbs discussed in the text. See Stewart (1996) for a discussion and analysis of this second class of manner adverbs.

${ }^{5}$ We have added the adverb in the ungrammatical position to the original example by Stewart following his observation and similar examples given by him.
} 
A manner adverb like 'giegie' can be separated from the verb by a frequency adverb like 'ghá' (repeatedly) as in (14).

(14) Òzó ghá giệ!giệ ghá kó!kó ọ̀gộ.

Ozo FUT quickly ITER gather bottle

'Ozo will quickly gather the bottles repeatedly.'

Stewart (2001:21)

The schematic representation of a simple sentence is given in (15) $(\mathrm{T} / \mathrm{A}=$ tense/aspect; F-Adv $=$ frequency adverb).

(15) simple sentence

$\mathrm{NP}_{1}$ (T/A) (M-Adv) (F-Adv) V $\left(\mathrm{NP}_{2}\right)\left(\mathrm{NP}_{3}\right)$

For manner adverbs like 'giegie', in an RSVC the only position admissible is the one which corresponds to the position that is also admissible in a simple sentence. By contrast, CSVCs and CCs license two positions for these adverbs. Besides the position that is admissible in a simple sentence, the adverbs can also occur before the second verb. An analogous argument applies to frequency adverbs like 'ghá'. The distribution of manner adverbs like 'giegie' is shown below.

(16) RSVC

a. Òzó giẹ́!giệ ghá sú!á ọ̀gọ́ dé.

Ozo quickly ITER push bottle fall

'Ozo quickly pushed the bottles down repeatedly.'

Stewart (2001:24)

b. Òzó sùá ọ̀gọ́ ("giệ!giệ) dé.

Ozo push bottle (*quickly) fall

Stewart (2001:26)

(17) CSVC

a. Òzó giệ!giẹ́ dún!mwún èmà khiện!nẹe.

Ozo quickly pound yam sell.PL

'Ozo quickly pounded the yams and sold them.'

Stewart (2001:24)

b. Òzó dùnmwún èmà giẹ́!giẹ khiẹ́n.

Ozo pound yam quickly sell

'Ozo pounded the yam and quickly sold it.'

Stewart (2001:29) 
(18)

CC

a. Òzó giẹégiẹe gbọ́!ộ ívìn bòló ợkà.

Ozo quickly plant coconut peel corn

'Ozo quickly planted the coconut and [he] peeled the corn.'

Stewart (2001:24)

b. Òzó gbọoọ ívìn giẹ́!giẹ bó!ló ộkà.

Ozo plant coconut quickly peel corn

'Ozo planted the coconut and [he] quickly peeled the corn.'

Stewart (2001:29)

The distributional pattern of manner adverbs is summarized below.

position 1: $\mathrm{NP}_{1}$ (T/A) Adv $\mathrm{V}_{1}\left(\mathrm{NP}_{2}\right)\left(\mathrm{NP}_{3}\right) \mathrm{V}_{2}\left(\mathrm{NP}_{4}\right)$

position 2: $\mathrm{NP}_{1}(\mathrm{~T} / \mathrm{A}) \mathrm{V}_{1}\left(\mathrm{NP}_{2}\right)\left(\mathrm{NP}_{3}\right) \operatorname{Adv} \mathrm{V}_{2}\left(\mathrm{NP}_{4}\right)$

\begin{tabular}{|l|c|c|}
\hline position & 1 & 2 \\
\hline RSVC & yes & no \\
\hline CSVC & yes & yes \\
\hline CC & yes & yes \\
\hline
\end{tabular}

In an RSVC a causal relation is expressed. The first verb expresses the cause and the second verb the effect. For example, in (19), taken from Stewart (2001:13) the falling of Uyi is an effect that is triggered by the pushing, which, therefore, functions as the cause of the falling event.

Òzó sùá Úyi dé.

Ozo push Uyi fall

'Ozo pushed Uyi down.'

tr. + unacc.

In contrast to RSVCs, CSVCs and CCs do not express a causal relation. In a CSVC the relation between the two verbs is that of a consequence. The two events are ordered in the sense that the beginning point of the second event weakly succeeds the end point of the first event. In addition, $e_{1}$ is executed by the agent in order to be able to execute $e_{2}$, i.e. $e_{1}$ is done by the agent with the eventual execution of $e_{2}$ in mind so that he can be said to follow a plan. Consider the example in (20). 
(20)
Òzó lé èvbàré ré.
Ozo cook food eat
'Ozo cooked food and ate it.'
Stewart (2001:60)

This sentence has the interpretation that Ozo cooked the rice with the intention to eat it afterwards, and, in effect, ate it. Thus, the cooking is a kind of a prerequisite for the eating so that the former is done on purpose to facilitate bringing about an event denoted by the second verb. As noted by Stewart (2001:80), the interpretation according to which Ozo had cooked the food with no intention in mind or with the intention of selling it afterwards but changed his mind later are both impossible. By contrast, no corresponding restriction on the interpretation exists for a CC. For instance, for the CC in (21), which directly corresponds to the CSVC in (20), all three interpretations are possible.

$$
\begin{aligned}
& \text { Òzó }_{k} \text { lé ízè̀j } \text { Ọ }_{k} \text { rrí ộrè } \\
& \text { Ozo cook rice he eat it } \\
& \text { 'Ozo cooked rice and he ate it.' }
\end{aligned}
$$

Stewart (2001:64)

(21) is true in a situation in which Ozo cooked the rice with the intention to eat it and in effect ate it, in a situation where the cooking was done with no particular intention as to how to use the cooked rice but was followed by eating it, and in a situation where the cooking was done with a particular intention in mind that was not to eat it afterwards, followed by a change of mind and eating the cooked rice.

Semantic interpretation of SVCs and CCs with manner adverbs

A manner adverb in position 1 of a CC has scope only over $V_{1}$. For example, sentence (22) means that the planting of the coconuts was quick. No corresponding assertion is made about the relative duration of the peeling of the corn. It could have been done quickly or not.

CC

Òzó giệ!giẹe gbọ̣!ộ ívìn bòló ộkà.

Ozo quickly plant coconut peel corn

'Ozo quickly planted the coconut and [he] peeled the corn.' Stewart (2001:24) 
By contrast, a manner adverb in position 1 of either an RSVC or a CSVC is interpreted as modifying both verbs. (23a) is true only if both pushing and falling were quick. (23b) gets the interpretation that the whole process of pounding-plus-selling the yams was quick (compared to other pounding-plus-sellings). It says nothing about how long the pounding and selling phases take separately, compared to each other or to simple poundings and sellings (Baker and Stewart 1999:16).

SVC

a. Òzó giẹ́!giẹ́ ghá sú!á ọ̀gọ́ dé.

Ozo quickly ITER push bottle fall

'Ozo quickly pushed the bottle down repeatedly.'

(Stewart 2001:24)

b. Òzó giệ!giẹ́ dún!mwún èmà khiện!nẹe.

Ozo quickly pound yam sell.PL

'Ozo quickly pounded the yams and sold them.'

Stewart (2001:24)

If the manner adverb occurs in position 2 , only $V_{2}$ is modified both for a CSVC and a CC. For (24a) to be true, the selling had to be quick whereas there is no condition on the relative duration of the pounding. Analogously, (24b) says that the peeling of the corn was done quickly but no corresponding claim is made about the planting of the coconuts.

(24) CSVC and CC position 2

a. Òzó dùnmwún èmà giẹ́!giẹe khiẹ́n.

Ozo pound yam quickly sell

'Ozo pounded the yam and quickly sold it.'

Stewart (2001:29)

b. Òzó gbọoọ ívìn giẹ́!giẹ bó!ló ộkà.

Ozo plant coconut quickly peel corn

'Ozo planted the coconut and [he] quickly peeled the corn.'

Stewart (2001:29)

From the discussion in this section one arrives at the following agenda of problems that have to be addressed. 
(i) How can two (or more) verbs combine with each other if that combination is realized by neither overt coordination nor overt subordination?

(ii) How can the difference between a CSVC and a CC with respect to object realization be explained? More precisely, how can we account for the fact that the object argument of a CSCV cannot be overtly realized while it can be in a CC, for example by an NP or a pronoun?

(iii) How can the distributional pattern of manner adverbs like 'giegie' be explained?

(iv) How can the semantic differences between SVCs and CCs be explained?

The answers to these questions are based on the semantic interpretation of SVCs and CCs. We assume an event-based NeoDavidsonian framework in which each verb has an additional event argument. The basic idea behind the interpretation of SVCs and CCs is that they are the result of extending an event structure made up by a single event predicate to a more complex structure with two (or possibly more) event predicates in which the events are linked by a particular relation, e.g. a causal one as in an RSVC. Such complex event structures are built by means of special constructors that operate on (the denotation of) projections of verbs. The general scheme for two transitive verbs is given in (25).

$$
\begin{aligned}
& \lambda V_{1} \cdot \lambda V P_{2} . \lambda y . \lambda x \cdot \lambda e . \exists e_{1} \cdot \exists e_{2} \\
& {\left[V_{1}(y)(x)\left(e_{1}\right) \wedge V P_{2}(x)\left(e_{2}\right) \wedge\right.} \\
& \left.\arg -p a t t e r n\left(e_{1}, e_{2}, x, y\right) \wedge \text { relation }\left(e, e_{1}, e_{2}\right)\right] .
\end{aligned}
$$

In (25) arg-pattern $\left(e_{1}, e_{2}, x, y\right)$ determines which arguments are shared; relation $\left(e, e_{1}, e_{2}\right)$ specifies the relation between the three events. If (25) is applied to a verb in the lexicon that can be the first verb in an SVC or a CC, one gets a complex verb which has an additional argument corresponding to the VP which specifies the sort of the event by which the event structure underlying the first verb is extended. Hence, our answer to the first question is that verbs in the lexicon can be lifted to complex predicates. Our answer to question (iv) is based on the way the events $e, e_{1}$ and $e_{2}$ are linked by relation $\left(e, e_{1}, e_{2}\right)$. In an SVC, $e$ always is the join of $e_{1}$ and $e_{2}$. As an 
effect, manner adverbs in position 1 are interpreted relative to this complex event, yielding the interpretation that the whole action sequence has the property expressed by the adverb. By contrast, in a CC $e$ is $e_{1}$ so that only this latter event gets modified, again in accordance with the data. Details will be given in Section 2.

Verbs in Edo that can occur as the first verb in an SVC and a CC have two different, though related subcategorization frames. The first one is the default frame assumed for canonical verbs in an SVO language. This default frame is extended by an argument of syntactic type VP if this verb occurs as the first verb in an SVC or a CC. This additional argument is looked for to the right and is the first on the subcategorization list. Proceeding in this way raises the following, further question that has to be added to the agenda.

(v) Since the order in which the arguments of an extended verb are discharged does not coincide with the linear order in which the arguments occur in an SVC, how can the latter order be accounted for?

Questions (ii) and (v) will be answered by assuming that the logic contains a permutation and a contraction rule. This strategy is outlined in Section 3 and fully developed in Section 4. The third question will be answered by using modal decorations. This strategy makes it possible to distinguish between expressions of type A and those of type $\odot$ A, where $\odot$ is a sequence of modal operators. If modification with an adverb requires the modified expression to be of type $A$, the second verb in an RSVC will only project expressions of type $\odot A$ (and not of type A), whereas first verbs will have projections of the licensing type A.

The rest of the article is organized as follows. In Section 2, we introduce the semantic analysis of SVCs and CCs in Edo. Section 3 explains the basic ideas underlying the syntactic derivations of SVCs and CCs. Sections 4.1-4.3 show how the (syntactic) VP constituent in SVCs and CCs is derived. In Section 4.4, a structural rule for the subject argument is provided. In addition, the derivational semantics for CSVCs and CCs with two transitive verbs is given using examples from Section 1. In the following two sections, simple sentences with transitive verbs (Section 4.5) and simple sentences and CCs with intransitive verbs are derived (Section 4.6). Section 4.7 derives RSVCs and in Sec- 
tion 4.8 we turn to the derivation of CSVCs with ditransitive verbs. In Section 4.9, we sketch the analysis of manner adverbs. In Section 5, we compare our theory to those of Baker \& Stewart and Ogie.

Any semantic interpretation of SVCs and CCs in Edo has to take into account (i) the meaning relation between the two event predicates, and (ii) the interpretation at the level of event structure these constructions get when they are modified by a manner adverb: an adverb in an SVC can semantically have scope over both verbs in the sense that it is the joint action made up by the action expressed by $V_{1}$ and the action expressed by $V_{2}$ that is required to have the property expressed by the adverb. By contrast, in a CC a manner adverb in position $1 \mathrm{im}-$ poses a condition only on the action expressed by the first verb and not on the joint action.

The starting point of our analysis is the most prominent semantic characterization of SVCs: they refer to 'single' or 'macro' events. For example, as already cited in (1) and repeated in (26), Aikhenvald (2006:1) defines SVCs as follows.

$$
\begin{aligned}
& \text { A serial verb construction (SVC) is a sequence of verbs which } \\
& \text { act together as a single predicate without any overt marker of } \\
& \text { coordination, subordination or syntactic dependency of any } \\
& \text { sort. Serial verb constructions describe what is conceptualized } \\
& \text { as a single event. }
\end{aligned}
$$

Other authors using this semantic characterization include Stewart (2001), Baker and Stewart (1999) and Dixon (2006). One problem with this definition is that the notion of a single or a macro event needs to be made precise. Consider first the example in (27) from Yimas, a Papuan language of new Guinea, taken from Foley (2010:81). ${ }^{6}$

${ }^{6}$ OBL: oblique; VIII: noun class 8; SG: singular; O: other argument; A: agentlike participant; SEQ: sequential. 
(27)

a. arm-n kay

water-OBL canoe-VIII-SG

i-ka-ak-mpi-wul.

VIII-SG-O-1SG-A-push-SEQ-put-in

'I pushed the canoe down into the water.'

This sentence is an SVC since it is monoclausal and the pronominal agreement affixes must precede the sequence of verbs. ${ }^{7}$ However, Foley argues that 'ak-mpi-wul' (push down into [the water]) does not denote a single event. It rather refers to 'one (or more commonly, multiple) actor(s) causing a canoe to move linearly along the ground away from the high ground of the riverbank toward the lower level of the river itself, so that it descends down the edge of the riverbank and comes to float on the water of the river', Foley (2010). One may counter this argument by requiring that by a 'single' or a 'macro' event is not necessarily meant an atomic event but possibly a complex event that can have other events as material or mereological parts. This move, however, immediately raises the following problem discussed in Bohnemeyer et al. (2007). If one assumes that the domain of events is structured by a material part-of relation $\sqsubseteq$ and a sum operation $\sqcup$ in the sense of Link (1998), and given that the interpretation of an expression requires the existence of $n$ events $e_{1}, \ldots, e_{n}$, then there always exists the sum event $e=e_{1} \sqcup \ldots \sqcup e_{n}$. Bohnemeyer et al. (2007:500) illustrate this problem with the following minimal pair taken from English and Ewe, a Gbe language of the Kwa family within Niger-Congo that is spoken in Ghana and Togo. ${ }^{8}$

(28) The circle rolled from the blue square past the house-shaped object to the green triangle.

(29) Circle lá mli tsó bluto gbó le mó-á dzí tó circle DEF roll from blue place LOC road-DEF top pass

xo-a yú yi dé triangle lá gbó.

house-DEF skin go ALL triangle DEF place

'The circle rolls from the blue place on the road, passes the side of the house, goes to the triangle.'

${ }^{7}$ Foley (1991) argues that it is in effect a single grammatical word.

${ }^{8}$ In the examples below one has: DEF: definite; LOC: locative; ALL: allative. 
Whereas in English a single VP is sufficient, Ewe requires three. Does this mean that in English only a single, though complex, event is described whereas in Ewe three events are described? Given a domain of events structured by a part-of and a sum operation, there always is a sum of three events in addition to the three events of rolling, passing and going-to so it is always possible to claim that the whole clause in (29) is interpreted relative to this sum. As a result, both options are at least theoretically possible. One attempt at solving this problem is to assume that if a clause contains $n$ event predicates, each predicate is interpreted relative to the sum of the $n$ events. For (29), this amounts to interpreting each of the three event predicates relative to the sum event consisting of a rolling, a passing and a going-to event. However, this strategy fails for the following reason. An atomic event predicate $P$ is always interpreted relative to (sums of) events of the same sort, e.g. a rolling or a passing but not relative to 'heterogeneous' events, for example sums of rollings and/or passings. From this it follows that each event predicate in a clause has to be interpreted relative to a (sum) event that is the join of events of the same sort. For example, in the Ewe example above 'mli' (roll) has to be interpreted relative to (sums of) rolling events, 'tó' (pass) has to be interpreted relative to (sums of) passing events, and 'yi' (go) has to be interpreted relative to (sums of) going (to) events. Hence, in order to be true, any clause containing $n$ event predicates requires the existence of $n$ 'homogeneous' events in relation to which the $n$ predicates are interpreted. Using a structured domain of events, this existence implies the existence of a corresponding sum event which consists of $\mathrm{n}$ homogeneous events. Since these $n$ events belong to different sorts, this sum is heterogeneous.

The above discussion tried to locate the difference between SVCs and other multi-verb constructions at the ontological level, i.e. at the level of real-world events. In contrast to this failed strategy, Bohnemeyer et al. propose to locate this distinction at the level of constructions. Specifically, they take this difference to be located at the level of the form-to-meaning property of event descriptions. They define this property, the macro event property (MEP), by reference to temporal operators: 
DEFINITION 1 Let expression $C$ denote an event predicate $P(\llbracket C \rrbracket=$ $\exists e . P(e))$. Let $T_{P O S}$ be any modifier of $C\left(\left[\ldots T_{P O S} \ldots\right]_{C}\right)$ that locates some subevent $e^{\prime} \sqsubseteq e$ at time $t\left(\llbracket T_{P O S} \rrbracket=\lambda Q . \lambda t . \exists e^{\prime}\left[Q\left(e^{\prime}\right) \wedge \tau\left(e^{\prime}\right) \subseteq t\right]\right.$, where $Q$ may or may not be identical to $P$ ). Then $C$ has the macro-event property (MEP) iff any syntactically and semantically acceptable $T_{P O S}$ necessarily also locates $e$ at $t$ (i.e. $A T\left(Q, e^{\prime}, t\right) \rightarrow A T(P, e, t)$ for any acceptable $T_{P O S}$ and $A T:=\lambda P . \lambda t . \exists e(P(e) \wedge \tau(e) \subseteq t))$.

Intuitively, an expression or construction has the MEP if it licenses only temporal operators that have scope over all subevents, (Bohnemeyer et al. 2007:507). Note that the MEP does not make any assertion about the kinds of events a construction having the MEP can refer to. In particular, no ontological type of 'macro-event' is singled out or presupposed that can be distinguished from other, non-macro events. The English example in (28) trivially has the MEP because there is only one event predicate in the VP. For the Ewe example in (29) the MEP follows from the fact that any time-positional operator must have scope over all three VPs. Modifying all three VPs separately with a time adverbial leads to ungrammaticality, see (30) taken from Bohnemeyer et al. (2007:506).

$$
\begin{aligned}
& \text { *Circle lá mli tsó bluto gbó le mó-a dzí le ga } \\
& \text { circle DEF roll from blue place LOC road-DEF top at hour } \\
& \text { enyí me tó xo-a yú le ga asiéke me yi dé } \\
& \text { eight in pass house-DEF skin at hour nine in go ALL } \\
& \text { triangle lá gbó le ga ewó me. } \\
& \text { triangle DEF place at hour ten in } \\
& \text { Intended: 'The circle rolls from the blue place on the road at } \\
& \text { eight o'clock, passes the side of the house at nine 'clock, goes } \\
& \text { to the triangle at ten o'clock.' }
\end{aligned}
$$

Bohnemeyer et al. (2007) discuss an additional example from English (The sentences in (31)-(34) are taken from Bohnemeyer et al. 2007).

Floyd went from Rochester via Batavia to Buffalo in the morning.

In (31) 'in the morning' modifies the whole motion event including the departure, the passing and the arriving. The time adverbial used must be of the appropriate sort. Since (31) refers to an event with an extended run-time, adverbials denoting a time point are excluded. 


$$
\begin{aligned}
& \text { ?Floyd went from Rochester via Batavia to Buffalo at seven/ } \\
& \text { eight-thirty. }
\end{aligned}
$$

Trying to 'time' the corresponding phases leads to ungrammaticality, see (33).

*Floyd went from Rochester at seven via Batavia at seven forty-five to Buffalo at eight thirty.

If one wants to modify the three phases separately, one has to use different verbs for the departure, the passing and the arrival as in (34).

(34) Floyd left Rochester at seven, passed through Batavia at seven forty-five, and arrived at Buffalo at eight thirty.

As it stands, the MEP only applies to temporal modifiers. Foley (2010) generalizes the MEP to other kinds of modifiers. According to him, the MEP requires that temporal operators, adjuncts, adverbial clauses and tense affixes have scope over all component sub-events that are denoted by event predicates in the construction. How can this modification be incorporated into an event-based framework? Foley's generalization shows that the MEP can be applied to various properties of events like their run-time or the speed with which they are executed. In a standard event semantics such properties are uniformly interpreted as sets of events, similarly to sortal distinctions like poundings and sellings. We have to leave open the question to which dimensions in a particular language the MEP can apply. For Edo, one dimension is that of speed for which the adverb 'giegie' specifies a particular value. A second important question that has to be left open is: is it possible that two modifiers differ with regard to the MEP in the sense that one imposes the MEP whereas the other does not?

The MEP in Edo

In this section we will adapt the results of the discussion in the previous section to Edo. In Bohnemeyer et al.'s account the mapping is guided by the interpretation of temporal operators. If such an operator has scope over all event predicates, the whole construction has the MEP. Applied to Edo, a weakness of this analysis is that it is not related to the semantic interpretation of the whole construction in the 
sense that no reference is made to the meaning relation that holds between the event predicates in the construction. In contrast to this way of defining the MEP, we will base our analysis on the semantic relation expressed by SVCs and CCs. Recall that both in an RSVC and a CSVC the two events are not only related at the temporal level by a weakly succession relation but there is an additional non-temporal relation that holds between the two events: a causal relation in the case of an RSVC and a plan (intention) relation in the case of a CSVC. One way of looking at an SVC from this perspective is to analyze it as something built from a complex predicate constructor that maps two (or possibly more) event predicates to a complex predicate. This process is constrained both at the level of shared arguments (argument pattern) and at the level of how the events are related to each other. ${ }^{9}$ A scheme of such a constructor for two event predicates is given in (35).

$$
\begin{aligned}
& \lambda P_{1} . \lambda P_{2} \cdot \lambda y . \lambda x . \lambda e . \exists e_{1} \cdot \exists e_{2}\left[P_{1}\left(e_{1}\right) \wedge P_{2}\left(e_{2}\right)\right. \\
& \left.\wedge \arg \text { pattern }\left(e_{1}, e_{2}, x, y\right) \wedge \text { relation }\left(e, e_{1}, e_{2}\right)\right] .
\end{aligned}
$$

$P_{1}$ and $P_{2}$ are two event predicates that correspond to $V_{1}$ and $V_{2}$ in a complex predicate, respectively. arg-pattern and relation are parameters whose value depends on the type of the complex predicate (CSVC, RSVC or CC). $\arg$-pattern $\left(e_{1}, e_{2}, x, y\right)$ is the constraint on the argument pattern while relation $\left(e, e_{1}, e_{2}\right)$ is the constraint on the relation between the events. For example, for the CSVC in (20), arg-pattern identifies both the actors and the themes of the events related to $P_{1}$ and $P_{2} \cdot{ }^{10}$ The result is a complex predicate whose subcategorization frame is that of the (identical) subcategorization frames related to the two event predicates. For the relation between the events, in particular the definition of $\square_{x}$, see below for details.

$$
\begin{aligned}
& \lambda y . \lambda x . \lambda e . \exists e_{1} . \exists e_{2}\left[\operatorname{cook}\left(e_{1}\right) \wedge \text { eat }\left(e_{2}\right) \wedge \operatorname{actor}\left(e_{1}\right)=x=\right. \\
& \text { actor }\left(e_{2}\right) \wedge \operatorname{theme}\left(e_{1}\right)=y=\operatorname{theme}\left(e_{2}\right) \wedge e=e_{1} \sqcup e_{2} \wedge e_{1} \preceq \\
& \left.e_{2} \wedge \square_{x}\left(\operatorname{occur}\left(e_{1}\right) \rightarrow \operatorname{occur}\left(e_{2}\right)\right)\right] .
\end{aligned}
$$

\footnotetext{
${ }^{9}$ The use of the word 'constructor' must not be misunderstood as referring to some form of construction grammar. Rather, it refers to the fact discussed and explained below that it is an operation which builds a complex event structure out of a simple one.

${ }^{10}$ arg-pattern and relation will be discussed below.
} 
In (37) the case of the RSVC in (19) is given. In this case the argument pattern identifies the theme arguments of $e_{1}$ and $e_{2}$ whereas the actor of $e_{1}$ remains unrelated. relation requires the two events to be causally related (see below for details).

$$
\begin{aligned}
& \lambda y . \lambda x \cdot \lambda e \cdot \exists e_{1} \cdot \exists e_{2}\left[\operatorname{push}\left(e_{1}\right) \wedge \operatorname{fall}\left(e_{2}\right) \wedge \operatorname{actor}\left(e_{1}\right)=\right. \\
& \left.x \wedge \operatorname{theme}\left(e_{1}\right)=y=\operatorname{theme}\left(e_{2}\right) \wedge e=e_{1} \sqcup e_{2} \wedge \operatorname{cause}\left(e_{1}, e_{2}\right)\right] .
\end{aligned}
$$

The constructor in (35) applies only to cases where all arguments related to the second event predicate are shared with an argument related to the first event predicate. At first sight this might be problematic for SVCs in which not all arguments are shared because then non-shared arguments would have to be added as arguments to the resulting complex predicate, which empirically is not the case. Recall that non-shared arguments (related to the second event predicate) are allowed in a CSVC with two ditransitive verbs where the indirect objects must be different, in an RSVC with two transitive verbs and in a CC where no constraints are imposed on the direct objects. This lack of generality stems from the fact that both event predicates are taken on a par. Rather, one has to view the complex predicate constructor as a way to extend an event structure comprising only one event predicate to a more complex event structure that contains two (or possibly more) event predicates and in which the events are related by particular constraints. What gets extended is always the event predicate whose corresponding event is executed first in the resulting event structure. The second event structure is not arbitrary. For example, both in an SVC and a CC the actors are required to be the same. A similar generalization across constructions is not possible for direct and indirect arguments. These conditions have to be reflected at the syntactic level. Instead of $P_{2}$, the projection $V P_{2}$ of the corresponding verb $V_{2}$ has to be taken as an argument. Hence, $V_{2}$ is already partially saturated when it enters the constructor. Similarly, to make sure that the argument structure of the complex predicate is that of the first verb, we have to use $V_{1}$ instead of $P_{1}$. Argument sharing is then expressed in terms of constraints on the respective arguments. The result for two transitive verbs is the constructor (scheme) in (38).

$$
\begin{aligned}
& \lambda V_{1} \cdot \lambda V P_{2} \cdot \lambda x \cdot \lambda y \cdot \lambda e . \exists e_{1} \cdot \exists e_{2}\left[V_{1}(y)(x)\left(e_{1}\right) \wedge V P_{2}(x)\left(e_{2}\right) \wedge\right. \\
& \left.\operatorname{arg-pattern}\left(e_{1}, e_{2}, x, y\right) \wedge \text { relation }\left(e, e_{1}, e_{2}\right)\right] .
\end{aligned}
$$


Let us next turn to the relation between $e, e_{1}$ and $e_{2}$. Our central thesis is that in Edo this relation depends on the (semantic) relation that holds between $e_{1}$ and $e_{2}$.

(39) If the relation between $e_{1}$ and $e_{2}$ cannot be reduced to a purely temporal one, one has $e=e_{1} \sqcup e_{2}$, otherwise one gets $e=e_{1}$.

The rationale behind (39) is the following. The unextended verb corresponding to an extended one expresses only one action $\left(e_{1}\right)$ without taking into consideration what actions (events) can follow this first action. Extended verbs are one way of extending verbs expressing a single action to more complex sequences of actions. Hence, the cognitive significance of extending a single event predicate to a complex one is just to express this relation between the two events. This relation should therefore be reflected in the complex predicate by letting the abstracted event variable refer to the sum of the two events. By contrast, in a CC the two events are related only at the temporal level (but see below for a revised view). In this case the event input to the complex predicate is the first event similar to the case of the unextended verb form. The sum event is not needed for this temporal succession. Compare this with the sequencing operation $\alpha ; \beta$ : do first $\alpha$ and then $\beta$ where the two actions need only be related at the temporal level. Hence, in an SVC, $e$ has to be $e_{1} \sqcup e_{2}$. By contrast, in a $\mathrm{CC} e$ is $e_{1}$ because it is the first event in the sequence and there is no additional relation linking the two events except the temporal one.

Furthermore, the temporal relation between $e_{1}$ and $e_{2}$ in all three kinds of complex predicates is that of weakly succeeding, denoted by $\preceq: e \preceq e^{\prime}$, which holds if the beginning point of $e^{\prime}$ follows shortly after the end point of $e$. This condition requires that no other events involving the direct object occur between $e_{1}$ and $e_{2}$ which makes the occurrence of $e_{2}$ unlikely. For example, if Ozu killed the goat in order to sell it, he must not have eaten its meat afterwards because this makes selling it impossible. For a CC, the temporal relation is the only condition on the two events. For a CSVC, a second condition requires that the two events are part of a common plan. This condition is modelled by $\square_{x}\left(\operatorname{occur}\left(e_{1}\right) \rightarrow \operatorname{occur}\left(e_{2}\right)\right)$, which requires that in all worlds that are compatible with what the agent $x$ plans to do an occurrence of $e_{1}$ implies an occurrence of $e_{2}$. For an RSVC, the two events are related by the relation cause. 
So far we assumed that the thematic roles of shared arguments match. Since this assumption may turn out to be too strong, we will formulate the condition on the argument pattern in terms of a thematic role hierarchy relative to the subcategorization frame of the two verbs. Since extended verbs extend the first verb, the thematic roles of this verb are known so that the actual roles can be used. One possible thematic role hierarchy is given by Actor $>$ Goal/Source $>$ Theme (Grimshaw 1990). $\operatorname{TR}\left(e_{1}\right)=n$-th $\left(e_{2}\right)$ is true if the object assigned by the thematic role $T R$ to $e_{1}$ is identical to the object that is assigned to $e_{2}$ by the $n$-th thematic role in the thematic role hierarchy restricted to those roles that are defined in its subcategorization frame. Specifically, we assume the following patterns for two transitive verbs (CSVC and $\mathrm{CC}$ ) and an RSVC with a transitive first and an intransitive second verb.

- $\operatorname{CSVC}: \operatorname{actor}\left(e_{1}\right)=\operatorname{first}\left(e_{2}\right) \wedge$ theme $\left(e_{1}\right)=\operatorname{second}\left(e_{2}\right)$

- RSVC : theme $\left(e_{1}\right)=$ first $\left(e_{2}\right)$

- CC : $\operatorname{actor}\left(e_{1}\right)=$ first $\left(e_{2}\right)$

We are now finally ready to give the meanings of verbs in an SVC and a CC. There are two strategies as to how the meaning of verbs that occur as first verbs in an SVC or a CC can be derived on the basis of a constructor. In the first strategy one explicitly derives the meaning from a constructor by applying this constructor to the meaning of a verb in a simple sentence. Such an operation can be performed either in the lexicon or at some later stage, say, during the derivation of an SVC or a CC. In the second strategy these meanings are not derived by an operation but rather, the result of applying one of the constructors to the meaning of a verb is taken as an additional meaning of the verb. We choose the second strategy because it is in accordance with the lexicalist assumption underlying TLG. (See below for details on how the lexicon in Edo is structured in our approach). In (40), the meaning of a CSVC with two transitive verbs and in (41), the meaning of an RSVC with a transitive and an unaccusative verb are given. In both cases, $P_{1}$ is the actual verb, for example 'cook' in a CSVC or 'hit' in an RSVC. Since these verbs have an additional argument of type $V P$, they will be called 'extended verb (forms)'. 


$$
\begin{aligned}
& \lambda V P_{2} \cdot \lambda y \cdot \lambda x \cdot \lambda e . \exists e_{1} . \exists e_{2}\left[e=e_{1} \sqcup e_{2} \wedge P_{1}\left(e_{1}\right) \wedge V P_{2}(x)\left(e_{2}\right) \wedge\right. \\
& \text { actor }\left(e_{1}\right)=x=\operatorname{first}\left(e_{2}\right) \wedge \text { theme }\left(e_{1}\right)=y=\operatorname{second}\left(e_{2}\right) \wedge e_{1} \preceq \\
& \left.e_{2} \wedge \square_{x}\left(\operatorname{occur}\left(e_{1}\right) \rightarrow \operatorname{occur}\left(e_{2}\right)\right)\right] . \\
& \lambda V P_{2} . \lambda y . \lambda x . \lambda e . \exists e_{1} . \exists e_{2}\left[e=e_{1} \sqcup e_{2} \wedge P_{1}\left(e_{1}\right) \wedge V P_{2}(y)\left(e_{2}\right) \wedge\right. \\
& \text { theme } \left.\left(e_{1}\right)=y=\operatorname{first}\left(e_{2}\right) \wedge e_{1} \preceq e_{2} \wedge \operatorname{cause}\left(e_{1}, e_{2}\right)\right] .
\end{aligned}
$$

(42) presents the extended verb form for a CC with two transitive verbs. Similarly to the examples of CSVCs and RSVCs, $P_{1}$ is the actual verb, e.g. 'cook'.

$$
\begin{aligned}
& \lambda V P_{2} . \lambda x \cdot \lambda y \cdot \lambda e . \exists e_{1} . \exists e_{2}\left[e=e_{1} \wedge P_{1}\left(e_{1}\right) \wedge V P_{2}(x)\left(e_{2}\right) \wedge \operatorname{actor}\left(e_{1}\right)\right. \\
& \left.=x=\operatorname{actor}\left(e_{2}\right) \wedge e_{1} \preceq e_{2}\right] .
\end{aligned}
$$

The meanings of (first) verbs in complex predicates can be taken as a formal rendering of Foley's insight. SVCs are interpreted relative to macro events whose component events are used in the interpretation of the atomic event predicates out of which the complex predicate is built. Interpreting SVCs relative to complex (macro) events has been suggested before (see Bohnemeyer et al. 2007 for an overview). However, these proposals are mostly not formalized. In particular, the exact relation between the complex event and the events denoted by the component event predicates remains unspecified.

We base our analysis on the fact that an SVC denotes a complex event structure that is built from an atomic event structure in order to express a complex action based on plans or causal relations. In what sense does this interpretation apply to CCs? Or, to put it differently: what is the cognitive or semantic significance of a CC compared to a construction that is made up by two separate sentences? In order to answer this question one has to look at the discourse level. At this level a sequence of sentences need not only be free of semantic anomalies (and be true) but in addition it has to be coherent. This means that two sentences have to be related by a coherence relation like narration, background or result. Viewed from this perspective, the thesis is that a CC and likewise an SVC are devices to build-in a coherence relation between two (or more) event predicates. For a CC, the coherence relation is that of narration. The two events are related by the temporal relation of weak succession and the two events must have a common actor. Hence, the condition for narration is satisfied (Asher and Lascarides 2001). The relation to the notion 'Question under Discussion' 
is the following. Given a context $c$ with an event $e$ and objects $o_{1}, \ldots o_{n}$ participating in $e$, a set of implicit questions related to the event and the objects is raised. In order for a continuation of this context to cohere with this context at least one of these questions needs to be answered in the continuation. Examples of questions are 'What next?' at the event level and 'What about x?' at the level of objects. In SVCs in Edo, these questions are further restricted. First, the events must be related by a plan or a causal relation, and, second, the next sentence must involve the same actor and the same theme, i.e. it provides further information on both objects. Hence, SVCs do by the way they are constructed answer QuDs so that, in effect, the text is coherent. ${ }^{11}$

How do the meanings of verbs that occur as the first verb in a complex predicate relate to the lexicon? In TLG each lexical item is assigned a set of syntactic types. If this set is a singleton, the grammar is called rigid. If a lexical item is assigned more than one type, this reflects the fact that it can occur in different syntactic contexts with different types of arguments. An example in English is 'know' which can have an argument of type np ('know the answer') or a clauselike argument ('know that p'). Similarly, a verb in Edo is in general assigned more than one syntactic type. Which types are assigned to a verb depends on the way it can be used in SVCs and CCs. Since there are three constructions (RSVC, CSVC and CC), one gets a maximal number of four different types. The maximal number is obtained if a verb can occur as $V_{1}$ in all three constructions (three types) plus the type it is assigned in simple sentences and as $V_{2}$ in any of the three constructions. In practice, the number is smaller. For example, in an RSVC, $V_{1}$ cannot be ditransitive and in a CSVC intransitive verbs are excluded as $V_{1}$.

Let $\sigma$ (verb) be the set of syntactic types assigned to the verb verb. Each element of $\sigma(v e r b)$ is paired with a typed $\lambda$-term as the meaning of verb. In Edo, one $\lambda$-term corresponds to the case of a verb in a simple sentence or as $V_{i}$ with $i \geq 2$ in a complex predicate, if admissible. Other possible $\lambda$-terms result if one of the constructors is applied to the 'standard' $\lambda$-term as argument. Importantly, this application is not part of the lexicon, as already said above. Rather, only the result-

${ }^{11}$ See Naumann and Petersen (2019) for a formal theory of QuDs in a dynamic semantics with frames. 
ing $\lambda$-term is. Examples are (40), (41) and (42). We leave open the question whether it is desirable to view the lexicon in Edo in such a way that at first only the meanings of simple verb forms are given and the complex meanings are derived, if admissible, by applying lifts to the meanings of these simple forms.

Let us summarize the results of this section. Both SVCs and CCs are analyzed in terms of extended verbs that are taken to be the result of applying a complex predicate constructor to an (unextended) verb. This interpretation is driven by the fact that the semantic (or cognitive) function of these constructors is to express complex event structures. The events denoted by such structures are related by particular constraints like (i) 'What actions are successively executed by an actor?', (ii) plans that are made up by a series of consecutive actions, and (iii) causal relations. Common to both types of construction is a built-in coherence relation (narration).

\section{A GRAMMATICAL ARGHITEGTURE FOR EDO IN TYPE LOGIG GRAMMAR}

In this section, we will introduce the logical architecture to be used in our analysis of the Edo data presented in Section 1. The theoretical framework is a multimodal variant of the non-associative Lambek calcalus NL enriched with two unary connectives. ${ }^{12}$ For many linguistic applications, the operations available in NL are too restrictive to account for the variety of phenomena found in natural languages. For example, the only way to combine two linguistic resources consists in concatenating them, and in addition NL imposes a rigid binary constituent (or dependency) tree structure. Extending NL with the structural rules in (43) leads to overgeneration.

$$
\begin{aligned}
& \text { a. } \quad \mathrm{A} \bullet \mathrm{B} \rightarrow \mathrm{B} \bullet \mathrm{A} \\
& \text { b. } \mathrm{A} \rightarrow \mathrm{A} \bullet \mathrm{A} \\
& \text { c. }(\mathrm{A} \bullet \mathrm{B}) \bullet \mathrm{C} \rightarrow \mathrm{A} \bullet(\mathrm{B} \bullet \mathrm{C})
\end{aligned}
$$

permutation $[\mathrm{P}]$ contraction $[\mathrm{C}]$ associativity [Ass]

\footnotetext{
${ }^{12}$ See Moot and Retoré (2012) for a more detailed introduction to multimodal calculi with unary connectives on which our presentation is based, as well as Morrill (2011).
} 
For instance, if permutation and associativity are globally available, not only the grammatical 'John dedicated the book to Bill' but also the ill-formed 'John dedicated to Bill the book' becomes derivable. Simply substitute in the derivation below 'the book' for $\mathrm{x}$ and skip the application of the $[/ \mathrm{I}]$ rule.

$$
\begin{aligned}
& \text { John } \Rightarrow \mathrm{np} \quad \frac{\text { dedicate } \Rightarrow \mathrm{vp} / \mathrm{pp} / \mathrm{np} \quad[\mathrm{x} \Rightarrow \mathrm{np}]^{1}}{\frac{(\text { dedicate } \mathrm{x}) \Rightarrow \mathrm{vp} / \mathrm{pp}}{((\text { dedicate } \mathrm{x}) \text { to Bill }) \Rightarrow \mathrm{vp}} \text { to Bill } \Rightarrow \mathrm{pp}}[\text { [/E] } \\
& \left.\begin{array}{l}
\frac{(\text { John }((\text { dedicate } \mathrm{x}) \text { to Bill })) \Rightarrow \mathrm{S}}{(\text { John }((\text { dedicate to Bill) } \mathrm{x})) \Rightarrow \mathrm{S}}[\mathrm{P}] \\
\frac{{ }^{\text {Ass }}}{((\mathrm{John}(\text { dedicate to Bill })) \mathrm{x}) \Rightarrow \mathrm{s}} \\
\text { (John (dedicate to Bill) }) \Rightarrow \mathrm{S} / \mathrm{np}
\end{array}\right]^{1}
\end{aligned}
$$

What is required is a controlled access to the device of structural rules in the sense that their application is restricted to the appropriate (licensing) contexts. One way to achieve this consists in using a multimodal variant of the base logic NL. Instead of a single family $\{/, \bullet, \backslash\}$ of connectives, one distinguishes different such families: $\left\{/_{i}, \bullet_{i}, \backslash_{i}\right\}, i \in I$. The elements of the index set $I$ are called modes of combination or simply modes. Each family comes with its own set of structural rules. The main function of such modes is to license or inhibit the use of structural rules only in particular contexts and to exclude it in all other contexts. Formally, the use of modes can be seen as the use of a combined logic, which is built of several subsystems, one for each mode. Underlying this strategy is the intuition that linguistic resources belonging to distinct types can have different properties. Distinguishing various modes of combination makes it possible to discern linguistic contexts that differ with respect to their properties. In each context, the same logical rules governing the operators hold. However, they possibly differ with respect to the structural rules that can be applied to them.

The various modes can be related by inclusion and interaction rules. Inclusion rules relate different modes with each other. For example, if mode $/_{i}$ includes mode $/{ }_{j}$ and one has $A{ }_{i} B, A /{ }_{j} B$ can be derived. An example given by Moot and Retoré (2012) is the following. If a formula of type $A /{ }_{i} B$ can select its $B$ argument both to the right and to the left as in LP, e.g., one also has $A /{ }_{j} B$ relative to $\mathrm{L}$, in which arguments can only be chosen to the right. Adding structural rules via 
a particular mode enables the application of this rule but it does not enforce it. Therefore an observation can be made that although the formulation of structural rules in the context of a multimodal system makes it possible to restrict their application to the intended contexts, it does not force their application in these contexts.

This problem can be solved by extending the base logic in a further direction. This extension consists in adding unary operators $\diamond$ and $\square$. Similarly to the family $(\bullet, /, \backslash)$, the two operators are related by a law of residuation, which is given in (44a). From this law the relationships in (44b) are derivable.

$$
\begin{aligned}
& \text { a. } \quad \diamond \mathrm{A} \vdash \mathrm{B} \text { iff } \mathrm{A} \vdash \square \mathrm{B} \\
& \text { b. } \diamond \square \mathrm{A} \vdash \mathrm{A} \text { and } \mathrm{A} \vdash \square \diamond \mathrm{A}
\end{aligned}
$$

Analogous to the binary operators, it is possible to have a multimodal system for these unary operators. Given an index set $J$, one distinguishes various families of residuated pairs $\left\{\diamond_{j}, \square_{j}\right\}$ with $j \in J$. Modal decorations are primarily used in the type assignments of lexical items and in interaction rules with binary connectives, i.e. so-called K-rules. When taken together, these two strategies can be used to solve the problem of enforcing the application of a structural rule. Let us illustrate this with an example.

$$
\begin{array}{ll}
\text { a. } & \mathrm{K}: \diamond_{j}\left(\mathrm{~A} \bullet \bullet_{i} \mathrm{~B}\right) \rightarrow \diamond_{j} \mathrm{~A} \bullet_{i} \diamond_{j} \mathrm{~B} \\
\text { b. } & \mathrm{K} 2: \diamond_{j}\left(\mathrm{~A} \bullet \bullet_{i} \mathrm{~B}\right) \rightarrow \mathrm{A} \bullet_{i} \diamond_{j} \mathrm{~B}
\end{array}
$$

The rule $\mathrm{K}$ distributes $\diamond_{j}$ over both components of $\bullet_{i}$, whereas K2 does this only for the right component. The relationship between the problem of enforcing the application of a structural rule in an intended context and the percolation (or distribution) of structural (modal) operators is the following. The percolation mechanism that passes a modal decoration from some substructure to a structure that is of an undecorated designated type has to be construed in such a way that it requires the application of the structural rules. Thus, structural rules are used to create contexts which license the percolation of modal decorations which are not possible if these rules are not applied.

Next we will sketch how the above architecture will be used in our analysis of the data in Edo described in Section 1. Recall that we assume that in SVCs and CCs a verb form is used that extends the 
subcategorization list by an additional argument of type vp. One way in which CSVCs differ from CCs with two transitive verbs is that in the former construction the direct objects are always identified with each other and that the direct object of $V_{2}$ must not be overtly realized, say, by a pronoun. Hence, SVCs and CCs differ in the way direct objects are treated and in a CC the subject is treated differently from the direct object: whereas the former are always identified, this need not be the case for the direct objects. This suggests to distinguish, first, between the way subjects combine with a VP and the way a (transitive or ditransitive) verb combines with its direct object, and, second, between two head adjunction modes for the combination of an extended verb with the additional VP argument in an SVC and a CC, respectively. This yields the modes in (46) for Edo.

$$
\begin{aligned}
& \text { a. }{ }_{1 l} \text { : head-(left) complement mode (verb object relation) } \\
& \text { b. }{ }_{1 r}: \text { head-(right) complement mode (verb subject rela- } \\
& \text { tion) } \\
& \text { c. }{ }_{i}: \text { head adjunction mode for } i=0 \text { or } i=2 \text { (verb addi- } \\
& \text { tional argument relation in an SVC and a CC) }
\end{aligned}
$$

Let us next illustrate an interaction rule which is a restricted form of permutation. If the extended (transitive) verb combines with the (additional) argument of type vp in an SVC or a CC, and then with the direct object, the order of the two arguments has to be changed. This is achieved by the mixed permutation rule in (47).

$$
\text { MP: }\left(\mathrm{A} \bullet{ }_{1 l} \mathrm{~B}\right) \bullet_{i} \mathrm{C} \rightarrow\left(\mathrm{A} \bullet \bullet_{i} \mathrm{C}\right) \bullet{ }_{1 l} \mathrm{~B}
$$

(The subscript ${ }_{i}$ is a head adjunction mode)

This rule requires a context in which two verbal elements forming a cluster $\left(\mathrm{A} \bullet \bullet_{i} \mathrm{C}\right.$ ) are composed with a nominal element (B), which is to the right of the cluster. The requirement on the left component to be a verbal cluster makes this rule applicable only in the context of an SVC and a CC. Hence, this structural rule has only a controlled access to lexical resources. Now consider the following example in which the complex VP $=\mathrm{V}_{1} \mathrm{NP}_{2} \mathrm{~V}_{2} \mathrm{NP}_{3}$ of a CC is derived $\left(\cdot_{2}\right.$ the head adjunction mode for a $\mathrm{CC}$ ), using both logical rules (elimination rules for two constructors $/{ }_{1 l}$ and $/ 2$ ) and the mixed permutation rule in (47). 


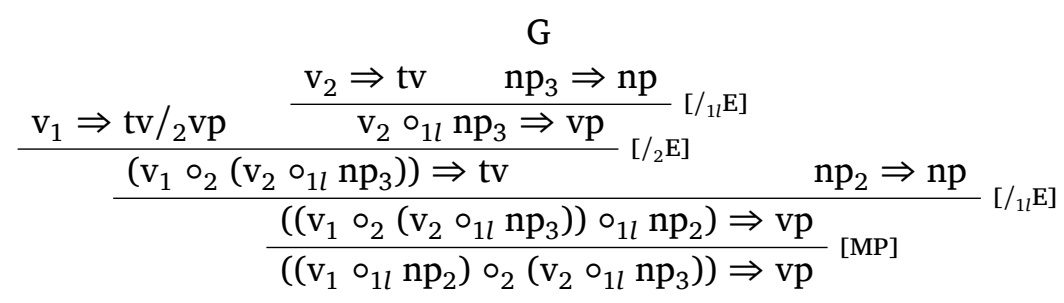

Applying MP in line 4 yields the correct word order: $\mathrm{NP}_{2}$ is adjacent to $V_{1}$ and precedes the additional argument, which is $\mathrm{VP}_{2}=\mathrm{V}_{2} \mathrm{NP}_{3}$. But if MP is not applied, one rests with the sequent in line 4 , which does not have a grammatical word order. This problem will be solved by introducing unary connectives. As already said above, modal decorations are used both in the type assignment to lexical items as well as in relation to the designated types, which are $\mathrm{vp}$ and $\mathrm{s}$ in our analysis. There are two different ways of how lexical items are modally decorated in our analysis: $\diamond_{j} \square_{j} A$ or $\square_{j} A$. The former is used as the lexical type assignment to verbs and the latter for lexical resources of type np. We start with the case of verbs. The type assignment A: $\diamond_{j} \square_{j}$ A holds both for the unextended and the extended form. Hence, verb forms used in SVCs and CCs do not differ at the level of modal decoration but at the level of the mode of combination. On the assignment $\mho_{j} \square_{j} A$, one starts a derivation with an identity axiom $\square_{j} \mathrm{~A} \Rightarrow \square_{j}$ A. Application of the logical rule $\left[\square_{j} \mathrm{E}\right]$ yields the sequent $\left\langle\square_{j} A\right\rangle^{j} \Rightarrow A$. Hence, this lexical resource can function as a being of type $A .\left\langle\square_{j} \mathrm{~A}\right\rangle^{j}$ eventually becomes part of a larger constituent $\Gamma$. In our application, $\Gamma$ is either $V P_{1}$ or the complex predicate consisting of $V P_{1}$ and $V P_{2}$. Finally, $\left\langle\square_{j} \mathrm{~A}\right\rangle^{j}$ gets substituted by the lexical resource of type $\nabla_{j} \square_{j}$ A using the identity axiom $\nabla_{j} \square_{j} \mathrm{~A} \Rightarrow \diamond_{j} \square_{j}$ A and an application of the logical rule $\left[\square_{j} \mathrm{E}\right]$. The derivation is schematically presented below.

$$
\begin{gathered}
\frac{\square_{j} \mathrm{~A} \Rightarrow \square_{j} \mathrm{~A}}{\left\langle\square_{j} \mathrm{~A}\right\rangle^{j} \Rightarrow \mathrm{A}}{ }^{\left.\square_{j} \mathrm{E}\right]} \\
\vdots \\
\frac{\Gamma\left[\left\langle\square_{j} \mathrm{~A}\right\rangle^{j}\right] \Rightarrow \mathrm{C}}{\vdots} \\
\frac{\Gamma\left[\left\langle\square_{j} \mathrm{~A}\right\rangle^{j}\right] \Rightarrow \mathrm{C} \quad \diamond_{j} \square_{j} \mathrm{~A} \Rightarrow \diamond_{j} \square_{j} \mathrm{~A}}{\Gamma\left[\left\langle\diamond_{j} \square_{j} \mathrm{~A}\right\rangle\right] \Rightarrow \mathrm{C}}\left[\diamond_{j} \mathrm{E}\right]
\end{gathered}
$$


Hence, for extended verbs, which are modally decorated by $\diamond_{j} \square_{j}$, the modal decoration must not be removed. As will be shown next, this is different for lexical resources of type np. In the lexicon, they get the type assignment $\square_{j}$ A. Similarly to the case of verbs, a derivation starts with an identity axiom $\square_{j} \mathrm{~A} \Rightarrow \square_{j} \mathrm{~A}$, followed by the application of the logical rule $\left[\square_{j} \mathrm{E}\right]$ yielding the sequent $\left\langle\square_{j} \mathrm{~A}\right\rangle^{j} \Rightarrow A$. Again similarly to the case of verbs, the modally decorated type eventually becomes part of a larger constituent $\Gamma$, which is either $V P_{1}$ or the complex predicate consisting of this VP and the additional argument of type vp. In contrast to the use of the modal decoration for verbs, the modal decoration for NPs must be removed. Otherwise, no lexical substitution would be possible because there are no lexical resources of type $\nabla_{j} \square_{j}$ A for $A=n p$. This removal is achieved by K-rules. If the NP corresponds to the direct object of $V_{1}$, two K-rules have to be applied. The first percolates the modal decoration to $V P_{1}$ and the second to the complex predicate, say $\Gamma:\langle\Gamma[\mathrm{A}]\rangle^{j} \Rightarrow \mathrm{C}$. To this sequent, rule $\left[\square_{j} \mathrm{I}\right]$ is applied, yielding $\Gamma[\mathrm{A}] \Rightarrow \square_{j} \mathrm{C}$. If $\mathrm{C}=$ vp or $\mathrm{C}=\mathrm{s}$, the task consists in deriving expressions of type $\square_{j}$ vp and $\square_{j}$ s and not the corresponding non-decorated types. This is the second principle use of modal decorations. A schematic derivation is represented below.

$$
\begin{gathered}
\frac{\square_{j} \mathrm{~A} \Rightarrow \square_{j} \mathrm{~A}}{\left\langle\square_{j} \mathrm{~A}\right\rangle^{j} \Rightarrow \mathrm{A}}{ }_{\left[\square_{j} \mathrm{E}\right]} \\
\Gamma\left[\left\langle\square_{j} \mathrm{~A}\right\rangle^{j}\right] \Rightarrow \mathrm{C} \\
\vdots \\
\frac{\left\langle\Gamma\left[\square_{j} \mathrm{~A}\right]\right\rangle^{j} \Rightarrow \mathrm{C}}{\Gamma\left[\square_{j} \mathrm{~A}\right] \Rightarrow \square_{j} \mathrm{C}}\left[\square_{j} \mathrm{I}\right]
\end{gathered}
$$

The use of both kinds of modal decorations is illustrated by the following example. Consider the sequent in (48), which is a result of applying an extended verb in a CSVC or a CC to the additional vp-argument and its direct object (in that order).

$$
\left(\left\langle\square_{j} \mathrm{~A}\right\rangle^{j} \circ_{k} \Gamma\right) \circ_{i}\left\langle\square_{j} \mathrm{~B}\right\rangle^{j} \Rightarrow \mathrm{C}
$$

Next, a rule of permutation needs to be applied in order to arrive at the correct word order. This can be achieved by the permutation rule in (49), which generalizes the corresponding rule in (47). 


$$
\mathrm{MP}:\left(\mathrm{C} \bullet \bullet_{i} \mathrm{D}\right) \bullet_{k} \mathrm{E} \rightarrow\left(\mathrm{C} \bullet_{k} \mathrm{E}\right) \bullet_{i} \mathrm{D}
$$

Next, the modal decoration of the B-resource must be percolated to $V P_{1}\left(=\left(\left\langle\square_{j} \mathrm{~A}\right\rangle^{j} o_{i}\left\langle\square_{j} \mathrm{~B}\right\rangle^{j}\right)\right)$. This is achieved by the K-rule in (50).

$$
\diamond_{j}\left(\diamond_{j} \mathrm{~A} \bullet_{i} \mathrm{~B}\right) \rightarrow \diamond_{j} \mathrm{~A} \bullet_{i} \diamond_{j} \mathrm{~B}
$$

Note that this rule does not remove the modal decoration of the (verbal) resource A. Otherwise, no lexical substitution would be possible after removing the decoration. The derivation looks as follows.

$$
\frac{\left(\left\langle\square_{j} \mathrm{~A}\right\rangle^{j} \circ_{k} \Gamma\right) \circ_{i}\left\langle\square_{j} \mathrm{~B}\right\rangle^{j} \Rightarrow \mathrm{C}}{\left.\left(\left\langle\square_{j} \mathrm{~A}\right\rangle^{j} \circ_{i}\left\langle\square_{j} \mathrm{~B}\right\rangle\right)^{j}\right) \circ_{k} \Gamma \Rightarrow \mathrm{C}}{ }_{[\mathrm{MP}]}^{[(50)]}
$$

Since $\langle\cdot\rangle^{j}$ has to be further percolated in order to eventually apply $\left[\square_{j} \mathrm{I}\right]$, a second K-rule is needed, as explained above. The required rule is (51). Using this rule, the above derivation continues as follows.

$$
\begin{aligned}
& \diamond_{j}\left(\mathrm{~A}^{\prime} \bullet_{k} \mathrm{~B}^{\prime}\right) \rightarrow \diamond_{j} \mathrm{~A}^{\prime} \bullet_{k} \mathrm{~B}^{\prime} \\
& \frac{\left\langle\left(\left\langle\square_{j} \mathrm{~A}\right\rangle^{j} \circ_{i} \square_{j} \mathrm{~B}\right)\right\rangle^{j} \circ_{k} \Gamma \Rightarrow \mathrm{C}}{\frac{\left\langle\left(\left\langle\square_{j} \mathrm{~A}\right\rangle^{j} \circ_{i} \square_{j} \mathrm{~B}\right) \circ_{k} \Gamma\right\rangle^{j} \Rightarrow \mathrm{C}}{[(51)]}}{ }_{\left[\square_{j} \mathrm{I}\right]}^{\left(\left\langle\square_{j} \mathrm{~A}\right\rangle^{j} \circ_{i} \square_{j} \mathrm{~B}\right) \circ_{k} \Gamma \Rightarrow \square_{j} \mathrm{C}}
\end{aligned}
$$

Suppose MP is not applied in line 1. (50) can then be applied only if (51) is used first since only in such case the left component is modally decorated. The result is the sequent in (52).

$$
\left\langle\left(\square_{j} \mathrm{~A} \circ_{k} \Gamma\right)\right\rangle^{j} o_{i}\left\langle\square_{j} \mathrm{~B}\right\rangle^{j} \Rightarrow \mathrm{C}
$$

For the antecedent term, no lexical substitution is possible because there are no lexical items of type $\square_{j}$ A. Let us finally show how structural rules interact with modal decorations to enforce the use of the former. The general scheme is the following. The percolation mechanism that passes a modal decoration from some substructure to a structure that is of an undecorated designated type has to be construed in such a way that it requires the application of the structural rules. In the above example the use of the rule of permutation creates a context in which the modal decoration 
on an np resource can be percolated by the application of two Krules to the whole complex predicate consisting of $V P_{1}$ and $V P_{2}$. Without this percolation no lexical substitution would be possible for the np resource as it requires the modally decorated type $\square_{j} \mathrm{~A}$ and not $\diamond_{j} \square_{j}$ A. Thus, structural rules are used to create contexts which license the percolation of modal decorations, which, in turn, is necessary for lexical substitutions. The above strategy will be key in the derivation of SVCs and CCs which is the topic of the next section.

The discussion in this section has yielded the following strategy for syntactic type assignments in the lexicon in order to enforce the use of structural rules: (i) Modal decorations are used for the syntactic type of both verbs and NPs. Whereas extended verbs are modally decorated by $\diamond \square$, NPs are decorated by $\square$. For example, a transitive verb in simple sentences or as $V_{i}, i>1$, in an SVC or CC (if admissible) is not assigned the syntactic type $n p \backslash(s / n p)$ but the type $\diamond \square\left(\left(\mathrm{np} \backslash_{r}\left(\mathrm{~s} /{ }_{l} \mathrm{np}\right)\right)\right.$. Hence, in addition to the modal decoration, there is a distinction between ${ }_{1 l}$, the verb-object (left head) mode, and $\cdot_{1 r}$, the subject-verb (right head) mode. If a verb is used as the first verb in an SVC or a CC, one gets $\diamond \square\left(\left(\mathrm{np} \backslash_{r}\left(\mathrm{~s} /{ }_{l} \mathrm{np}\right)\right) /{ }_{i} \mathrm{vp}\right)$, which reflects the fact that there is an additional argument of type $v p$, (ii) the extended forms of verbs differ at the level of the mode by which the additional argument of type vp combines with the verb, and (iii) the head adjunction modes are ${ }_{0}$ (for CSVCs) and $\cdot_{2}$ (for RSVCs and CCs).

\section{THE DERIVATION OF SVGS AND GGS IN EDO}

The syntactic derivation of CCs and CSVCs

with two transitive verbs

Both in an SVC and a CC with a transitive first verb this verb first combines with a resource of type vp and then with a resource of type $\mathrm{np}$ yielding a structure of type $\mathrm{vp}$, which corresponds to the sequent $\mathrm{V}_{1} \mathrm{VP}_{2} \mathrm{NP}_{2}$. In order to arrive at the correct word order, which is 
$\mathrm{V}_{1} \mathrm{NP}_{2} \mathrm{VP}_{2}$, the mixed permutation rule $\mathrm{MP}_{1}$ in (53) is used, with $\bullet_{i}$ a head adjunction mode. ${ }^{13}$

$$
\text { MP1: }\left(\mathrm{A} \bullet \bullet_{1 l} \diamond \mathrm{B}\right) \bullet_{i} \mathrm{C} \rightarrow\left(\mathrm{A} \bullet{ }_{i} \mathrm{C}\right) \bullet_{1 l} \diamond \mathrm{B}
$$

Note that MP1 does not require one of the verbal elements in the verbal cluster to be modally decorated with $\diamond$. The use of $\mathrm{MP}_{1}$ is linked to the use of the K-rule in (54).

$$
\mathrm{K} * 2\left(\bullet_{1 l}\right): \diamond\left(\diamond \mathrm{A} \bullet{ }_{1 l} \mathrm{~B}\right) \rightarrow \diamond \mathrm{A} \bullet{ }_{1 l} \diamond \mathrm{B}
$$

This rule requires that the left (verbal) element and the right (nominal) element are both modally decorated. Whereas the decoration of the left component is not percolated, the decoration of the right component is percolated to the whole verbal structure.

Using MP1 and $\mathrm{K} * 2(\bullet 1)$, produces Derivation 1 below:

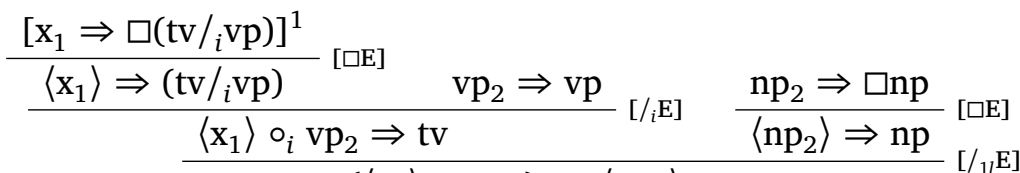

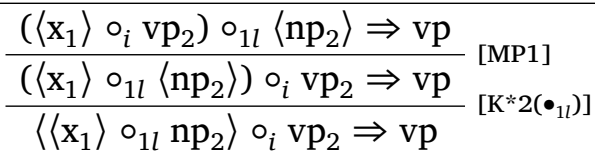

Since the left component is a non-lexical VP, its modal decoration originates from its (nominal) right element and has therefore to be percolated to the whole antecedent structure. This consideration is independent of the exact form of $\mathrm{vp}_{2}$. The three possible percolation rules are given in (55).

$$
\begin{array}{ll}
\text { a. } & \mathrm{K}\left(\bullet_{i}\right): \diamond\left(\mathrm{A} \bullet_{i} \mathrm{~B}\right) \rightarrow \diamond \mathrm{A} \bullet_{i} \diamond \mathrm{B} \\
\text { b. } & \mathrm{K} 1\left(\bullet_{i}\right): \diamond\left(\mathrm{A} \bullet_{i} \mathrm{~B}\right) \rightarrow \diamond \mathrm{A} \bullet_{i} \mathrm{~B} \\
\text { c. } & \mathrm{K} * 1\left(\bullet_{i}\right): \diamond\left(\mathrm{A} \bullet_{i} \diamond \mathrm{B}\right) \rightarrow \diamond \mathrm{A} \bullet_{i} \diamond \mathrm{B}
\end{array}
$$

$\mathrm{K}\left(\bullet_{i}\right)$ and $\mathrm{K} * 1\left(\bullet_{i}\right)$ both require the right component to be modally decorated, too. They differ with respect to the way this decoration is handled. Whereas $\mathrm{K}\left(\bullet_{i}\right)$ removes the modal decoration, this is not the

\footnotetext{
${ }^{13}$ In this and subsequent sections, only the algebraic presentation of structural rules is given. The corresponding inference rule in the natural deduction format can be found in the Appendix.
} 
case for $\mathrm{K} * 1\left(\bullet_{i}\right), \mathrm{K} 1\left(\bullet_{i}\right)$ does not impose any condition on the modal decoration of the right component. It may but need not be modally decorated. Note that $\mathrm{K} 1\left(\bullet_{i}\right)$ subsumes $\mathrm{K} * 1\left(\bullet_{i}\right)$ as a special case.

Recall the syntactic structure of a CC with two transitive verbs, exemplified by an example repeated from Section 1 .

CC: $\mathrm{NP}_{1} \mathrm{~V}_{1} \mathrm{NP}_{2} \mathrm{~V}_{2} \mathrm{NP}_{3}$

Òzó ghá gbè è̀wé khiẹ̀n ùhùnmwùn érẹ̀n.

Ozo FUT hit goat sell head its

'Ozo will kill the goat and sell its head.'

Baker and Stewart (1999:3)

In this type of CC, there is an overt NP after $\mathrm{V}_{2}$, which is in addition not required to be coreferential with the direct object of $\mathrm{V}_{1}$ $\left(=\mathrm{NP}_{2}\right)$. In derivation $1, \mathrm{vp}_{2}$ is therefore a structure of the form $\left\langle\left\langle\mathrm{x}_{2}\right\rangle \circ_{1 l} \mathrm{np}_{3}\right\rangle$ of type vp, i.e. a non-lexical VP. Consequently, its modal decoration originates from the NP argument and therefore has to be passed to the whole antecedent structure, i.e. to the sequence corresponding to the complex $\mathrm{VP}=\mathrm{V}_{1} \mathrm{NP}_{2} \mathrm{~V}_{2} \mathrm{NP}_{3}$. Thus, both components of $o_{i}$ are structures of the form $\left\langle\langle\mathrm{x}\rangle \circ_{1 l} \mathrm{np}\right\rangle$, corresponding to a nonlexical VP. The required K-rule therefore is (55a), which distributes $\diamond$ over both components. Setting the head adjunction mode to $\cdot_{2}$, one gets (57).

$$
\mathrm{K}\left(\bullet_{2}\right): \diamond\left(\mathrm{A} \bullet_{2} \mathrm{~B}\right) \rightarrow \diamond \mathrm{A} \bullet_{2} \diamond \mathrm{B}
$$

Given $\mathrm{K}\left(\bullet_{2}\right)$ and setting $\mathrm{vp}_{2}=\left\langle\left\langle\mathrm{x}_{2}\right\rangle \circ_{1 l} \mathrm{np}_{3}\right\rangle$ and $\circ_{i}=\circ_{2}$, the Derivation 1 from above continues as follows.

$$
\frac{\left\langle\left\langle\mathrm{x}_{1}\right\rangle \circ_{1 l} \mathrm{np}_{2}\right\rangle \circ_{2}\left\langle\left\langle\mathrm{x}_{2}\right\rangle \circ_{1 l} \mathrm{np}_{3}\right\rangle \Rightarrow \mathrm{vp}}{\left\langle\left(\left\langle\mathrm{x}_{1}\right\rangle \circ_{1 l} \mathrm{np}_{2}\right) \circ_{2}\left(\left\langle\mathrm{x}_{2}\right\rangle \circ_{1 l} \mathrm{np}_{3}\right)\right\rangle \Rightarrow \mathrm{vp}}\left[\mathrm{K}\left(\bullet_{2}\right)\right]
$$

So far, we have shown how the assumed structural rules enable deriving a sequent of type vp with the correct word order corresponding to the complex $\mathrm{VP}=\mathrm{V}_{1} \mathrm{NP}_{2} \mathrm{~V}_{2} \mathrm{NP}_{3}$. It remains to show that they also enforce it. Suppose in line 4 in Derivation 1 from above, repeated below with the necessary substitution, the rule $\mathrm{MP}_{1}$ is not applied. 
4.

$$
\left(\left\langle\mathrm{x}_{1}\right\rangle \circ_{2}\left(\left\langle\mathrm{x}_{2}\right\rangle \circ_{1 l} \mathrm{np}_{3}\right)\right) \circ_{1 l}\left\langle\mathrm{np}_{2}\right\rangle \Rightarrow \mathrm{vp}
$$

The structure in the antecedent is of the form $\Gamma \circ_{1 l}\langle\Delta\rangle$. Since the structural operator on the right component has to be percolated to the antecedent term, rule $\mathrm{K} * 2\left(\bullet_{11}\right)$ has to be applied. This is possible only if rule $\mathrm{K}\left(\bullet_{2}\right)$ has been applied to the left component since $\mathrm{K} * 2\left(\bullet_{1 l}\right)$ requires that the left component be modally decorated. Application of this rule yields line $5^{*}$.

$5 *$

$$
\left\langle\left(\mathrm{x}_{1} \circ_{2}\left(\left\langle\mathrm{x}_{2}\right\rangle \circ_{1 l} \mathrm{np}_{3}\right)\right)\right\rangle \circ_{1 l}\left\langle\mathrm{np}_{2}\right\rangle \Rightarrow \mathrm{vp}
$$

This step is fatal because the modal decoration of the left component is percolated by $\mathrm{K}\left(\bullet_{2}\right)$. Consequently, since $\mathrm{x}_{1}$ is of type $\square\left(\mathrm{tv} / \mathrm{2}_{2} \mathrm{vp}\right)$, the sequent requires a lexical element that is of that type. But there are no such lexical entries, transitive verbs being of a type that is modally decorated with $\diamond \square: \diamond \square \mathrm{tv}$ or $\diamond \square\left(\mathrm{tv} /{ }_{i} \mathrm{vp}\right)$. As a result, the sequent in line $5 *$ does not admit a substitution of lexical elements. To put it differently, removing the decoration of the left component, it is no longer possible to apply $[\diamond \mathrm{E}]$ at a later stage, using the lexical axiom $\mathrm{v}_{1} \Rightarrow \diamond \square\left(\mathrm{tv} /{ }_{i} \mathrm{vp}\right){ }^{14}$

Let us analyze the success and the failure in more detail. $\mathrm{K}\left(\bullet_{2}\right)$ requires the left component of $\bullet_{i}, i=0$ or $i=2$, to be $\diamond$-decorated. In the intended case, in which MPl is applied, this left component does not correspond to the extended verb $\left(=V_{1}\right)$ but to the VP built in terms of this verb. Assuming that $\mathrm{K}^{*} 2\left(\bullet \bullet_{1 l}\right)$ has been applied, this component is of the form $\left\langle\langle\Gamma\rangle \circ_{1 l} \Delta\right\rangle$ with $\langle\Gamma\rangle$ corresponding to $\mathrm{V}_{1}$ and $\Delta$ corresponding to the object argument of $\mathrm{V}_{1}$. In this case the

${ }^{14}$ One has the derived rule below, which is the left rule for $\diamond$ in a Gentzen sequent presentation

$$
\text { (*) } \frac{\Gamma[\langle\mathrm{A}\rangle] \Rightarrow \mathrm{C}}{\Gamma[\diamond \mathrm{A}] \Rightarrow \mathrm{C}}
$$

Therefore, in a non-sugared presentation one has (with $\alpha=\mathrm{tv}$ or $\alpha=\left(\mathrm{tv} /{ }_{i} \mathrm{vp}\right)$ )

$$
(* *) \frac{\Gamma[\langle\square \alpha\rangle] \Rightarrow C}{\Gamma[\diamond \square \alpha] \Rightarrow C}
$$

Since there are lexical items of type $\diamond \square \alpha$, they can be substituted for an occurrence of this categorial formula in $\Gamma$. After removing the modal decoration, the step (**) is no longer possible. 
outer $\diamond$-decoration should be passed to the whole structure since it originated from the decoration of the NP argument which should be percolated to the whole structure.

By contrast, in the derivation yielding the incorrect word order, the order in which $\mathrm{K}\left(\bullet_{2}\right)$ and $\mathrm{K} * 2\left(\bullet_{1 l}\right)$ are applied is reversed. This is the case because $\mathrm{K} * 2\left(\bullet_{1 l}\right)$ requires the left component to be modally decorated. Contrary to the intended case, the left component of the verbal cluster composed by $o_{i}$ is a resource corresponding to $\mathrm{V}_{1}$ and not to the VP built from it. This is a simple consequence of the fact that permutation has not yet been applied so that the linear order corresponds to the order in which the arguments are discharged. Since $\mathrm{K}\left(\bullet_{2}\right)$ removes the decoration of the left component, the result is linguistically ill-formed because it requires a resource of type $\square\left(\operatorname{tv} /{ }_{2} v p\right)$. However, there happen to be no lexical entries meeting this condition.

The above argument only requires a percolation rule involving a head adjunction mode to remove the decoration of the left component. As was shown above in the preceding section, this condition is satisfied by all possible percolation rules. Thus, the argument equally applies if instead of $\mathrm{K}\left(\bullet_{2}\right) \mathrm{K} 1\left(\bullet_{i}\right)$ or $\mathrm{K} * 1\left(\bullet_{i}\right)$ is used. The failure of a derivation in which the mixed permutation rule is not applied becomes even more apparent in the non-sugared presentation.

$$
\begin{aligned}
& \frac{\frac{\square\left(\mathrm{tv} /{ }_{i} \mathrm{vp}\right) \Rightarrow \square\left(\mathrm{tv} /{ }_{i} \mathrm{vp}\right)}{\left\langle\square\left(\mathrm{tv} /{ }_{i} \mathrm{vp}\right)\right\rangle \Rightarrow\left(\mathrm{tv} /{ }_{i} \mathrm{vp}\right)}[\mathrm{\square E}] \quad \mathrm{vp}_{2} \Rightarrow \mathrm{vp}}{\left[\square\left(\mathrm{tv} /{ }_{i} \mathrm{vp}\right)\right\rangle \circ_{i} \mathrm{vp}_{2} \Rightarrow \mathrm{tv}} \quad \frac{\mathrm{np}_{2} \Rightarrow \square \mathrm{np}}{\left\langle\mathrm{np}_{2}\right\rangle \Rightarrow \mathrm{np}}\left[{ }^{[\square]}\right] \\
& \frac{\left(\left\langle\square\left(\mathrm{tv} /{ }_{i} \mathrm{vp}\right)\right\rangle \circ_{i} \mathrm{vp}_{2}\right) \circ_{1 l}\left\langle\mathrm{np}_{2}\right\rangle \Rightarrow \mathrm{vp}}{\left\langle\square\left(\mathrm{tv} /{ }_{i} \mathrm{vp}\right) \circ_{i} \mathrm{vp}_{2}\right\rangle \circ_{1 l}\left\langle\mathrm{np}_{2}\right\rangle \Rightarrow \mathrm{vp}}\left[\mathrm{K}-\text { rule for }^{*} \bullet^{*}\left(\bullet_{1 l}\right]\right]
\end{aligned}
$$

In addition, application of $\mathrm{K} * 2\left(\bullet_{11}\right)$ does not remove the modal decoration from the verbal cluster, as the last line 6 shows. As a consequence, application of rule $[\diamond \mathrm{E}]$ to this line requires a verbal cluster $\left(\mathrm{x}_{1} \circ_{i} \mathrm{vp}_{2}\right)$ to be of type $\diamond \square \mathrm{tv}$, i.e. $\left(\mathrm{v}_{1} \circ_{i} \mathrm{vp}_{2}\right) \Rightarrow \diamond \square \mathrm{tv}$, with $\mathrm{x}_{1} \Rightarrow$ $\square\left(\mathrm{tv} /{ }_{i} \mathrm{vp}\right)$, which is not derivable.

The above discussion has shown that a percolation rule involving a head adjunction mode has to be applied after the rule $\mathrm{K} * 2\left(\bullet_{11}\right)$ has been applied in order to work correctly. Consequently, the order 
in which the rules are applied matters. This order is sensitive to the application of the rule of permutation MPl. If it is applied, the order in which the K-rules are applied is the correct one, otherwise not. To put it differently, the correct order requires a structure of the form (58a) and not a structure of the form (58b). The effect of MPl is just to transform (58b) into (58a).

$$
\begin{array}{ll}
\text { a. } & \left(\langle\Gamma\rangle \circ_{1 l}\langle\Delta\rangle\right) \circ_{i} \Delta^{\prime} \\
\text { b. } & \left(\langle\Gamma\rangle \circ_{i} \Delta^{\prime}\right) \circ_{1 l}\langle\Delta\rangle
\end{array}
$$

Applying $\mathrm{K} * 2\left(\bullet_{11}\right)$ and one of the percolation rules for the head adjunction modes in the wrong order always yields sequents that do not admit lexical substitutions for the terms in the antecedent.

The problem of getting the correct order of rule applications can be solved by distinguishing two different kinds of phrasal structures of type vp: $\left(\left\langle\mathrm{x}_{1}\right\rangle \circ_{1 l}\langle\mathrm{np}\rangle\right)$ and $\left(\left(\left\langle\mathrm{x}_{1}\right\rangle \circ_{i} \mathrm{vp}\right) \circ_{1 l}\langle\mathrm{np}\rangle\right)$. Only the first is linguistically admissible, in which the left component of ${ }^{\circ} 1$ is not a verbal cluster consisting of two verbs. The task, therefore, is reduced to distinguishing such clusters from simple verbs in the contexts of a left-headed phrasal structure. A first key in achieving this consists in modally decorating transitive verbs in the lexicon in such a way that first they enter a derivation as structures modally decorated with $\diamond$ (or $\langle\cdot\rangle$ ) and second this decoration must not be percolated until a structure of type vp is built up (i.e. until application of rule $\left.\mathrm{K}^{*} 2\left(\bullet_{11}\right)\right)$. This is achieved by assigning transitive verbs the types $\diamond \square \mathrm{tv}$ and $\diamond \square\left(\mathrm{tv} /{ }_{i} \mathrm{vp}\right), i=0$ or $i=2$. The second key consists in letting rule $\mathrm{K} * 2\left(\bullet \bullet_{1 l}\right)$ be sensitive to this modal decoration in the sense that it is explicitly checked whether the component is modally decorated. Since verbal clusters are not lexical in Edo, one arrives at a structure of the form required by rule $\mathrm{K} * 2\left(\bullet_{1 l}\right)$ only if a percolation rule for a head adjunction mode is applied. But, and this is the third key, these rules remove the modal decoration of the left component of the verbal cluster, i.e. of the extended verb, so that it is no longer possible to find a lexical substitution.

The modal decoration of transitive verbs, therefore, functions as a domain modality. In the context of structures composing a verbal element and a direct object it admits to distinguish simple transitive verbs from verbal clusters both of which can be composed 
with an np resource by $o_{1 l}$ due to the mixed permutation rule MPl. Whereas the former are modally decorated without application of a percolation rule, the latter are modally decorated only if such a rule is applied. Thus, rule $\mathrm{K}^{*} 2\left(\bullet_{1 l}\right)$ can be said to require lexical verbal heads.

The failure that results if MP1 is not applied can also be shown by trying to parse an expression of type vp with the incorrect word order.

$$
\frac{\text { fail }}{\frac{\left\langle\left(\left\langle\square\left(\mathrm{tv} /{ }_{2} \mathrm{vp}\right)\right\rangle \circ_{2}\left(\langle\square \mathrm{tv}\rangle \circ_{1 l} \square \mathrm{np}\right)\right) \circ_{1 l} \square \mathrm{np}\right\rangle \Rightarrow \mathrm{vp}}{\left(\left\langle\square\left(\mathrm{tv} /{ }_{2} \mathrm{vp}\right)\right\rangle \circ_{2}\left(\langle\square \mathrm{tv}\rangle \circ_{1 l} \square \mathrm{np}\right)\right) \circ_{1 l} \square \mathrm{np} \Rightarrow \square \mathrm{vp}}}\left[{ }_{\left[{ }^{\prime}\right]}(\mathrm{I}]\right.
$$

The derivation already stops at the third line, which is of the form $\left\langle\Gamma \circ_{1 l} \Delta\right\rangle \Rightarrow$ vp, because application of $\mathrm{K} * 2\left(\bullet_{1 l}\right)$ requires the left component to be modally decorated. Yet it is only possible to get $\left(\left\langle\square\left(\mathrm{tv} /{ }_{2} \mathrm{vp}\right)\right\rangle \circ_{2}\left(\langle\square \mathrm{tv}\rangle \circ_{1 l} \square \mathrm{np}\right)\right)$ since this component is not a lexical verbal head.

Deriving the sequence $V_{1} N P_{2} V_{2}$ in a CSVC

In contrast to a CC, the object arguments of $\mathrm{V}_{1}$ and $\mathrm{V}_{2}$ are identified with each other in a CSVC and the direct object of $\mathrm{V}_{2}$ cannot be overtly realized, either as an NP or as a pronoun which is coreferential with $\mathrm{NP}_{2}$ ( $=$ the DO of $\mathrm{V}_{1}$ ). Below, we repeat an example from Section 1.

CSVC: $\mathrm{NP}_{1} \mathrm{~V}_{1} \mathrm{NP}_{2} \mathrm{~V}_{2}$

Òzó ghá gbè ẹ̀wé khiẹ̀n.

Ozo FUT hit goat sell

'Ozo will kill the goat and sell it.'

Baker and Stewart (1999:3)

If both verbs in a CSVC are transitive and the additional argument of the extended first verb is of type vp, one gets Derivation 2 below assuming the head adjunction mode to be ${ }_{0}$ : 


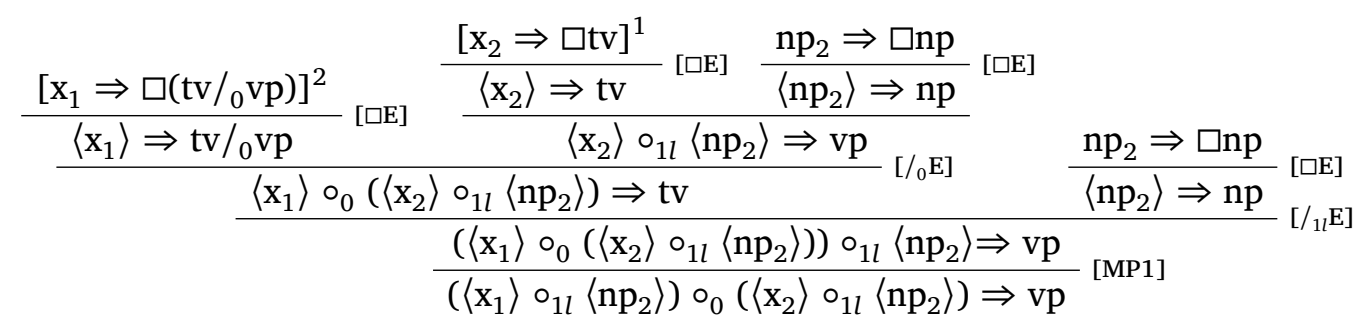

Up to that point the derivation is parallel to that for a CC with two transitive verbs, except that the head adjunction modes are assumed to be different and that the $\mathrm{np}$ resource $\mathrm{np}_{2}$ has been used twice. This second difference reflects the fact that in a CSVC the DO are identified and that the $\mathrm{DO}$ of $\mathrm{V}_{2}$ cannot be overtly realized. Consequently, in a CSVC, the np resource corresponding to the shared DO has to be used twice if it is assumed that the additional argument by which the subcategorization frame of $\mathrm{V}_{1}$ is extended is of type vp. It is used both as the object argument of $\mathrm{V}_{1}$ and as the object argument of $\mathrm{V}_{2}$. From what has been said it follows that at line 6 a rule of Mixed Contraction has to be applied. In the present context, it takes the form (60).

$$
\text { MC: }\left(\mathrm{A} \bullet_{0} \mathrm{~B}\right) \bullet_{1 l} \diamond \mathrm{C} \rightarrow\left(\mathrm{A} \bullet_{1 l} \diamond \mathrm{C}\right) \bullet_{0}\left(\mathrm{~B} \bullet_{1 l} \diamond \mathrm{C}\right)
$$

Applying MC to line 6 in Derivation 2 yields line 7.

7.

$$
\left(\left\langle\mathrm{x}_{1}\right\rangle \circ_{0}\left\langle\mathrm{x}_{2}\right\rangle\right) \circ_{1 l}\left\langle\mathrm{np}_{2}\right\rangle \Rightarrow \mathrm{vp}
$$

After the rule of mixed contraction has been applied, the np resource must again be infixed in the verbal cluster, using the rule MP1 of mixed permutation. This gives line 8 .

8.

$$
\left(\left\langle\mathrm{x}_{1}\right\rangle \circ_{1 l}\left\langle\mathrm{np}_{2}\right\rangle\right) \circ_{0}\left\langle\mathrm{x}_{2}\right\rangle \Rightarrow \mathrm{vp}
$$

Comparing this line with line 6 in Derivation 1 of a CC, one notices that in a CSVC $\mathrm{vp}_{2}$ ultimately is only $\mathrm{V}_{2}$ since the object argument has been elided due to the application of the rule of mixed contraction. Thus, it is a structure of the form $\langle\mathrm{x}\rangle$ with $\mathrm{x}$ of type $\square \mathrm{tv}$. The modal decoration of the right component of a $\circ_{0}$-structure must therefore not be percolated. The appropriate percolation rule for $\bullet_{0}$ is therefore (61), which distributes $\diamond$ only over the left component. 


$$
\mathrm{K} 1\left(\bullet_{0}\right): \diamond\left(\mathrm{A} \bullet_{0} \mathrm{~B}\right) \rightarrow \diamond \mathrm{A} \bullet_{0} \mathrm{~B}
$$

Applying $\mathrm{K} 1\left(\bullet_{0}\right)$ to line 8 yields line 9 .

9.

$$
\left\langle\left(\left\langle\mathrm{x}_{1}\right\rangle \circ_{1 l} \mathrm{np}_{2}\right) \circ_{0}\left\langle\mathrm{x}_{2}\right\rangle\right\rangle \Rightarrow \mathrm{vp}
$$

In the derivation of a CSVC the rule MP1 is used twice. In both cases an np resource is infixed in a verbal cluster. In the first application this verbal cluster has the form $\left(\left\langle\mathrm{x}_{1}\right\rangle \circ_{0}\left(\left\langle\mathrm{x}_{2}\right\rangle \circ_{1 l}\left\langle\mathrm{np}_{2}\right\rangle\right)\right)$. In this situation application of MP1 is enforced because otherwise the only way to proceed consists in first applying $\mathrm{K} * 2\left(\bullet_{1 l}\right)$ to $\left(\left\langle\mathrm{x}_{2}\right\rangle \circ_{1 l}\right.$ $\left.\left\langle\mathrm{np}_{2}\right\rangle\right)$ and then $\mathrm{K} 1\left(\bullet_{0}\right)$ to $\left(\left\langle\mathrm{x}_{1}\right\rangle \circ_{0}\left\langle\left\langle\mathrm{x}_{2}\right\rangle \circ_{1 l} \mathrm{np}_{2}\right\rangle\right)$, which percolates the structural operator of the left but not that of the right component. As a result, no lexical substitution is possible because the undecorated $\mathrm{x}_{1}$ is of type $\square\left(\mathrm{tv} /{ }_{0} \mathrm{vp}\right)$ and there are no extended verbs of this type. The problem is that $\mathrm{K} 1\left(\bullet_{0}\right)$ works correctly only if the verbal cluster consists of a left component that corresponds to a non-lexical VP, i.e. it is of the form $\left(\langle\mathrm{x}\rangle \circ_{1 l} \mathrm{np}\right)$, whereas the right component is a verbal element, i.e. it is of the form $\left\langle\mathrm{x}^{\prime}\right\rangle$ in the case of a CSVC. One arrives at such a structure only by applying MP1 (and, in addition, MC). The second application of the rule MP1 occurs after contraction so that the right component of the verbal cluster is no longer of the form $\left(\left\langle\mathrm{x}_{2}\right\rangle \circ_{1 l}\left\langle\mathrm{np}_{2}\right\rangle\right)$ but of the form $\left\langle\mathrm{x}_{2}\right\rangle$. This application is enforced too for the same reasons the previous applications of this rule have been enforced: a verbal cluster is composed with a nominal element to its right.

If in line 6 of Derivation 2 rule MC is not applied, applying $\mathrm{K} * 2\left(\bullet_{1 l}\right)$ to both components of the antecedent term yields substructures of the form $\left(\langle\mathrm{x}\rangle \circ_{1 l} \mathrm{np}\right)$. Since $\mathrm{K} 1\left(\bullet_{0}\right)$ only removes the modal decoration of the left component of a structure composed by $\circ_{0}$, the modal decoration of the right component is left intact. Application of $[\diamond \mathrm{E}]$ to this component is not possible because this requires the derivability of the sequent $\left(\square \mathrm{tv} \circ_{0} \square \mathrm{np}\right) \Rightarrow \diamond \square \mathrm{vp}$. Even if this sequent were derivable, its antecedent term does not admit substituting lexical items for the left component since there are no lexical items of type $\square$ tv.

Since both in a CSVC and in a CC the sequent in (62) below is derived, it is necessary to distinguish two different kinds of head adjunction modes. With respect to this sequent, the two types of constructions are structurally indistinguishable. In order to enforce the 
difference that results beginning from that sequent, principally due to the application of the rule MC in the CSVC, two head adjunction modes must be used for which different structural rules apply.

$$
\left(\left\langle\mathrm{x}_{1}\right\rangle \circ_{1 l}\langle\mathrm{np}\rangle\right) \circ_{i}\left(\left\langle\mathrm{x}_{2}\right\rangle \circ_{1 l}\langle\mathrm{np}\rangle\right) \Rightarrow \mathrm{vp}
$$

Deriving the sequence $N P_{1} V P$ :

a structural rule for the subject argument

The rules in (54) and (57) must be supplemented with a corresponding rule for the composition of the subject argument with the VP. From the discussion so far it follows that the sequence $\mathrm{V}_{1} \mathrm{NP}_{2} \mathrm{~V}_{2}\left(\mathrm{NP}_{3}\right)$ in a CSVC or a CC corresponds to a sequent of the form $\langle\Gamma\rangle \Rightarrow \mathrm{vp}$. Since the external argument corresponds to a sequent of the form $\left\langle\mathrm{np}_{1}\right\rangle \Rightarrow \mathrm{np}$, composing the two resources requires the following percolation rule for $\bullet_{1}$, which is the composition mode for right-headed head-complement structures (subject-verb relation).

$$
\mathrm{K}\left(\bullet_{1 r}\right): \diamond\left(\mathrm{A} \bullet \bullet_{1 r} \mathrm{~B}\right) \rightarrow \diamond \mathrm{A} \bullet \bullet_{1 r} \diamond \mathrm{B}
$$

The justification of $\mathrm{K}\left(\bullet_{1 r}\right)$ runs as follows. First, the $\diamond$-decoration of an np resource has to be percolated. Second, the $\diamond$-decoration of any non-minimal verbal projection of a transitive verb has to be percolated since it originates from the decoration of an NP complement. ${ }^{15}$ The relevant derivation is given below.

$$
\frac{\frac{\mathrm{np}_{1} \Rightarrow \square \mathrm{np}}{\left\langle\mathrm{np}_{1}\right\rangle \Rightarrow \mathrm{np}}[\square \mathrm{E}] \quad\langle\mathrm{vp}\rangle \Rightarrow \mathrm{vp}}{\frac{\left\langle\mathrm{np}_{1}\right\rangle \circ_{1 r}\langle\mathrm{vp}\rangle \Rightarrow \mathrm{s}}{\left\langle\mathrm{K}\left(\bullet_{1 r}\right)\right]}\left[{ }_{1 r} \mathrm{E}\right]}
$$

Given the K-rule for the subject argument, the complete derivations for a CC and a CSVC with two transitive verbs are given below. We start with a CC. The derivation is displayed on page 377.

Since we finally derived objects of syntactic type $\square$ s, we will also provide information about the semantics. For the sake of readability,

${ }^{15}$ This argument also holds for verbal VPs, i.e. a VP projected by an intransitive verb; see Section 4.7 for details. 
A type-logical analysis of SVCs and CCs in Edo

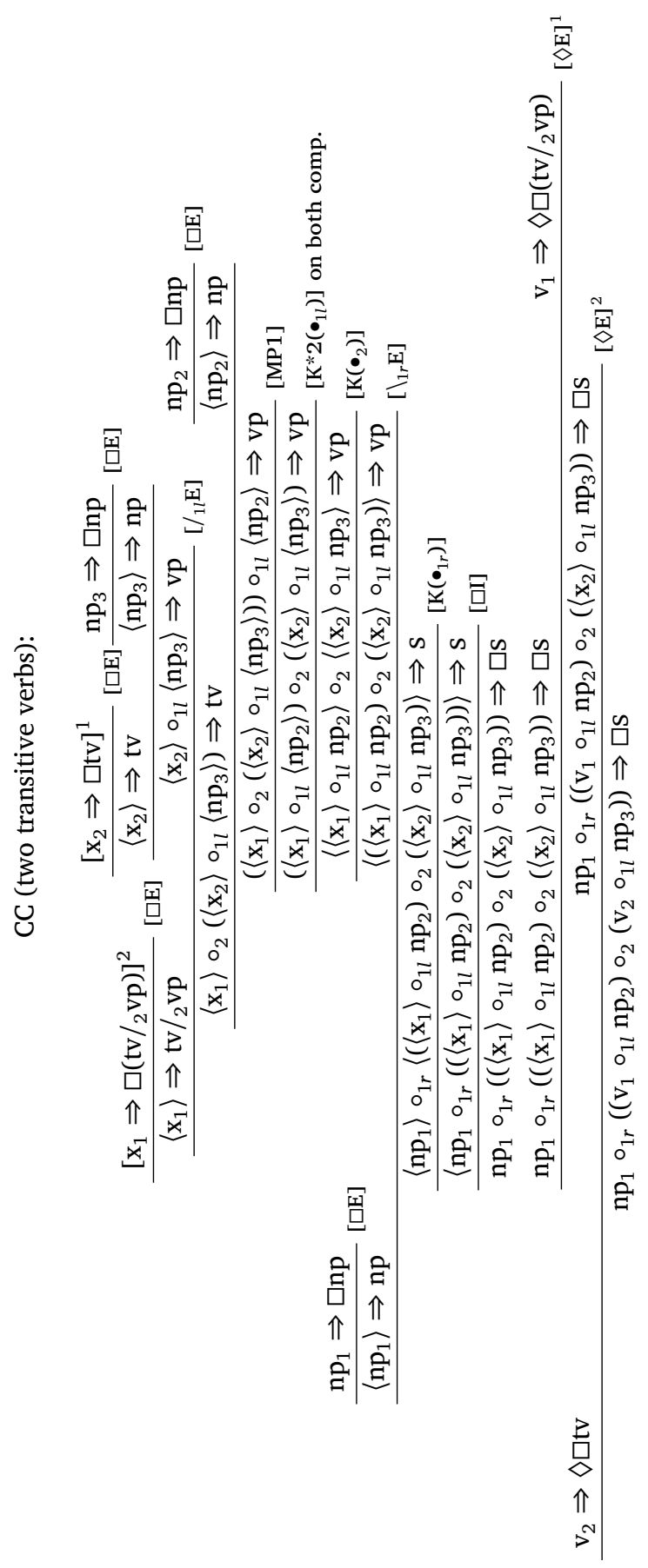


we will not annotate the syntactic proof tree with semantic terms. Instead, we follow a common practice and only give the semantic term at the end of a derivation together with an example from Section 1. We translate proper names, common nouns and mass nouns as expressions of type $e$. There are two reasons for this. Since we do not examine quantification in this article, we choose the most simple translation. On the empirical side, one has that 'bare' common nouns in Edo are standardly interpreted as singular definite expression 'the $\mathrm{cn}^{\prime}$. We assume this standard interpretation also for mass nouns and use the iota-operator: $c n \rightarrow \iota z . c n(z)$ and the same for mass nouns. ${ }^{16}$ The interpretation of $\lambda$ terms is given in the Appendix.

Recall that in a CC there is no constraint that the direct objects have to be shared. For (64) in which the direct objects are different, one gets (65a) as derivational semantics. When substituting the lexical semantics into this derivational semantics using the meaning of 'gboo' (plant) in (65c) one gets (65b). ${ }^{17}$ Note that for $V_{1}$ 'gboo' (plant) the extended form is used at the syntactic level and, therefore, the complex meaning in $(65 \mathrm{c}) .^{18}$

$$
\text { Òzó }{ }_{k} \text { gbọọ̣ ívìn bòló ộkà. }
$$

Ozo plant coconut peel corn

'Ozo planted coconut and peeled the corn.'

Stewart (2001:65)

$$
\begin{array}{ll}
\text { a. } & \left(\left(\left(x_{v_{1}}\left(x_{v_{2}} x_{n p_{3}}\right)\right) x_{n p_{2}}\right) x_{n p_{1}}\right) . \\
\text { b. } & \lambda e . \exists e_{1} \cdot \exists e_{2}\left[e=e_{1} \wedge \operatorname{plant}\left(e_{1}\right) \wedge \operatorname{peel}\left(e_{2}\right) \wedge \operatorname{actor}\left(e_{1}\right)=\right. \\
& \text { ozo } \wedge \text { theme }\left(e_{1}\right)=\iota w \cdot \operatorname{coconut}(w) \wedge \operatorname{actor}\left(e_{1}\right)=\operatorname{actor}\left(e_{2}\right) \wedge \\
& \text { theme } \left.\left(e_{2}\right)=\iota z \cdot \operatorname{corn}(z) \wedge e_{1} \preceq e_{2}\right] . \\
\text { c. } \quad \lambda V P_{2} \cdot \lambda y \cdot \lambda x \cdot \lambda e \cdot \exists e_{1} \cdot \exists e_{2}\left[e=e_{1} \wedge \operatorname{plant}\left(e_{1}\right) \wedge V P_{2}(x)\left(e_{2}\right) \wedge\right. \\
& \left.\operatorname{actor}\left(e_{1}\right)=x=\operatorname{first}\left(e_{2}\right) \wedge e_{1} \preceq e_{2}\right] .
\end{array}
$$

${ }^{16}$ Though the translation contains a term of type $\langle e, t\rangle$, i.e. $c n$, this term is not used as the translation of 'cn'.

${ }^{17}$ In (65b) we already applied simplifications related to thematic roles using equational reasoning. We did not apply the simplification $e=e_{1}$ in order to highlight the similarities and differences to SVCs.

${ }^{18}$ The original example in Stewart (2001) has an overt subject pronoun which is left out in (64). 
If the direct objects are identified, the direct object of $V_{2}$ is realized by a pronoun. A proper analysis of CCs in which the direct objects are shared requires an interpretation of pronouns in a dynamic semantics. Since such an analysis is beyond the scope of this article, we make the following assumption. Similarly to Dynamic Predicate Logic and Compositional Discourse Representation Theory, it is assumed that anaphora-antecedent relationships are represented at the level of logical form in the form of preindexation so that the antecedent of a pronoun is known. ${ }^{19}$ Using (65a) and (65c), one gets (67) for (66).

$$
\text { Òzó }{ }_{k} \text { lé ízẹ̀j } \text { Q̣ }_{k} \text { rrí ộrè̀. }
$$

Ozo cook rice he eat it

'Ozo cooked rice and he ate it.'

Stewart (2001:64)

$$
\begin{aligned}
& \lambda e . \exists e_{1} . \exists e_{2}\left[e=e_{1} \wedge \operatorname{plant}\left(e_{1}\right) \wedge \operatorname{peel}\left(e_{2}\right) \wedge \operatorname{actor}\left(e_{1}\right)=\text { ozo } \wedge\right. \\
& \text { theme }\left(e_{1}\right)=\iota \text { w.rice }(w) \wedge \operatorname{actor}\left(e_{1}\right)=\operatorname{actor}\left(e_{2}\right) \wedge \operatorname{theme}\left(e_{1}\right)= \\
& \text { theme } \left.\left(e_{2}\right) \wedge e_{1} \preceq e_{2}\right] .
\end{aligned}
$$

Next we turn to a CSVC. The derivation is displayed on page 380 .

For an illustration of the semantic derivation of a CSVC, we will use the example in (68). The derivational semantics is given in (69a). Applying (69c) to the representation of $V P_{2}$ and the two arguments of $V_{1}$ yields (69b). Note that also in this case the extended verb form is used for $V_{1}$ and hence the (complex) meaning.

(68) Òzó lé èvbàré ré.

Ozo cook food eat

'Ozo cooked food and ate it.'

Stewart (2001:60)

$$
\begin{array}{ll}
\text { a. } & \left(\left(\left(x_{v_{1}}\left(x_{v_{2}} x_{n p_{2}}\right)\right) x_{n p_{2}}\right) x_{n p_{1}}\right) . \\
\text { b. } & \lambda e . \exists e_{1} \cdot \exists e_{2}\left[e=e_{1} \sqcup e_{2} \wedge \operatorname{cook}\left(e_{1}\right) \wedge \operatorname{eat}\left(e_{2}\right) \wedge \operatorname{actor}\left(e_{1}\right)=\right. \\
& \text { ozo } \wedge \text { theme }\left(e_{1}\right)=\iota z . f o o d(z) \wedge \operatorname{actor}\left(e_{1}\right)=\operatorname{actor}\left(e_{2}\right) \wedge \\
& \text { theme }\left(e_{1}\right)=\operatorname{theme}\left(e_{2}\right) \wedge e_{1} \preceq e_{2} \wedge \square_{o z o}\left(\operatorname{occur}\left(e_{1}\right) \rightarrow\right. \\
& \left.\left.\operatorname{occur}\left(e_{2}\right)\right)\right] .
\end{array}
$$

\footnotetext{
${ }^{19}$ See Jäger (2005) for an analysis of pronouns in TLG.
} 


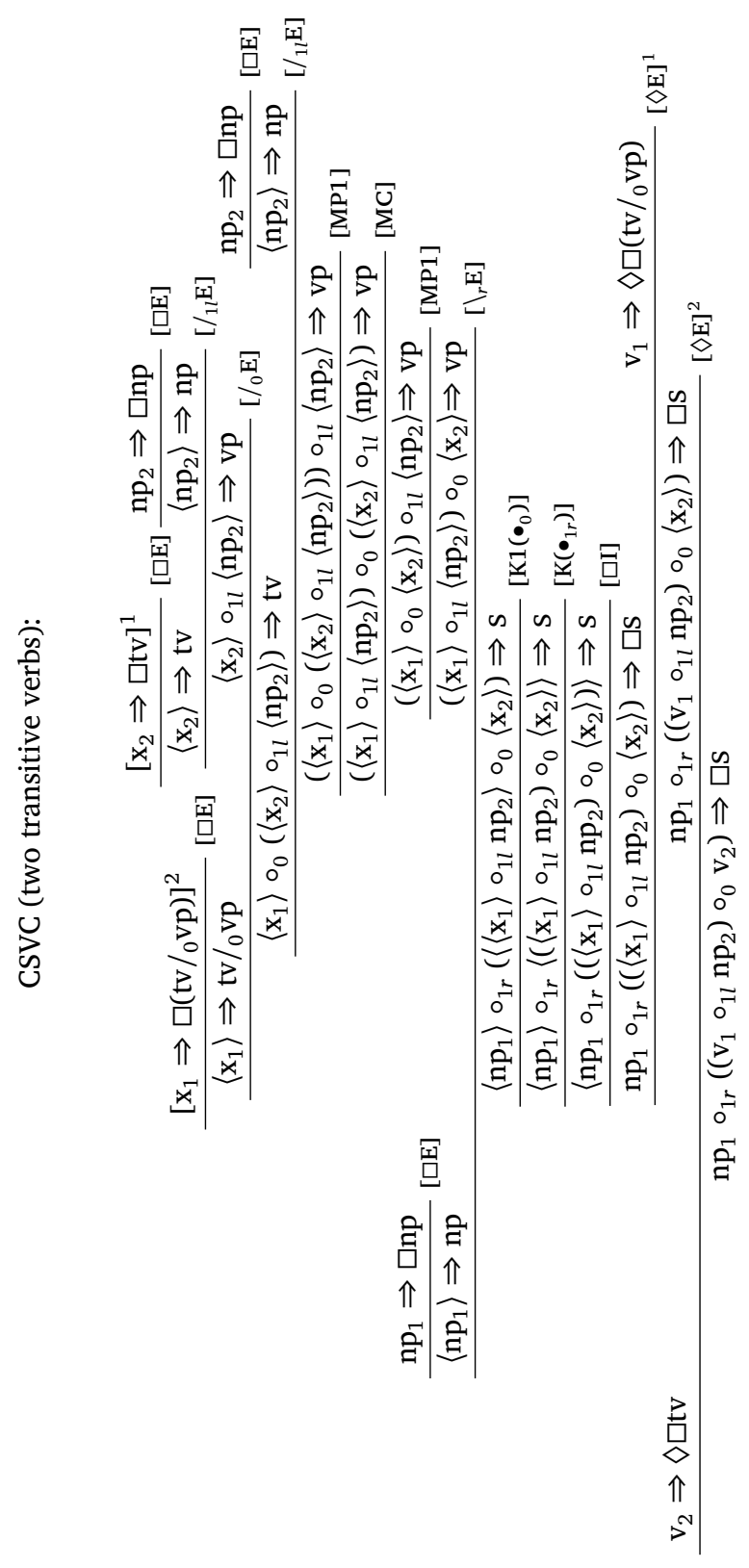


c. $\quad \lambda V P_{2} \cdot \lambda y \cdot \lambda x \cdot \lambda e . \exists e_{1} \cdot \exists e_{2}\left[e=e_{1} \sqcup e_{2} \wedge \operatorname{cook}\left(e_{1}\right) \wedge V P_{2}(x)\left(e_{2}\right) \wedge\right.$ $\operatorname{actor}\left(e_{1}\right)=x=\operatorname{first}\left(e_{2}\right) \wedge$ theme $\left(e_{1}\right)=y=\operatorname{second}\left(e_{2}\right) \wedge$ $\left.e_{1} \preceq e_{2} \wedge \square_{x}\left(\operatorname{occur}\left(e_{1}\right) \rightarrow \operatorname{occur}\left(e_{2}\right)\right)\right]$.

The derivation of simple sentences with transitive verbs

So far, CSVCs and CCs in which both verbs are transitive have been considered. In order to show the theory to be successful it is necessary to be able to also derive simple sentences with transitive verbs. The derivation is given below.

Simple Sentence (transitive verb):

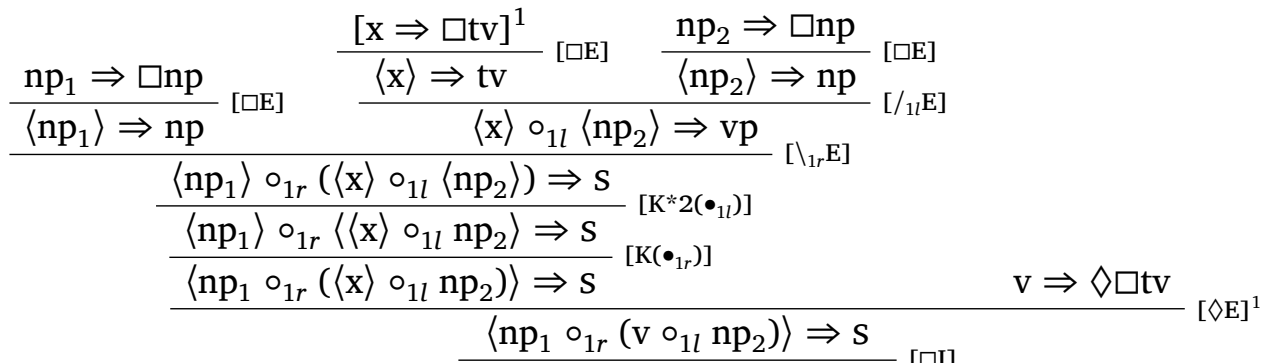

$$
\begin{aligned}
& \frac{\left\langle\mathrm{np}_{1} \circ_{1 r}\left(\mathrm{v}_{1 l} \mathrm{np}_{2}\right)\right\rangle \Rightarrow \mathrm{s}}{\left(\mathrm{np}_{1} \circ_{1 r}\left(\mathrm{v}_{1 l} \mathrm{np}_{2}\right)\right) \Rightarrow \square \mathrm{s}}[\square \mathrm{I}]
\end{aligned}
$$

Since in a simple sentence with a transitive verb the latter is not extended, it is of type $\diamond \square \mathrm{tv}$ rather than of type $\diamond \square\left(\mathrm{tv} /{ }_{i} \mathrm{vp}\right)$. Similarly to a CSVC and a CC, the derivation starts with hypothetically assuming a resource of type $\square$ tv, which gets eventually discharged using $\mathrm{v} \Rightarrow \diamond \square\left(\mathrm{tv} /{ }_{i} \mathrm{vp}\right)$ and $[\diamond \mathrm{E}]$. After composing $\mathrm{x}$ with $\mathrm{np}_{2}$ to form a vp, $\mathrm{K} * 2\left(\bullet_{1 l}\right)$ is applied, percolating the $\diamond$-decoration of the right but not that of the left component. The result is the structure $\left\langle\langle\mathrm{x}\rangle \circ_{1 l} \mathrm{np}_{2}\right\rangle$. This structure is next composed with the structure corresponding to the subject argument. Applying $\mathrm{K}\left(\bullet_{1 r}\right)$ to the resulting structure, percolates both $\diamond$-decorations, yielding the structure $\left\langle\mathrm{np}_{1} \circ_{1 r}\left(\langle\mathrm{x}\rangle \circ_{1 l} \mathrm{np}_{2}\right)\right\rangle$ of type s. Next, the hypothetical assumption is discharged. Finally, application of $[\square \mathrm{I}]$, gives the last line of the derivation. Thus, this argument actually reproduces that for the corresponding substructures in a CSVC or CC. The semantic level is illustrated with (70).

Òzó lé èvbàré.

Ozo cook food

'Ozo cooked the food.'

Stewart (2001:44) 


$$
\begin{aligned}
& \text { a. } \quad\left(\left(x_{v} x_{n p_{2}}\right) x_{n p_{1}}\right) . \\
& \text { b. } \quad \lambda e .[\operatorname{cook}(e) \wedge \operatorname{actor}(e)=o z o \wedge \operatorname{theme}(e)=\iota z . f o o d(z)] .
\end{aligned}
$$

For a CC and an RSVC, both verbs can be intransitive. From the possibility that intransitive verbs can occur as the first verb in multiverb sequences it follows that they too can have an extended subcategorization frame. This does not mean, however, that the modal decoration for intransitive verbs, either extended or not, is the same as that for transitive verbs. The choice of a modal decoration is, of course, already restricted by the rules that have been assumed for the derivation of CSVCs and CCs with two transitive verbs. In particular, the two structural rules distributing the unary connective $\diamond$ across compositions of a verb with one of its default subcategorized arguments (i.e. either the subject or the object argument) are required to hold for RSVCs and CCs with intransitive verbs, too. This constraint already excludes a modal decoration of the form $\diamond \square$ that has been used for transitive verbs in the lexicon. In a simple sentence with an intransitive verb the VP usually consists only of the verb since there is no argument to the right of the verb with which it combines first. Consequently, only $\mathrm{K}\left(\bullet_{1 r}\right)$ applies. Assuming intransitive verbs to be of type $\diamond \square \mathrm{vp}$, one gets the derivation below.

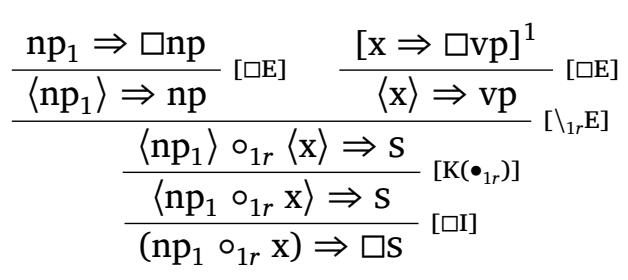

Since the vp resource is of the form $\langle\Gamma\rangle$, its decoration is percolated by the application of $\mathrm{K}\left(\bullet_{1 r}\right)$. But this means that it is no longer possible to apply the lexical axiom $\mathrm{v} \Rightarrow \diamond \square \mathrm{vp}$ to $\mathrm{x}$, using the rule $[\diamond \mathrm{E}]$ in order to discharge the hypothetical assumption and get a possible lexical substitution for the final antecedent term. The problem is that $\mathrm{K}\left(\bullet_{1 r}\right)$ was introduced in the first place for VPs that are built from a vp and an np resource, i.e. for non-lexical VPs. In this case, as has been 
shown in the preceding section, the $\diamond$-decoration of the right component originates from the np resource and should therefore be passed to the whole structure of type $s$ in order to license application of the $[\square \mathrm{I}]$ rule.

The failure of the above derivation already shows a possible solution. An intransitive verb is assigned the type $\square$ vp in the lexicon. One then gets the following derivation, which poses no problem.

Simple Sentence (intransitive verb):

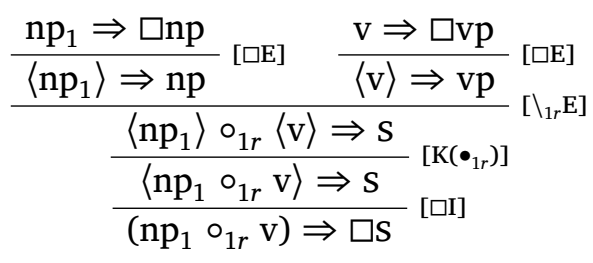

We illustrate the semantic derivation with (72).

$$
\begin{aligned}
& \text { Òzó dé. } \\
& \text { Ozo fall } \\
& \text { 'Ozo fell.' } \\
& \text { Stewart (2001:87) } \\
& \text { a. } \quad x_{\nu} x_{n p_{2}} x_{n p_{1}} \cdot \\
& \text { b. } \lambda e .[\text { fall }(e) \wedge \operatorname{theme}(e)=o z o] .
\end{aligned}
$$

For a CC with a transitive first and an intransitive second verb one gets the derivation presented below.

CC (transitive and intransitive verb):

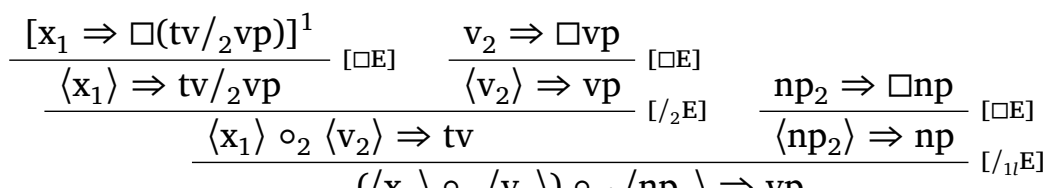

$$
\begin{aligned}
& \left(\left\langle\mathrm{x}_{1}\right\rangle \circ_{2}\left\langle\mathrm{v}_{2}\right\rangle\right) \circ_{1 l}\left\langle\mathrm{np}_{2}\right\rangle \Rightarrow \mathrm{vp} \\
& \frac{\left(\left\langle\mathrm{x}_{1}\right\rangle \circ_{1 l}\left\langle\mathrm{np}_{2}\right\rangle\right) \circ_{2}\left\langle\mathrm{v}_{2}\right\rangle \Rightarrow \mathrm{vp}}{\left[\mathrm{MP}{ }^{*}\left(\bullet_{1 l}\right)\right]} \\
& \frac{\mathrm{np}_{1} \Rightarrow \square \mathrm{np}}{\left\langle\mathrm{np}_{1}\right\rangle \Rightarrow \mathrm{np}} \quad \frac{\left\langle\left(\mathrm{x}_{1}\right\rangle \circ_{1 l} \mathrm{np}_{2}\right\rangle \circ_{2}\left\langle\mathrm{v}_{2}\right\rangle \Rightarrow \mathrm{vp}}{\left\langle\left(\left\langle\mathrm{x}_{1}\right\rangle \circ_{1 l} \mathrm{np}_{2}\right) \circ_{2} \mathrm{v}_{2}\right\rangle \Rightarrow \mathrm{vp}}\left[\mathrm{K}_{\left.\left.\bullet_{2}\right)\right]}\right. \\
& \frac{\left\langle\mathrm{np}_{1}\right\rangle \circ_{1 r}\left\langle\left(\left\langle\mathrm{x}_{1}\right\rangle \circ_{1 l} \mathrm{np}_{2}\right) \circ_{2} \mathrm{v}_{2}\right\rangle \Rightarrow \mathrm{S}}{\left\langle\mathrm{np}_{1} \circ_{1 r}\left(\left(\left\langle\mathrm{x}_{1}\right\rangle \circ_{1 l} \mathrm{np}_{2}\right) \circ_{2} \mathrm{v}_{2}\right)\right\rangle \Rightarrow \mathrm{S}}\left[\mathrm{K}\left(\bullet_{1 r}\right)\right]
\end{aligned}
$$


We illustrate the semantic composition with (74). The derivational semantics is given in (75a). Applying the extended meaning of 'ghogho' (rejoice) in (75c) to the representation of $V P_{2}$ and the two arguments of $V_{1}$ yields (75b).

$$
\begin{aligned}
& \text { Òzó ghọ̀ghọ́ ègiè khuọ̀mwín. } \\
& \text { Ozo be-happy title be-sick } \\
& \text { 'Ozo became sick after rejoicing over his title.' } \\
& \text { Stewart (2001:77) }
\end{aligned}
$$

$$
\begin{array}{ll}
\text { a. } & \left(\left(\left(x_{v_{1}} x_{v_{2}}\right) x_{n p_{2}}\right) x_{n p_{1}}\right) . \\
\text { b. } & \lambda e . \exists e_{1} \cdot \exists e_{2}\left[e=e_{1} \wedge \operatorname{rejoice}\left(e_{1}\right) \wedge \text { be-sick }\left(e_{2}\right) \wedge \operatorname{actor}\left(e_{1}\right)=\right. \\
& \text { ozo } \wedge \text { theme }\left(e_{1}\right)=\iota \text { เtitte }(z) \wedge \operatorname{actor}\left(e_{1}\right)=\operatorname{theme}\left(e_{2}\right) \wedge e_{1} \preceq \\
& \left.e_{2}\right] . \\
\text { c. } & \lambda V P . \lambda y . \lambda x . \lambda e . \exists e_{1} . \exists e_{2}\left[e=e_{1} \wedge \operatorname{rejoice}\left(e_{1}\right) \wedge V P(x)\left(e_{2}\right) \wedge\right. \\
& \text { actor }\left(e_{1}\right)=x \wedge \text { theme }\left(e_{1}\right)=y \wedge \operatorname{actor}\left(e_{1}\right)=\operatorname{first}\left(e_{2}\right) \wedge e_{1} \preceq \\
& \left.e_{2}\right] .
\end{array}
$$

For reasons of symmetry to transitive verbs, an extended intransitive verb is assigned the type $\square\left(\mathrm{vp} /{ }_{i} \mathrm{vp}\right)$, i.e. the extension of the subcategorization frame is of type vp and the modal decoration is the same as that for the unextended verb. ${ }^{20}$ With this assignment one gets the following derivation for a CC consisting of two intransitive verbs.

CC (two intransitive verbs):

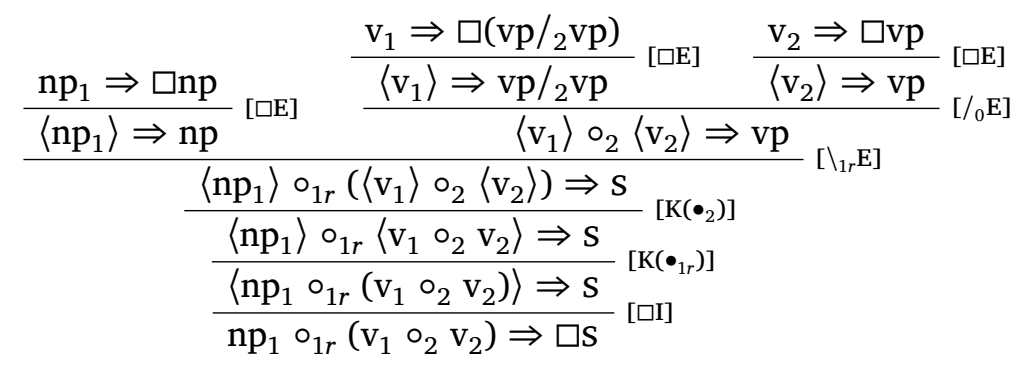

Note that the modal decoration of the extended verb with $\square$ is exactly what is required. Since $\mathrm{VP}_{1}$ consists only of $\mathrm{V}_{1}$, there being no

${ }^{20}$ The situation is more complex since one has to take into account the fact that modification with a manner adverb before the second verb is inadmissible in an RSVC but not in a CSVC and a CC; see Section 4.8 below for details. 
right-adjoined $\mathrm{NP}, \mathrm{K}\left(\bullet_{2}\right)$ removes the modal decoration of the linguistic resource corresponding to $\mathrm{V}_{1}$. If an extended intransitive verb were of type $\diamond \square\left(\mathrm{vp} /{ }_{2} \mathrm{vp}\right)$, this would lead to a sequent the antecedent term of which would not correspond to any substitution of lexical items (assuming the hypothesis $\mathrm{x}_{1} \Rightarrow \square\left(\mathrm{vp} /{ }_{2} \mathrm{vp}\right)$ ).

The derivation of an RSVC has to take into account that in this type of SVC a manner adverb can occur only before the first but not before the second verb. Assuming that each position corresponds to a particular projection of the verb that is modified, manner adverbs require two such projections. For both the CSVC and the CC, there are subexpressions that are of type vp. The first corresponds to the VP built in terms of $\mathrm{V}_{2}$, which is the first argument of the (extended) verb $\mathrm{V}_{1}$. The second subexpression of type vp is that corresponding to the sequence $\mathrm{V}_{1} \mathrm{NP}_{2} \mathrm{~V}_{2}\left(\mathrm{NP}_{3}\right)$. Modification of this expression takes place in position 1 .

If one takes a manner adverb in position 2 to modify $\mathrm{VP}_{2}$, i.e. the VP with head $\mathrm{V}_{2}$, the task consists in explaining why modification of this VP is possible in the context of an CSVC and a CC but not in the context of an RSVC. One strategy to explain this phenomenon is to use the unary connectives from the underlying logic. Recall that these connectives basically have two functions. They can either be used to license operations that are not available in the base logic or they can be used to restrict operations that are by default available in this logic. Theoretically, either of the two functions can be used to interpret the distribution of adverbs. In this article the second strategy will be adopted.

Manner adverbs are basically of type $\mathrm{vp} /{ }_{a} \mathrm{vp}$ or $\mathrm{vp} \backslash{ }_{a} \mathrm{vp} .{ }^{21}$ In order to block modification with an adverb, the second verb in an RSVC must be of a modally decorated type. Since the default type assigned to intransitive verbs is $\square \mathrm{vp}$, it has to be decorated differently. Suppose one makes the following assumptions in the context of an RSVC. The

$21 .{ }_{a}$ is the adverbial adjunction mode that combines a verbal (phrasal) structure with an adverb. 
head adjunction mode is ${ }_{2}$, i.e. the same mode that is used for a CC. The type of an intransitive second verb is $\square \square \square v p$ whereas that of extended intransitive verbs is $\square\left(\mathrm{vp} /{ }_{2} \square \square \mathrm{vp}\right)$. An extended transitive verb has type $\diamond \square\left(\mathrm{tv} /{ }_{2} \square \square v p\right)$ and its unextended variants that occur as the second verb have type $\diamond \square\left(\square \square \mathrm{vp} /{ }_{11} \mathrm{np}\right)$. Below the derivations for the three types of an RSVC are given. The derivation of an RSVC with two transitive verbs is displayed on page 387 and that with a transitive and an intransitive verb on page 388.

RSVC (two intransitive verbs):

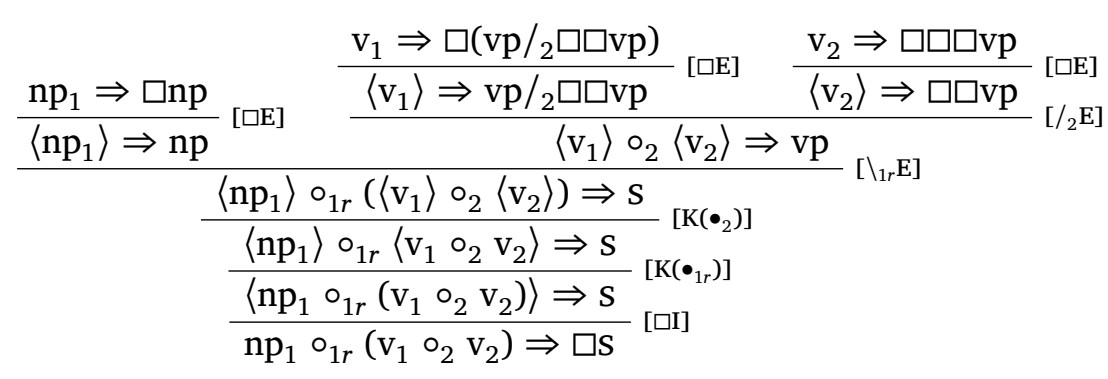

The case of two transitive verbs is illustrated with (76). The derivational semantics is given in (77a): the meaning representation of the extended $V_{1}$ 'gbe' (hit) in (77c) applied to $V P_{2}$ and the two arguments of $V_{1}$ yields (77b).

$$
\begin{aligned}
& \text { Òzó gbé ẹ̀khù làá òwá. } \\
& \text { Ozo hit door enter house } \\
& \text { 'Ozo hit the door into the house.' } \\
& \text { Stewart (2001:145) }
\end{aligned}
$$

$$
\begin{aligned}
& \text { a. } \quad\left(\left(x_{v_{1}}\left(x_{v_{2}} x_{n p_{3}}\right) x_{n p_{2}}\right) x_{n p_{1}}\right) \text {. } \\
& \text { b. } \lambda e . \exists e_{1} . \exists e_{2}\left[e=e_{1} \sqcup e_{2} \wedge \operatorname{hit}\left(e_{1}\right) \wedge \operatorname{enter}\left(e_{2}\right) \wedge \operatorname{actor}\left(e_{1}\right)=\right. \\
& \text { ozo } \wedge \text { theme }\left(e_{1}\right)=\iota w \text {.door }(w) \wedge \text { theme }\left(e_{1}\right)=\operatorname{actor}\left(e_{2}\right) \wedge \\
& \text { theme } \left.\left(e_{2}\right)=\imath z \text {.house }(z) \wedge \text { cause }\left(e_{1}, e_{2}\right)\right] \text {. } \\
& \text { c. } \quad \lambda V P_{2} . \lambda y . \lambda x . \lambda e . \exists e_{1} . \exists e_{2}\left[e=e_{1} \sqcup e_{2} \wedge h i t\left(e_{1}\right) \wedge V P_{2}(y)\left(e_{2}\right) \wedge\right. \\
& \operatorname{actor}\left(e_{1}\right)=x \wedge \text { theme }\left(e_{1}\right)=y \wedge \text { theme }\left(e_{1}\right)=\operatorname{first}\left(e_{2}\right) \wedge \\
& \left.\operatorname{cause}\left(e_{1}, e_{2}\right)\right] \text {. }
\end{aligned}
$$

The semantics for an RSVC with a transitive and an intransitive verb is illustrated with (78). The derivational semantics applied to the example is given in (79). 
A type-logical analysis of SVCs and CCs in Edo

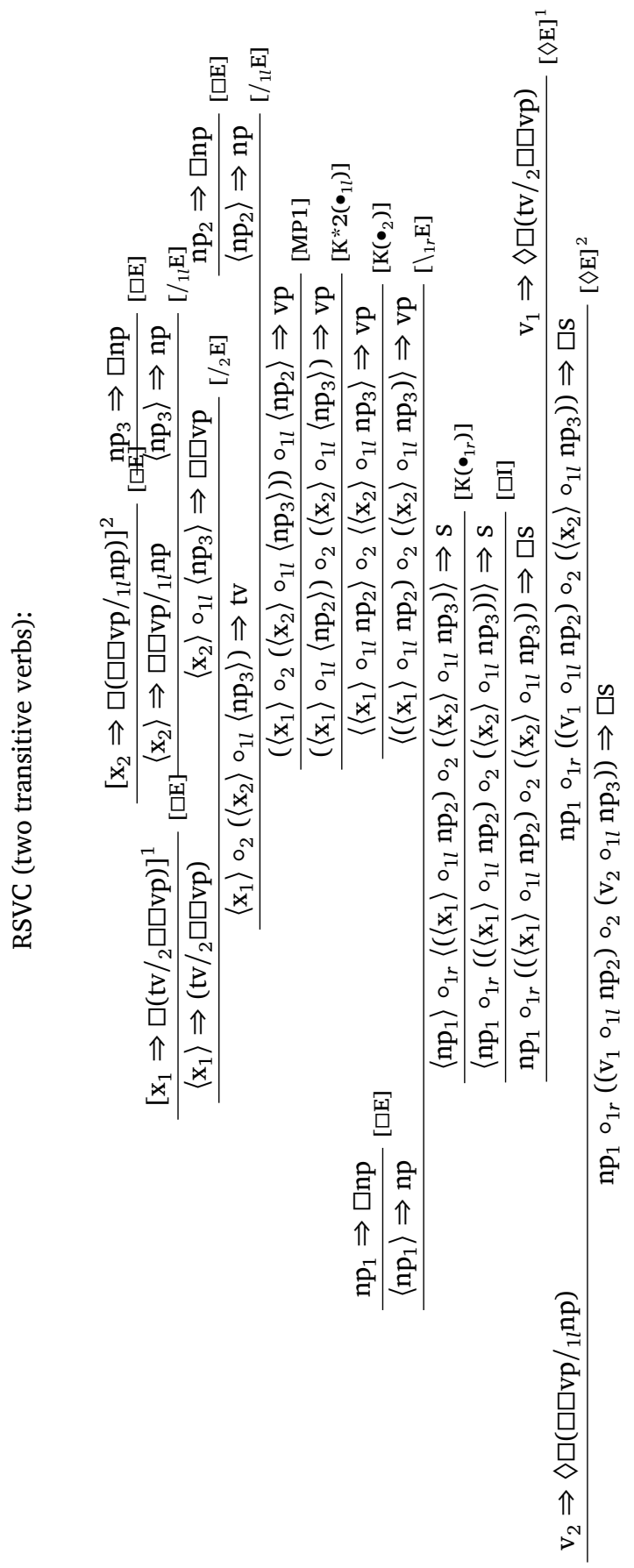




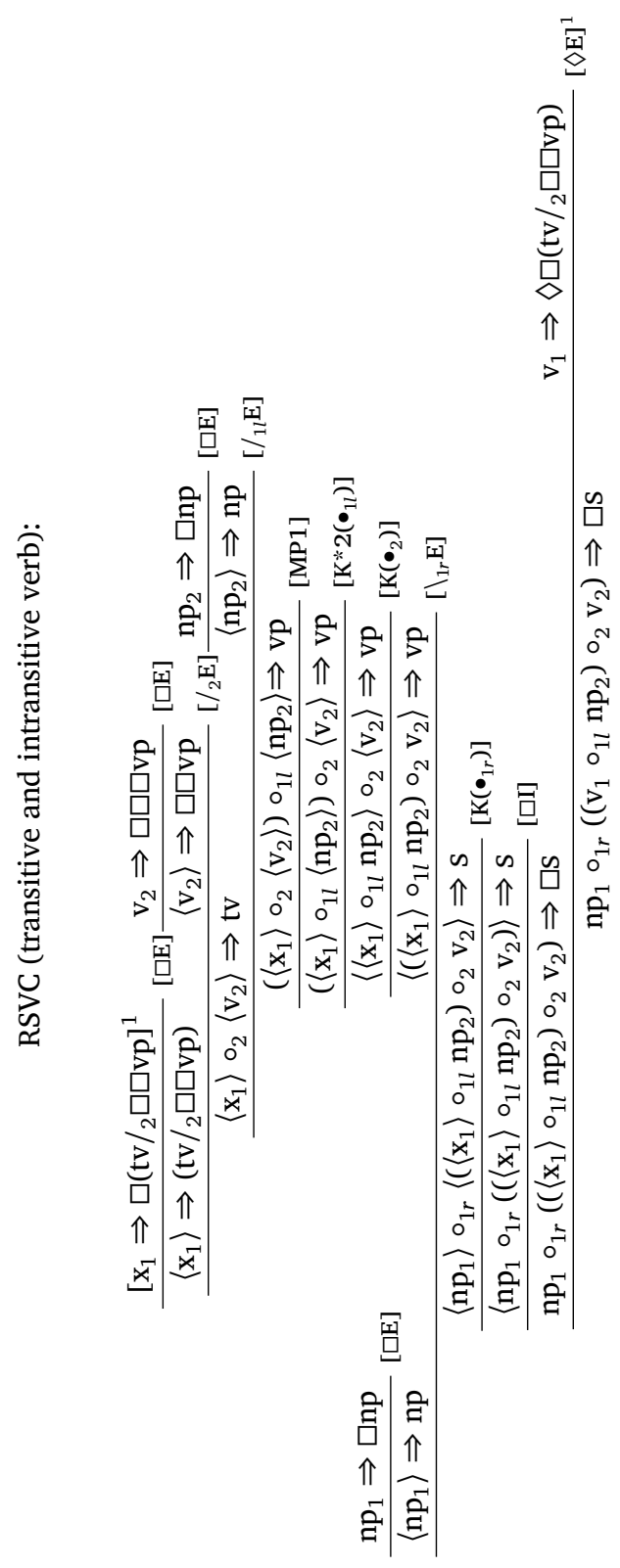


(78) Òzó kòkó Àdésúwà mòsé.

Ozo raise Adesuwa be-beautiful

'Ozo raised Adesuwa to be beautiful.'

Stewart (2001:12)

(79)
a. $\left.\quad\left(\left(x_{v_{1}} x_{v_{2}}\right) x_{n p_{2}}\right) x_{n p_{1}}\right)$.
b. $\quad \lambda e . \exists e_{1} . \exists e_{2}\left[e=e_{1} \sqcup e_{2} \wedge\right.$ raise $\left(e_{1}\right) \wedge$ be_beautiful $\left(e_{2}\right) \wedge$ actor $\left(e_{1}\right)=$ ozo $\wedge$ theme $\left(e_{1}\right)=$ adusewa $\wedge$ theme $\left(e_{1}\right)=$ theme $\left.\left(e_{2}\right) \wedge \operatorname{cause}\left(e_{1}, e_{2}\right)\right]$
c. $\quad \lambda V P_{2} \cdot \lambda y . \lambda x \cdot \lambda e \cdot \exists e_{1} \cdot \exists e_{2}\left[e=e_{1} \sqcup e_{2} \wedge\right.$ raise $\left(e_{1}\right) \wedge V P_{2}(y)\left(e_{2}\right) \wedge$ $\operatorname{actor}\left(e_{1}\right)=x \wedge$ theme $\left(e_{1}\right)=y \wedge$ theme $\left(e_{1}\right)=\operatorname{first}\left(e_{2}\right) \wedge$ $\left.\operatorname{cause}\left(e_{1}, e_{2}\right)\right]$

For an RSVC with two intransitive verbs, we consider (80).

$$
\begin{aligned}
& \text { Òzó dé wú. } \\
& \text { Ozo fall die } \\
& \text { 'Ozo fell to death.' } \\
& \text { Stewart (2001:15) }
\end{aligned}
$$

$$
\begin{array}{ll}
\text { a. } & \left(\left(x_{v_{1}} x_{v_{2}}\right) x_{n p}\right) . \\
\text { b. } & \lambda e . \exists e_{1} \cdot \exists e_{2}\left[e=e_{1} \sqcup e_{2} \wedge \operatorname{fall}\left(e_{1}\right) \wedge \operatorname{die}\left(e_{2}\right) \wedge \operatorname{actor}\left(e_{1}\right)=\right. \\
& \left.o z o \wedge \operatorname{actor}\left(e_{1}\right)=\operatorname{theme}\left(e_{2}\right) \wedge \operatorname{cause}\left(e_{1}, e_{2}\right)\right] . \\
\text { c. } & \lambda V P_{2} \cdot \lambda x \cdot \lambda e \cdot \exists e_{1} \cdot \exists e_{2}\left[e=e_{1} \sqcup e_{2} \wedge \operatorname{fall}\left(e_{1}\right) \wedge V P_{2}(x)\left(e_{2}\right) \wedge\right. \\
& \text { actor } \left.\left(e_{1}\right)=x \wedge \operatorname{actor}\left(e_{1}\right)=\operatorname{first}\left(e_{2}\right) \wedge \operatorname{cause}\left(e_{1}, e_{2}\right)\right] .
\end{array}
$$

In contrast to a CSVC, the manner adverb 'giegie' cannot occur in position 2 of an RSVC. In the text this inadmissibility has been explained by a modal decoration at the syntactic level. One may argue that there is an alternative, semantic explanation. The inadmissibility of this type of adverb in position 2 results if one assumes that the VP headed by $V_{2}$ is not a constituent of the sentence. One way of achieving this is to assume that in an RSVC the complex predicate is not an extended verb that has an additional VP argument but a basic complex predicate. For example, the meaning of 'de' (fall) when used as first verb in an RSVC would be (82).

$$
\begin{aligned}
& \lambda y \cdot \lambda x \cdot \lambda e \cdot \exists e_{1} \cdot \exists e_{2}\left[e=e_{1} \sqcup e_{2} \wedge \operatorname{fall}\left(e_{1}\right) \wedge \operatorname{die}\left(e_{2}\right) \wedge \operatorname{actor}\left(e_{1}\right)=\right. \\
& \text { first } \left.\left(e_{2}\right) \wedge \text { theme }\left(e_{1}\right)=\operatorname{second}\left(e_{2}\right) \wedge \operatorname{cause}\left(e_{1}, e_{2}\right)\right] .
\end{aligned}
$$


Generalizing this argument, one may say that this strategy applies whenever all arguments of the second verb are shared with an argument of the first verb. From this perspective it also applies to a CSVC with two transitive verbs. However, this strategy faces the following two problems. First, in a CSVC with two transitive verbs a manner adverb can occur in position 2 . This problem could be solved by assuming that 'giegie' can itself infix into a complex predicate. This means however that 'giegie' needs to be assigned an additional syntactic type and that an additional mechanism is necessary to explain why this infixation is blocked for an RSVC. The second problem is that this strategy cannot be applied if not all arguments of the second verb are shared with one argument of the first verb. This means that it cannot be applied to CSVCs with two ditransitive verbs (indirect objects must be different) and in RSVCs with two transitive verbs (direct objects need not be shared). Hence, this strategy fails to apply even to one subtype of an SVC without exception.

Similarly to a CSVC with two transitive verbs, in a CSVC with a ditransitive verb the subjects and direct objects are identified and the direct object of the second verb cannot be overtly realized. By contrast, the indirect object of the ditransitive verb is not identified with any object of the other verb. In particular, in the case of a CSVC with two ditransitive verbs, the indirect objects are not identified.

If, for a ditransitive verb, one assumes the order of arguments that are looked for to the right to be IO - DO, a ditransitive verb poses no problems at the level of word order since the objects are concatenated in the correct order: $\mathrm{V} \mathrm{NP}_{\mathrm{IO}} \mathrm{NP}_{\mathrm{DO}}$. However, if the order is DO - IO, as this is assumed for instance in Lexical Decomposition Grammar (Gamerschlag 2005), one gets $\mathrm{V} \mathrm{NP}_{\mathrm{DO}} \mathrm{NP}_{\mathrm{IO}}$. One strategy that has been applied to achieve the correct word order is the use of so-called discontinuity operators (see e.g. Morrill 1994, 1995). The functors built from the directional slashes adjoin either to the left or to the right of their arguments to form a continuous string. For functors built from a discontinuity operator, functor and argument are composed in a different way. The first sort of such operators are wrapping 
and infixing operators. A functor $\mathrm{B} \uparrow \mathrm{A}$ wraps around an argument of type A to form a B. By contrast, a functor $B \downarrow A$ infixes itself in an A to form a B. In order to wrap around an $A$ the functor expression must consist of two parts. For example, if these parts are $s$ and $s^{\prime}$, wrapping yields $s+s^{\prime \prime}+s^{\prime}$, for $s^{\prime \prime}$ being an expression of type A. The second sort of discontinuity operators are used to construe such 'splitting' or pair expressions. An expression of type $\mathrm{B}<\mathrm{A}$ takes an expression of type $\mathrm{A}$ to form a pair expression with the functor expression as first and the argument expression as second element: Using $<$ and $\uparrow$, a ditransitive verb can be assigned the type (vp $\uparrow \mathrm{np})<\mathrm{np}$. Given an appropriate permutation rule, $\mathrm{vp} /{ }_{l} \mathrm{np}_{2} / \mathrm{np}_{1}$ is derivable from $\left(\mathrm{vp} \uparrow \mathrm{np}_{1}\right)<\mathrm{np}_{2}$.

In a multimodal variant of $\mathrm{NL}(\diamond)$ this strategy can be simulated in the following way. A wrapping or infixing operation is modelled by a permutation rule. The discontinuity operators can be represented by particular modes of composition. Moortgat and Oerhle (1993) distinguish four types of head wrapping modes: $\cdot_{i j}$ with $i=1 l$ or $i=1 r$ and $j=h$ or $j=d$. The first index indicates the infix and the second index indicates whether the infix is the head $(h)$ or the dependent $(d)$ of the combination. The mixed permutation rule MP2 says that a left dependent infix (B) can be infixed in a $\circ_{1 l}$ structure.

$$
\text { MP2: }\left(\mathrm{A} \bullet \bullet_{r d} \mathrm{~B}\right) \bullet{ }_{1 l} \mathrm{C} \rightarrow\left(\mathrm{A} \bullet{ }_{1 l} \mathrm{C}\right) \bullet_{r d} \mathrm{~B}
$$

The relationship between ${ }{ }_{1 l}$ and ${ }{ }_{1 r}$ on the one hand and the head wrapping modes ${ }_{i j}$ is captured by rules such as that in (84).

$$
\mathrm{K}(\mathrm{l} / \mathrm{rd}): \mathrm{A} \bullet{ }_{1 l} \mathrm{~B} \rightarrow \mathrm{A} \bullet_{r d} \mathrm{~B}
$$

Adopting this strategy, a ditransitive verb is assigned the types in (85).

$$
\begin{aligned}
& \diamond \square\left(\mathrm{vp} /{ }_{r d} \mathrm{np} /{ }_{1 l} \mathrm{np}\right) \text { (unextended); } \diamond \square\left(\mathrm{vp} /{ }_{r d} \mathrm{np} /{ }_{1 l} \mathrm{np} /{ }_{0} \mathrm{vp}\right) \text { (ex- } \\
& \text { tended) }
\end{aligned}
$$

In order to derive a simple sentence with a ditransitive verb needed are the two structural rules in (86).

$$
\begin{array}{ll}
\text { a. } & \mathrm{K}^{*}\left(\bullet_{1 l}\right): \diamond\left(\left(\diamond \mathrm{A} \bullet_{r d} \mathrm{~B}\right) \bullet_{1 l} \mathrm{C}\right) \rightarrow \diamond\left(\diamond \mathrm{A} \bullet_{r d} \mathrm{~B}\right) \bullet_{1 l} \diamond \mathrm{C} \\
\text { b. } & \mathrm{K} * 2\left(\bullet_{r d}\right): \diamond\left(\diamond \mathrm{A} \bullet_{r d} \mathrm{~B}\right) \rightarrow \diamond \mathrm{A} \bullet_{r d} \diamond \mathrm{B}
\end{array}
$$

The rule $\mathrm{K}^{*}\left(\bullet_{11}\right)$ allows for the percolation of the modal decorations of both components of a $\circ_{1 l}$-structure if the left component is 
a $\circ_{r d}$-structure, i.e. a structure which composes a (lexical) verbal element with an NP. Thus, this rule is applicable only in the context of ditransitive verbs. The rule $\mathrm{K}^{*}\left(\bullet_{r d}\right)$ is similar to the rule $\mathrm{K}^{*}\left(\bullet_{1 l}\right)$. It allows for the percolation of the modal decoration of the right component of a $\circ_{r d}$-structure, provided its left component is modally decorated, too.

Derivation of the VP in a simple sentence with a ditransitive verb:

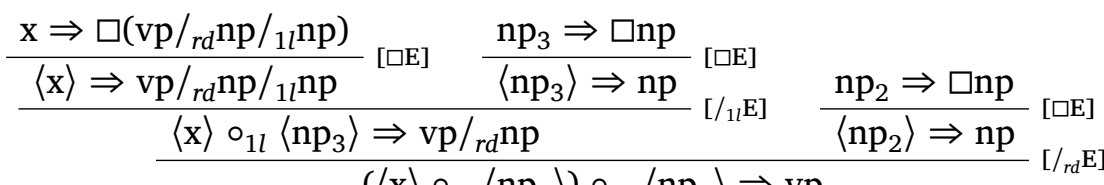

$$
\begin{aligned}
& \begin{array}{l}
\frac{\left(\langle\mathrm{x}\rangle \circ_{1 l}\left\langle\mathrm{np}_{3}\right\rangle\right) \circ_{r d}\left\langle\mathrm{np}_{2}\right\rangle \Rightarrow \mathrm{vp}}{\left[\left(\langle\mathrm{x}\rangle \circ_{r d}\left\langle\mathrm{np}_{2}\right\rangle\right) \circ_{1 l}\left\langle\mathrm{np}_{3}\right\rangle \Rightarrow \mathrm{vp}\right.}\left[{ }^{\mathrm{MP} 2]}\right. \\
\frac{\left\langle\langle\mathrm{x}\rangle \circ_{r d} \mathrm{np}_{2}\right\rangle \circ_{1 l}\left\langle\mathrm{np}_{3}\right\rangle \Rightarrow \mathrm{vp}}{\left\langle\left(\bullet_{r d}\right)\right]}\left[\mathrm{K}^{*}\left(\bullet_{\bullet_{1 l}}\right)\right] \\
\frac{\left\langle\left(\langle\mathrm{x}\rangle \circ_{r d} \mathrm{np}_{2}\right) \circ_{1 l} \mathrm{np}_{3}\right\rangle \Rightarrow \mathrm{vp}}{\left\langle\left(\langle\mathrm{x}\rangle \circ_{1 l} \mathrm{np}_{2}\right) \circ_{1 l} \mathrm{np}_{3}\right\rangle \Rightarrow \mathrm{vp}}[\mathrm{K}(1 / \mathrm{rd})]
\end{array}
\end{aligned}
$$

Not applying MP2 has the same effect as in the case of MPl. If in line $6 \mathrm{~K}^{*} 1\left(\bullet_{1 l}\right)$ instead of $\mathrm{K}^{*}\left(\bullet_{11}\right)$ is used, the structural operator of $\left\langle\langle\mathrm{x}\rangle \circ_{r d} \mathrm{np}_{2}\right\rangle$ is not percolated. Since the semantics adds nothing new, it is skipped.

For the derivation of a CSVC with a ditransitive first and a transitive second verb, the mixed permutation rule MP3 is needed.

$$
\text { MP3: }(\mathrm{A} \bullet r d \mathrm{C}) \bullet_{0} \mathrm{~B} \rightarrow\left(\mathrm{A} \bullet_{0} \mathrm{~B}\right) \bullet_{r d} \mathrm{C}
$$

Below the relevant steps of the derivation of the VP are given.

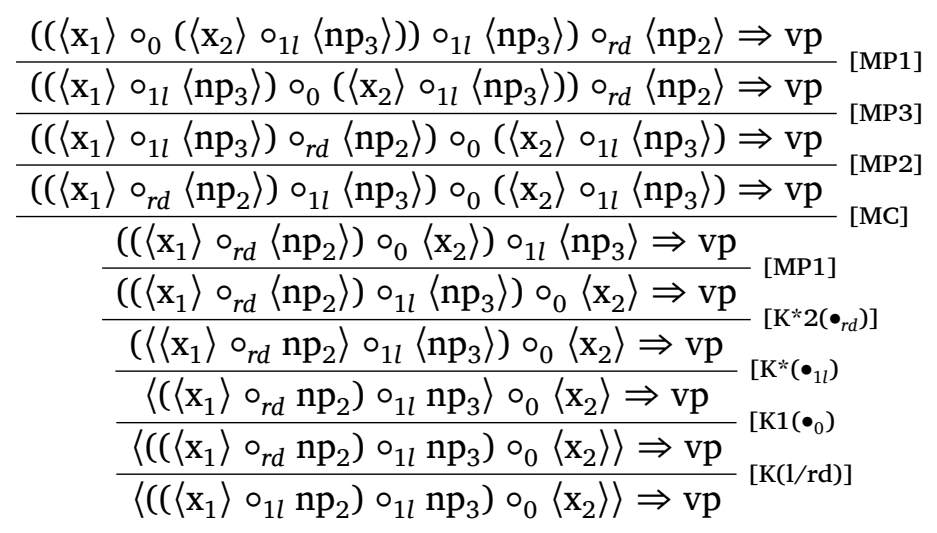

The by now familiar arguments apply if particular rules are not used or if the order is reversed. For example, if MC is not applied, one 
only gets a structure of the form $\langle\Gamma\rangle \circ_{0}\left(\left\langle\mathrm{x}_{2}\right\rangle \circ_{1 l}\left\langle\mathrm{np}_{3}\right\rangle\right)$. The structural operator from $\mathrm{np}_{3}$ must be percolated. Yet this is not possible because $\mathrm{K} 1\left(\bullet_{0}\right)$ only percolates the structural operator of the left component. If MP1 is not applied in line 5, one gets the following continuation.

$$
\frac{\left(\left(\left\langle\mathrm{x}_{1}\right\rangle \circ_{r d}\left\langle\mathrm{np}_{2}\right\rangle\right) \circ_{0}\left\langle\mathrm{x}_{2}\right\rangle\right) \circ_{1 l}\left\langle\mathrm{np}_{3}\right\rangle \Rightarrow \mathrm{vp}}{\left(\left\langle\left\langle\mathrm{x}_{1}\right\rangle \circ_{r d} \mathrm{np}_{2}\right\rangle \circ_{0}\left\langle\mathrm{x}_{2}\right\rangle\right) \circ_{1 l}\left\langle\mathrm{np}_{3}\right\rangle \Rightarrow \mathrm{vp}}\left[\mathrm{K}^{\left.* 2\left(\bullet_{r d}\right)\right]}\left[\mathrm{K}\left(\bullet_{0}\right)\right]\right.
$$

Now only rule $\mathrm{K} * 2\left(\bullet_{1 l}\right)$ can be used, which does not percolate the structural operator of the left component. Yet, this operator has to be percolated since it originates from $\mathrm{np}_{2}$. An analogous argument applies if in line 7 instead of $\mathrm{K} *\left(\bullet_{1 l}\right) \mathrm{K} * 2\left(\bullet \bullet_{1 l}\right)$ is used.

Skipping the application of the structural rule for the subject, we will give the semantic derivation for (88).

$$
\text { Úyi hàe İsọ̀kẹ̀n íghó dó-rhié }
$$

Uyi pay Isoken money steal

'Uyi paid Isoken the money and stole it.'

Stewart (2001:137)

$$
\begin{array}{ll}
\text { a. } & \left(\left(\left(\left(x_{v_{1}}\left(x_{v_{2}} x_{n p_{3}}\right)\right) x_{n p_{3}}\right) x_{n p_{2}}\right) x_{n p_{1}}\right) . \\
\text { b. } \quad & \lambda e . \exists e_{1} \cdot \exists e_{2}\left[e=e_{1} \sqcup e_{2} \wedge \operatorname{pay}\left(e_{1}\right) \wedge \operatorname{steal}\left(e_{2}\right) \wedge \operatorname{actor}\left(e_{1}\right)=\right. \\
& \text { uyi } \wedge \text { theme }\left(e_{1}\right)=\iota w \cdot \operatorname{money}(w) \wedge \operatorname{goal}\left(e_{1}\right)= \\
& \text { isoken } \wedge \operatorname{actor}\left(e_{1}\right)=\operatorname{actor}\left(e_{2}\right) \wedge \operatorname{theme}\left(e_{1}\right)= \\
& \text { theme }\left(e_{2}\right) \wedge e_{1} \preceq e_{2} \wedge \square_{u y i}\left(\operatorname{occur}\left(e_{1}\right) \rightarrow \operatorname{occur}\left(e_{2}\right)\right) . \\
\text { c. } \quad & \lambda V P_{2} . \lambda z . \lambda y . \lambda x . \lambda e . \exists e_{1} . \exists e_{2}[e= \\
& e_{1} \sqcup e_{2} \wedge \operatorname{pay}\left(e_{1}\right) \wedge V P_{2}(x)\left(e_{2}\right) \wedge \operatorname{actor}\left(e_{1}\right)=x \wedge \operatorname{theme}\left(e_{1}\right)= \\
& z \wedge \operatorname{goal}\left(e_{1}\right)=y \wedge \operatorname{actor}\left(e_{1}\right)=\operatorname{first}\left(e_{2}\right) \wedge \operatorname{theme}\left(e_{1}\right)= \\
& \operatorname{second}\left(e_{2}\right) \wedge e_{1} \preceq e_{2} \wedge \square_{x}\left(\operatorname{occur}\left(e_{1}\right) \rightarrow \operatorname{occur}\left(e_{2}\right)\right) .
\end{array}
$$

For a CSVC with a transitive first and a ditransitive second verb, the relevant steps of the derivation of the VP are shown below.

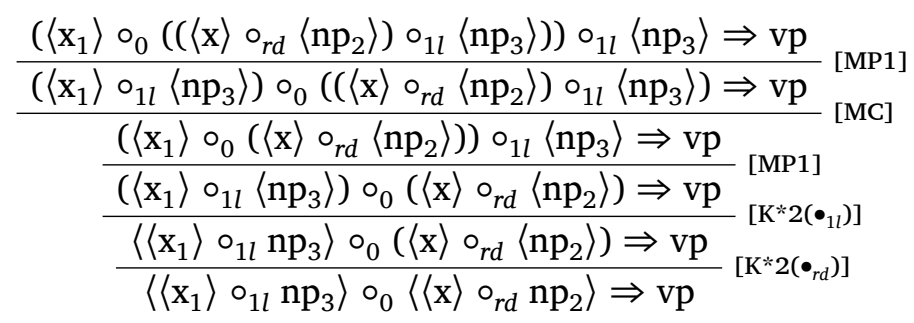


Now a problem arises because $\mathrm{K} 1\left(\bullet_{0}\right)$ only percolates the structural operator of the left component and leaves the right component unchanged. Yet, in this particular case the structural operator of the left component has to be percolated, too. Noticing that the right structure is composed by $\circ_{r d}$, this problem can be overcome by adding the rule $\mathrm{K}^{*}\left(\bullet_{0}\right)$.

$$
\mathrm{K}^{*}\left(\bullet_{0}\right): \diamond\left(\mathrm{A} \circ_{0}\left(\diamond \mathrm{B} \circ_{r d} \mathrm{C}\right)\right) \rightarrow \diamond \mathrm{A} \circ_{0} \diamond\left(\diamond \mathrm{B} \circ_{r d} \mathrm{C}\right)
$$

$\mathrm{K}^{*}\left(\bullet_{0}\right)$ is applicable only in the context of a verbal cluster with a ditransitive verb to which MC has been applied. Using this rule, one gets line 7.

7.

$$
\left\langle\left(\left\langle\mathrm{x}_{1}\right\rangle \circ_{1 l} \mathrm{np}_{3}\right) \circ_{0}\left(\langle\mathrm{x}\rangle \circ_{r d} \mathrm{np}_{2}\right)\right\rangle \Rightarrow \mathrm{vp}
$$

Applying $\mathrm{K} 1\left(\bullet_{0}\right)$ in line 6 does not percolate the structural operator originating from $\mathrm{np}_{3}$. If MPl is not used in line 3 , the structural operator of this resource is likewise not percolated. If MC is not applied in line 2, it is possible to derive the sequent in (91) by applying $\mathrm{K} * 2\left(\bullet_{r d}\right)$ and $\mathrm{K} * 2\left(\bullet_{1 l}\right)$ to the left component of this line.

$$
\left(\left\langle\mathrm{x}_{1}\right\rangle \circ_{1 l}\left\langle\mathrm{np}_{3}\right\rangle\right) \circ_{0}\left\langle\left\langle\langle\mathrm{x}\rangle \circ_{r d} \mathrm{np}_{2}\right\rangle \circ_{1 l} \mathrm{np}_{3}\right\rangle \Rightarrow \mathrm{vp}
$$

$\mathrm{K}^{*}\left(\bullet_{0}\right)$ can be applied to this sequent. Yet since the structural operator of the left component of $\left\langle\left\langle\langle\mathrm{x}\rangle \circ_{r d} \mathrm{np}_{2}\right\rangle \circ_{1 l} \mathrm{np}_{3}\right\rangle$ is not percolated, the sequent is linguistically ill-formed. If instead of $\mathrm{K}^{* 2} 2\left(\bullet_{1 l}\right) \mathrm{K} *\left(\bullet_{1 l}\right)$ is used, one gets the sequent in (92).

$$
\left(\left\langle\mathrm{x}_{1}\right\rangle \circ_{1 l}\left\langle\mathrm{np}_{3}\right\rangle\right) \circ_{0}\left\langle\left(\langle\mathrm{x}\rangle \circ_{r d} \mathrm{np}_{2}\right) \circ_{1 l} \mathrm{np}_{3}\right\rangle \Rightarrow \mathrm{vp}
$$

Though this removes the structural operator of the left component of $\left\langle\left(\langle\mathrm{x}\rangle \circ_{r d} \mathrm{np}_{2}\right) \circ_{1 l} \mathrm{np}_{3}\right\rangle$, now rule $\mathrm{K}^{*}\left(\bullet_{0}\right)$ cannot be applied because it requires this left component to be modally decorated. Application of rule $\mathrm{K} 1\left(\bullet_{0}\right)$ only percolates the structural operator of the left but not that of the right component. Yet, both operators must be percolated to the dominating ${ }_{0}$-structure.

Due to space restrictions we cannot give a detailed analysis of manner adverbs. Manner adverbs are basically of syntactic type $v p /{ }_{a} v p$ or $v p \backslash_{a} v p$ with ${ }_{a}$ the adverbial adjunction mode that combines a verbal 
(phrasal) structure with an adverb. Hence, there is nothing new compared to standard analyzes of adverbs in other languages. In an SVC or a CC there are two VPs. One is projected by $V_{2}$ and the other is projected by the extended verb $V_{1}$. In position 2 the adverb modifies the $V P$ projected by $V_{2}$ whereas in position 1 it is the $V P$ projected by $V_{1}$ that gets modified. Since $V_{2}$ is interpreted relative to $e_{2}$, it is this event that is ascribed the property expressed by the adverb. By contrast, if the VP projected by $V_{1}$ is modified, the property is ascribed to the event denoted by the complex predicate. In an SVC this is the sum event $e=e_{1} \sqcup e_{2}$ whereas in a CC it is $e_{1}$.

The analysis in Baker and Stewart (1999) is based on two assumptions. Following Hale and Keyser (1993), they assume that (canonical) ${ }^{22}$ transitive verbs semantically decompose into a causal/process and a transition/result component. This bipartition at the semantic level is reflected in the syntax by distinguishing between a $\mathrm{v}$ and a $\mathrm{V}$ element, with the former corresponding to the causal/process and the latter corresponding to the transition/result component. In addition to this distinction, it is assumed that agentive subjects are generated in the specifier position of a Voice Phrase (Kratzer 1996). The dominance relation is Voice $>\mathrm{v}>\mathrm{V}$. The three multiverb sequences are then distinguished in terms of the types of nodes that are independently projected by the two component verbs.

a. RSVC: there are no independent projections common to both verbs. Rather, since $\mathrm{V}_{1}$ is a (canonical) transitive verb, it has both a $\mathrm{v}$ and a $\mathrm{V}$ component. In an RSVC, this VP does not immediately dominate V but V', which,

${ }^{22}$ An example for non-canonical transitive verbs given by Baker and Stewart (1999:18) are stative verbs, which are not admissible as the first verb in an RSVC and a CSVC. 
in turn, immediately dominates $\mathrm{V}_{1}$ and $\mathrm{V}_{2}$ (Baker and Stewart 1999:18). Consequently, there is only one VP, one $\mathrm{vP}$ and one VoiceP.

b. CSVC: each verb projects its own VP and vP. Since vP is the highest node independently projected by a component verb, the two verbs are merged at the level of $\mathrm{vP}$. As a result, one has two VPs but three $\mathrm{vPs}^{\mathrm{NP}} \mathrm{vP}_{1}, \mathrm{vP}_{2}$ and $\mathrm{vP}_{1 / 2}$, which immediately dominates both $\mathrm{vP}_{1}$ and $\mathrm{vP}_{2}$.

c. CC: each verb projects its own VP, vP and VoiceP. Consequently, there are two VPs and two vPs. Since VoiceP is the maximal node independently projected by a component verb, the maximal projections of the verbs are merged at the level of VoiceP so that there are three nodes of this type: Voice $\mathrm{P}_{1}$, VoiceP $_{2}$ and VoiceP $\mathrm{P}_{1 / 2}$, the latter immediately dominating both Voice $_{1}$ and VoiceP $_{2}$.

Since both in a CSVC and a CC the two component verbs are treated on a par in the sense that each verb projects the same types of nodes, it follows that there should be no asymmetries in the interpretation of adverbs. Yet this is not the case. Manner adverbs like 'giegie' (quickly) behave asymmetrically in a CSVC. Before the first verb, it is the joint action expressed by both verbs that is required to have the property expressed by the adverb whereas an adverb of this type between $\mathrm{NP}_{2}$ and the second verb imposes this requirement only on the action expressed by the second verb. According to Baker and Stewart (1999, 2001), adverbs like 'giegie' can be attached either to VoiceP or to $\mathrm{VP}$, but not to VP. The authors account for the interpretation of those adverbs before the second verb by attaching it to $\mathrm{vP}_{1 / 2}$, i.e. the vP node at which the two projections are merged in a CSVC. Consequently, both events (or their join) must be semantically accessible at this node. By contrast, attaching an adverb of this type to $\mathrm{vP}_{2}$ accounts for the interpretation before the second verb according to which only the action expressed by $V_{2}$ is required to have the property. The problem now is that, by symmetry, an adverb of this type should also be attachable to $\mathrm{vP}_{1}$, yielding the interpretation that it is the action expressed by $\mathrm{V}_{1}$ which has the corresponding property. Yet, an adverb like 'giegie' does not have such an interpretation. An analogous prob- 
lem arises for adverbially modified CCs. A similar criticism applies to Stewart (2001).

Thus, in an analysis which treats both verbs on a par, an adverb that attaches to XP such that there can be up to three nodes of this type in an SVC or a CC should (i) induce three different interpretations and (ii) have the same interpretations relative to $V_{1}$ and $V_{2}$. Both predictions are not borne out by manner adverbs like 'giegie'. By contrast, in our analysis these adverbs always modify expressions of type vp. ${ }^{23}$ Since the two component verbs are treated asymmetrically, only two subexpressions of type vp are generated. One is headed by the unextended second verb whereas the second is projected by the extended first verb.

In contrast to Baker and Stewart, Ogie (2010) does not analyze CSVCs in terms of pro in the object position of $\mathrm{V}_{2}$. Working in the HPSG framework and following Hellan et al. (2003), she bases her analysis on a distinction between different types of argument sharing patterns. The first pattern is token sharing by grammatical functions. In this pattern the verbs $V_{1} \ldots V_{n}$ share an NP token that is syntactically realized as an argument of $V_{1}$. As an effect, there is one token NP bearing a particular grammatical function to the verbs in the series. This pattern is used for subjects and objects in a CSVC. At the formal level, this pattern is represented as identity between the values of the QVAL attribute of the head-daughter and the non-head-daughter with the token being instantiated on the VAL list of the head-daughter. For an RSVC, token sharing by grammatical function is not possible because in this pattern two argument positions share all (grammatical) properties. This constraint on token sharing does not hold in an RSVC simply because the argument is assigned the grammatical function of direct object relative to $V_{1}$ and subject relative to $V_{2}$. Hence, the argument sharing pattern must be different. For an RSVC, the pattern is switch sharing.

${ }^{23}$ Note that we follow the conventions of Type Logical Grammar in using lower case letters for maximal projections of lexical heads. In this sense 'vp' is headed by a verb and must not be confused with 'vp' projected by a head such as 'cause' in present day generative syntax. 
In this pattern, the NP which bears the grammatical function of direct object to $V_{1}$ and which is overtly realized in its canonical position also bears the subject function to $V_{2}$. Formally, this is represented by identifying the referential index of the non-head-daughter SUBJECT value with the value of the head-daughter's DOBJ's value. For the subjects in a CC, the argument sharing pattern is that of covert reference sharing. In this pattern, the NP which bears the grammatical function of subject to $V_{1}$ shares its referential index with the unsaturated subject argument of $V_{2}$. A subject is unsaturated if it is not realized on the valence list of the verb to which it bears this grammatical function. At the formal level the value of the SUBJECT attribute is identified with the XARG value for the non-head-daughter. The non-head-daughter's XARG value is in turn identified with its SUBJECT's INDEX value by identifying the referential index.

Ogie uses the distribution of the 'tobore' anaphora as empirical evidence for her assigning of argument sharing patterns. This anaphora is used for emphasis and its basic use is as a subject oriented adverb. Importantly, it cannot occur in object position. For CSVCs, CCs and RSVCs, one gets the following pattern (Ogie 2010:295). ${ }^{24}$
a. Òzó ${ }_{k}$ lé èvbàrè tòbọ́rè ${ }_{k}$ ré.
Ozo cook food by.himself eat intended: Ozo cooked food and ate it by himself.' CSVC
b. Òzó ${ }_{k}$ dẹ ízẹ̀ tòbọ́rè ${ }_{k}$ rrí ọ̀ré.
Ozo buy rice by.himself ate it
Ozo bought rice and ate it by himself.'
CC
c. 'Òzó ${ }_{k}$ kòkó Àdésúwà tòbọ́rè ${ }_{k}$ mòsé.
Ozo raise Adesuwa by.himself be.beautiful
intended: 'Ozo raised Adesuwa by himself to be beauti-
ful.'
RSVC

These examples show that 'tobore' is admissible before $\mathrm{V}_{2}$ only in the CC construction. Having three argument sharing patterns in place, Ogie analyzes the distribution of the anaphora 'tobore' as follows, (Ogie 2010:302). Clauses in which this anaphora is not licensed before

${ }^{24}$ For the sake of simplicity, we have reduced the more detailed glosses by Ogie in (94) and (95). 
$V_{2}$ are analyzed as having one token NP bearing the subject grammatical function of the verbs in the construction. By contrast, clauses in which 'tobore' can occur before $V_{2}$ are analyzed as sharing referents between the subject arguments of the verbs in the series and $V_{2} \ldots V_{n}$ have unsaturated subjects. When taken at face value this explanation only accounts for the cases of CSVCs and CCs but not for the case of an RSVC. Ogie is aware of this and adds that a second type of clause, prohibiting the anaphora before $V_{2}$, is characterized by the switch argument pattern.

However, this move is not convincing because it brings about the question as to what is the property common to the token sharing pattern and the switch sharing pattern that sets them aside from the overt reference sharing pattern underlying a CC. This property cannot be token sharing because this requires identity of grammatical function, a requirement that is not met in an RSVC where the direct object of $V_{1}$ is related to the subject of $V_{2}$. Recall that in an RSVC the switch sharing is realized by identity of the referential index between the direct object of $V_{1}$ and the subject of $V_{2}$. One possibility is to assume that token sharing by grammatical function implies identity of their corresponding referential indices. As an effect, this latter property would be common to the two argument sharing patterns characterizing the two types of SVCs. The problem with this explanation is that identity of the referential indices is also used for the pattern of overt reference sharing. Hence, one has to conclude that identity of referential indices cannot be the common property of the argument patterns underlying SVCs that explains the distribution of 'tobore'.

Ogie defines the relation between the events denoted by SVCs and CCs in terms of the temporal relation between them. Two relations are distinguished. Disjointness of two events requires that the first event (completely) precedes the second. Two events are partially ordered if they are disjoint and if, in addition, the second event occurs immediately after the first $\left(e_{1}\right.$ meets $\left.e_{2}\right)$. Whereas disjointness characterizes the relation between the events both in CSVCs and in CCs, events denoted by RSVCs are related by the partial order relation. From these definitions it follows that Ogie does not define the difference between SVCs and CCs at the level of single vs. non-single (join) of events. This has the effect that there is no difference between CSVCs and CCs at the level of events because the relation between the events is reduced 
to the temporal relation between them. However, this does not capture the constraint on the events denoted by a CSVC that the actor carries out the first event with the intention to carry out the second event afterwards. Furthermore, it is not captured that manner adverbs in position 1, i.e. before $V_{1}$ are interpreted as determining a property of the sum of the events and not only of the event contributed by the interpretation of the first verb. By contrast, in our approach SVCs are semantically characterized by the fact that the complex predicate is interpreted relative to the sum of the events. As a result, manner adverbs in position 1 are interpreted with respect to this sum, in accordance with the data.

A third criticism has to do with the question of whether Ogie's analysis of the distribution of 'tobore' generalizes to other kinds of expressions which show a particular distributional pattern in SVCs and CCs, like manner adverbs, for example. Her analysis of 'tobore' does not directly generalize to this class of adverbs since they are not syntactically related to an NP but to a verb or the VP headed by it. In particular, the adverb applies to $V P_{2}$ before the modified VP combines with the extended verb related to $V_{1}$ both in a CSVC and a CC. It does, therefore, play no role whether the subject of $V_{2}$ is 'unsaturated' or whether it is token-identical to the subject of $V_{1}$. Hence, Ogie needs a different mechanism to explain the distribution of manner adverbs.

A final question is the following: what is the relation between the templates for SVCs and CCs on the one hand and that for verbs in simple sentences on the other? It seems that different entries are required depending on whether the verb occurs as the second verb in an SVC or in a CC. For example, in a CC the subject of $V_{2}$ is unsaturated whereas in a CSVC this is not the case. In our approach verbs that can occur as the first verb in an SVC or CC have different types.

Let us compare Ogie's approach with ours. Ogie develops her analysis at the level of argument sharing patterns. In contrast to this approach, argument sharing patterns are not used to explain differences between RSVCs, CSVCs and CCs. Rather these differences are explained as differences at the semantic level and, hence, at the level of event structure. But even at the level of argument sharing patterns the analyses differ. In our approach, there is no difference between token and reference sharing. For example, if two arguments are shared, this means that they are 'token-identical' in the sense that there is a 
single referent that bears the thematic relation(s) to the two events.

We will close by discussing an example involving quantification. In Ogie's approach, one effect of token sharing by grammatical function is that it ensures that all properties of the NP, including scope resolution with $V_{2}$ in an adjunction relation to $V_{1}$, are shared. This becomes relevant for the interpretation of the two examples below (Ogie 2010:416).
a. Òzó dẹ èbé khéré tìé.
Ozo buy book few read
'Ozo bought a few books and read them (all).'
CSVC
b. Òzó sùá èrhán khéré dè-lé.
Ozo push tree few fall
'Ozo pushed a few trees down.'
RSVC

Baker and Stewart (2002) observed that (95a) has an E-type reading. It is true only if Ozo bought a few books in total and read them all. By contrast, (95b) is true in a situation in which Ozo pushed many trees but only a few fell as an effect of the pushing. Ogie (2010:417) argues that the interpretation of (95a) follows from the fact that due to token sharing of the objects the quantifier has scope over both verbs since all properties are shared. By contrast, in the RSVC the switch sharing pattern applies. This pattern involves different grammatical functions so that the scopal properties are not shared. As an effect the quantifier has scope only over $\mathrm{V}_{2}$.

Though we cannot give an account of quantification in this article, mainly due to the fact that this requires an extension of compositional semantics and event semantics along the lines proposed in Champollion (2015) and Bott and Sternefeld (2017), we will sketch how the above data can be analyzed in our approach. So far we assumed that there is a single event that is targeted, via $\lambda$-abstraction, in a complex predicate. For SVCs, this is the join $e=e_{1} \sqcup e_{2}$ of the events in the action sequence whereas it is only the first event $e_{1}$ in this sequence in a CC. Data like (95) show that the actual situation is more complex. There need not be a single event that is targeted by operators that take the complex predicate as argument. Rather, which event is targeted depends on the operator. One way to account for this dependency on the operator is to interpret complex predicates relative to sets of events. As a result, the operator can 'select' one event in this set. We 
assume the following selection criteria. For manner adverbs: the maximal event relative to $\sqsubseteq$ in this set is selected, and for quantifiers like 'khere': the first event in the action sequence that is minimal relative to $\sqsubseteq$ is selected. Using these two criteria, one can set $E=\left\{e, e_{1}, e_{2}\right\}$ as the most general solution, i.e. each complex predicate makes both the single events and their join accessible for operations. However, given the fact that $e_{1}$ is always targeted in a CC and $e$ in an RSVC, for both operations considered here it is possible to restrict the choices in the following way. For a CSVC: $E=\left\{e, e_{1}\right\}$, for an RSVC: $E=\{e\}$ and for a CC: $E=\left\{e_{1}\right\}$.

The distribution of 'tobore' can equally be explained by a selection criterion. It selects the maximal event in the set, provided it is of a (homogeneous) sort and not a (heterogeneous) sum event. This excludes SVCs because the maximal event is not homogeneous. A CC is admissible because there is only one event in the set which is of a basic sort.

\section{GONGLUSION}

In this article, we presented an analysis of SVCs and CCs in the Kwa language Edo. The basic idea of our analysis is that SVCs and CCs denote complex event structures that are derived from simple ones denoted by verbs in isolation. At the semantic level verbs that occur as first verbs in one of these constructions are interpreted as mapping a VP denotation to an n-ary relation denoting a complex event structure. For SVCs, the events in this structure are linked either by a plan (CSVC) or a causal relation (RSVC). For a CC, the events are only related by temporal succession. SVCs are interpreted relative to the join consisting of the events in the sequence whereas a CC is interpreted relative to $e_{1}$. As a result, manner adverbs modifying a complex predicate express a property of the complex event in an SVC and of $e_{1}$ in a CC. From this semantic characterization it follows that at the syntactic level (first) verbs in complex predicates take an additional argument of type $v p$. Hence, SVCs and CCs express complex event structures without using overt coordination or subordination. The application of structural rules like permutation and contraction at the syntactic 
level is enforced by a combination of modal decoration and K-rules. Modal decorations are used for verbs and NPs though the way they are decorated is different.

We will close by mentioning two open questions and directions for future work. Since the use of a contraction rule does not guarantee the finite reading property, it is interesting to look for an alternative analysis which dispenses with such a rule. A second question concerns the analysis of CCs in which the subject of $V_{2}$, which is coreferential with the subject of $\mathrm{V}_{1}$, is realized by an overt pronoun. The analysis presented in this article does not capture this case but only those in which this subject is not overtly realized. Furthermore, the analysis must be extended to negated and other types of adverbially modified multiverb sequences. Due to lack of space, no analysis of manner adverbs could be given.

\section{APPENDIX: \\ MULTIMODAL NON-ASSOGIATIVE LAMBEK-CALGULUS WITH UNARY MULTIPLICATIVE OPERATORS}

The base logic from the landscape of substructural logics that is used in this article is a multimodal variant of the non-associative Lambek calculus enriched with unary (modal) operators (or connectives) that function as control devices. This logic will be referred to by $\mathrm{NL}(\diamond)$. We start by defining the categorial language. A categorial formula (or category) is inductively defined on the basis of a set $\Omega$ of atomic category formulas and a set $i \in I$ as

$$
\Phi::=\Omega\left|\Phi /{ }_{i} \Phi\right| \Phi \bullet_{i} \Phi\left|\Phi \backslash_{i} \Phi\right| \diamond \Phi \mid \square \Phi
$$

The collection of categorial formulas, inductively defined on the basis of $\Omega$ and $I$, will also be referred to by $\operatorname{CAT}_{I}(\Omega)$. For the fragment of Edo considered in this article, it is sufficient to set $\Omega=\{\mathrm{np}, \mathrm{s}\}$. The elements of $I$ are modes of compositions. Each family $\left\{/_{i}, \bullet_{i}, \backslash_{i}\right\}$ is interpreted relative to a ternary accessibility relation $R_{i}$. By contrast, the unary connectives are interpreted relative to a binary accessibility 
relation $R_{\diamond}$. Given a valuation $v$ that assigns to each atomic categorial formula a subset of a set $W$ of linguistic resources, $v$ is extended to complex formulas as given in (96). ${ }^{25}$

$$
\begin{array}{ll}
\text { a. } & v\left(\mathrm{~A} \bullet_{i} \mathrm{~B}\right)=\left\{x \mid \exists y \exists z\left[R_{i}(x, y, z) \wedge y \in v(\mathrm{~A}) \wedge z \in v(\mathrm{~B})\right]\right\} \\
\text { b. } & v\left(\mathrm{C} /{ }_{i} \mathrm{~B}\right)=\left\{y \mid \forall x \forall z\left[\left(R_{i}(x, y, z) \wedge z \in v(\mathrm{~B})\right) \rightarrow x \in v(\mathrm{C})\right]\right\} \\
\text { c. } & v\left(\mathrm{~A} \backslash \backslash_{i} \mathrm{~B}\right)=\left\{z \mid \forall x \forall y\left[\left(R_{i}(x, y, z) \wedge y \in v(\mathrm{~A})\right) \rightarrow x \in v(\mathrm{~B})\right]\right\} \\
\text { d. } & v(\diamond \mathrm{A})=\left\{x \mid \exists y\left[R_{\diamond}(x, y) \wedge y \in v(\mathrm{~A})\right]\right\} \\
\text { e. } & v(\square \mathrm{A})=\left\{x \mid \forall y\left[R_{\diamond}(y, x) \rightarrow y \in v(\mathrm{~A})\right]\right\}
\end{array}
$$

The set $\Sigma$ of antecedent terms (or structures) is inductively defined by $\Sigma::=\Omega\left|\left(\Sigma \circ_{i} \Sigma\right)\right|\langle\Sigma\rangle$. The binary structural connectives $\circ_{i}$ match the $\bullet_{i}$ at the level of categorial formulas. Analogously, $\langle\cdot\rangle$ matches the unary connective $\diamond .{ }^{26}$

The relation between syntax and semantics is based on a function $\tau: \operatorname{CAT}_{I}(\Omega) \mapsto$ Types. The set of types is defined below.

DEFINITION 2 Types The set of basic types is Base $=\{e, t\}$. Given Base, the set of types Types is the smallest set s.t.

- Base $\subseteq$ Types,

- $\langle a, b\rangle \in$ Types, if $a \in$ Types and $b \in$ Types.

The mapping $\tau$ from syntactic types to semantic types is driven by the semantic interpretation of SVCs and CCs. Since we are working in a Neo-Davidsonian event framework, verbs in general get an additional (last) argument of sort 'event'. This has the effect that after discharging the $n-1$ non-event arguments one gets a term of type $\langle e, t\rangle$, i.e. a set of events. Standardly, one gets a term of type $t$ by applying existential closure $(\lambda P . \exists e . P(e)$.). We will not implement this operation and assume that the syntactic type $s$ is mapped to the semantic type $\langle e, t\rangle$ : $\tau(s)=\langle e, t\rangle .{ }^{27}$ Since we do not treat quantification, the syntactic type $n p$ is mapped to the semantic type $e: \tau(n p)=e$.

${ }^{25}$ Thus, categorial formulas are interpreted relative to frames $\left\langle W,\left\{R_{i}\right\}_{i \in I}, R_{\diamond}\right\rangle$.

${ }^{26}$ Instead of $\circ_{i}$ and $\langle\cdot\rangle$ one also finds $(\cdot)^{i}$ and $(\cdot)^{\diamond}$. Thus, one has $(\Sigma, \Sigma)^{i}$ and $(\Sigma)^{\diamond}$.

${ }^{27}$ See Winter and Zwarts (2011) for one way of how such an operation can be incorporated into (abstract) categorial grammar. Our mapping for $s$ resembles that in possible world semantics where sentences are propositions, i.e. sets of possible worlds. 

a. $\tau(n p)=e$.
b. $\tau(s)=\langle e, t\rangle$.
c. $\quad \tau\left(A \backslash_{i} B\right)=\tau\left(A /{ }_{i} B\right)=\langle\tau(A), \tau(B)\rangle$.
d. $\tau(A \bullet B)=\tau(A) \times \tau(B)$.

Unary modalities are semantically inactive so that one has $\tau(\square A)=$ $\tau(\diamond A)=\tau(A)$, Morrill (1994).

Given the mapping $\tau$, each category formula (syntactic type) $A$ assigned to a lexical item is paired with a typed $\lambda$-term representing the meaning of the item when it is assigned the syntactic type $A$. The set of $\lambda$-terms is defined below.

DEFINITION 3 Typed $\lambda$-term $\quad V A R_{\alpha}$ is a countable infinite set of variables of type $\alpha$ and $\mathrm{CON}_{\alpha}$ a set of constants of type $\alpha$. The set $\lambda$-term ${ }_{\alpha}$ of types $\lambda$-terms of type $\alpha$ is recursively defined as:

- $V A R_{\alpha} \subseteq \lambda$-term ${ }_{\alpha}$

- $\mathrm{CON}_{\alpha} \subseteq \lambda$-term ${ }_{\alpha}$

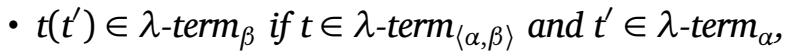

- $\lambda x$.t $\in \lambda$-term ta, $\beta\rangle_{i}$ if $x \in V A R_{\alpha}$ and $t \in \lambda$-term ${ }_{\beta}$.

Term $=\bigcup_{\alpha \in \text { Types }} \lambda$-term ${ }_{\alpha}$ is the set of all (typed) $\lambda$-terms. Given a model $\mathfrak{M}$ and a variable assignment $\theta$, the denotation (or interpretation) of a $\lambda$-term is defined as follows: (i) $\llbracket x \rrbracket_{\mathfrak{M}}^{\theta}=\theta(x)$ if $x \in$ $V A R_{\alpha}$, (ii) $\llbracket c \rrbracket_{\mathfrak{M}}^{\theta}=\llbracket c \rrbracket$ if $c \in C O N_{\alpha}$, (iii) $\llbracket t\left(t^{\prime}\right) \rrbracket_{\mathfrak{M}}^{\theta}=\llbracket t \rrbracket_{\mathfrak{M}}^{\theta}\left(\llbracket t^{\prime} \rrbracket_{\mathfrak{M}}^{\theta}\right)$, and (iv) $\llbracket \lambda x . t \rrbracket_{\mathfrak{M}}^{\theta}=f$ such that $f(a)=\llbracket t \rrbracket_{\mathfrak{M}}^{\theta[x:=a]}$.

Sequents are annotated with $\lambda$-terms. A sequent is a pair $\left(\Gamma^{\prime}, B^{\prime}\right)$. $\Gamma^{\prime}$ is of the form $\left(x_{1}: A_{1}, \ldots, x_{n}: A_{n}\right)$ where each $A_{i} \in \Sigma$ and the variables $x_{i}$ in the antecedent are mutually distinct. $B^{\prime}$ is of the form $t: B$ where $B \in \Phi$ and the term $t$ is constructed out of the $x_{i}$. Hence, a derivation of an annotated sequent represents the computation of a denotation recipe $t$ of (syntactic) type $B$ with input parameters $x_{i}$ of (syntactic) type $A_{i}$, Moortgat (1997). Sequents are written as $\Gamma \Rightarrow B$.

The logic is a combination of inference rules for the constructors $\{/, \backslash, \bullet, \square, \diamond\}$, relativized to a particular mode, and a set of structural rules of inference for the manipulation of the antecedents in sequents. Below, a sequent presentation of NL $(\diamond)$ in the Natural Deduction format is given. Besides the identity axiom and the cut rule (which is 
eliminable), one has as inference rules introduction and elimination rules for each binary and unary connective.

The base logic NL $(\diamond)$ :

$$
\begin{aligned}
& {[\mathrm{Ax}] \overline{x: \mathrm{A} \Rightarrow x: \mathrm{A}}} \\
& {\left[/_{i} \mathrm{I}\right] \frac{\left(\Gamma \circ_{i} x: \mathrm{B}\right) \Rightarrow t: \mathrm{A}}{\Gamma \Rightarrow \lambda x \cdot t: \mathrm{A} /{ }_{i} \mathrm{~B}}} \\
& {\left[\backslash_{i} \mathrm{I}\right] \frac{\left(x: \mathrm{B} \circ_{i} \Gamma\right) \Rightarrow t: \mathrm{A}}{\Gamma \Rightarrow \lambda x . t: \mathrm{B} \backslash_{i} \mathrm{~A}}} \\
& {\left[\bullet_{i} \mathrm{I}\right] \frac{\Gamma \Rightarrow t: \mathrm{A} \quad \Delta \Rightarrow u: \mathrm{B}}{\left(\Gamma \circ_{i} \Delta\right) \Rightarrow\langle t, u\rangle: \mathrm{A} \bullet_{i} \mathrm{~B}}} \\
& {[\square \mathrm{I}] \frac{\langle\Gamma\rangle \Rightarrow t: \mathrm{A}}{\Gamma \Rightarrow t: \square \mathrm{A}}} \\
& {[\diamond \mathrm{I}] \frac{\Gamma \Rightarrow t: \mathrm{A}}{\langle\Gamma\rangle \Rightarrow t: \diamond \mathrm{A}}} \\
& \frac{\Gamma \Rightarrow t: \mathrm{A} \quad \Delta[x: \mathrm{A}] \Rightarrow u: \mathrm{C}}{\Delta[\Gamma] \Rightarrow u[\mathrm{t} / x]: \mathrm{C}}[\mathrm{Cut}] \\
& \frac{\Gamma \Rightarrow t: \mathrm{A} /{ }_{i} \mathrm{~B} \quad \Delta \Rightarrow u: \mathrm{B}}{\left(\Gamma \circ_{i} \Delta\right) \Rightarrow(t u): \mathrm{A}}\left[/{ }_{i} \mathrm{E}\right] \\
& \frac{\Gamma \Rightarrow u: \mathrm{B} \quad \Delta \Rightarrow t: \mathrm{B} \backslash_{i} \mathrm{~A}}{\left(\Gamma \circ_{i} \Delta\right) \Rightarrow(t u): \mathrm{A}}\left[\backslash_{i} \mathrm{E}\right] \\
& \frac{\Delta \Rightarrow u: \mathrm{A} \bullet_{i} \mathrm{~B} \quad \Gamma\left[x: \mathrm{A} \circ_{i} y: \mathrm{B}\right] \Rightarrow t: \mathrm{C}}{\Gamma[\Delta] \Rightarrow t\left[\pi^{0}(u) / x, \pi^{1}(u) / x\right]: \mathrm{C}}\left[\bullet_{i} \mathrm{E}\right] \\
& \frac{\Gamma \Rightarrow t: \square \mathrm{A}}{\langle\Gamma\rangle \Rightarrow t: \mathrm{A}}[\square \mathrm{E}] \\
& \frac{\Delta \Rightarrow u: \diamond \mathrm{A} \quad \Gamma[\langle x: \mathrm{A}\rangle] \Rightarrow t: \mathrm{B}}{\Gamma[\Delta] \Rightarrow t[u / x]: \mathrm{B}}[\diamond \mathrm{E}] .
\end{aligned}
$$


Whereas the logical rules are fixed, the structural rules depend on the application. Since we are using a multimodal setting, the structural rules are relativized to particular modes. The following modes of composition are distinguished for Edo.

$\cdot_{1 r}$ : right-headed verb-complement (subject-verb relation)

${ }_{1 l}$ : left-headed verb-complement (non-subject (object)-verb relation)

${ }_{0}$ : verb-adjunction mode for an CSVC (relation between extended verb and additional argument in this kind of SVC)

$\cdot_{2}$ : verb-adjunction mode for an RSVC and a CC (relation between extended verb and additional argument in these two kinds of multiverb sequences)

$\cdot_{r d}$ : head wrapping mode for ditransitive verbs

Thus, in the present context $I=\left\{\cdot_{1 r},{ }_{11 l},{ }^{\circ},{ }^{\cdot},{ } \cdot{ }_{r d}\right\}$. Given $I, \mathrm{NL}(\diamond)$ is extended by the following structural rules. As already said above, this kind of rule is used to manipulate the antecedents of sequents. Furthermore, except for the rule of contraction, structural rules are semantically inert, i.e. they do not operate on the $\lambda$-term in the consequent. We give both the algebraic and the natural deduction sequent presentation. ${ }^{28}$

K-Rules:

a. $\mathrm{K}\left(\bullet_{1 r}\right): \diamond\left(\mathrm{A} \bullet \bullet_{1 r} \mathrm{~B}\right) \rightarrow \diamond \mathrm{A} \bullet \bullet_{1 r} \diamond \mathrm{B}$

$$
\frac{\Gamma\left[\left(\langle\Delta\rangle \circ_{1 r}\left\langle\Delta^{\prime}\right\rangle\right)\right] \Rightarrow \mathrm{t}: \mathrm{C}}{\Gamma\left[\left\langle\left(\Delta \circ_{1 r} \Delta^{\prime}\right)\right\rangle\right] \Rightarrow \mathrm{t}: \mathrm{C}}\left[\mathrm{K}\left(\bullet_{1 r}\right)\right]
$$

b. $\mathrm{K} * 2\left(\bullet_{1 l}\right): \diamond\left(\diamond \mathrm{A} \bullet \bullet_{1 l} \mathrm{~B}\right) \rightarrow \diamond \mathrm{A} \bullet_{1 l} \diamond \mathrm{B}$

$$
\frac{\Gamma\left[\left(\langle\Delta\rangle \circ_{1 l}\left\langle\Delta^{\prime}\right\rangle\right)\right] \Rightarrow \mathrm{t}: \mathrm{C}}{\Gamma\left[\left\langle\left(\langle\Delta\rangle \circ_{1 l} \Delta^{\prime}\right)\right\rangle\right] \Rightarrow \mathrm{t}: \mathrm{C}}\left[\mathrm{K}^{* 2} 2\left(\bullet_{1 l}\right)\right]
$$

${ }^{28}$ Assuming that structural rules are formulated using only the unary connective $\diamond$ and the $\bullet_{i}$ from the logical vocabulary of the categorial language, there is the following back-and-forth translation between the two representations. A rule $\mathrm{A} \rightarrow \mathrm{B}$ in the algebraic format corresponds to a rule of inference that admits to replace a subterm $\Delta^{\prime}$ in the premise by $\Delta$ in the conclusion, with $\Delta$ and $\Delta^{\prime}$ the equivalences of $\mathrm{A}$ and $\mathrm{B}$, respectively:

$$
\mathrm{A} \rightarrow \mathrm{B} \leadsto \frac{\Gamma\left[\Delta^{\prime}\right] \Rightarrow \mathrm{t}: \mathrm{C}}{\Gamma[\Delta] \Rightarrow \mathrm{t}: \mathrm{C}} .
$$


c. $\mathrm{K} 1\left(\bullet_{0}\right): \diamond\left(\mathrm{A} \bullet_{0} \mathrm{~B}\right) \rightarrow \diamond \mathrm{A} \bullet_{0} \mathrm{~B}$

$$
\frac{\Gamma\left[\left(\langle\Delta\rangle \circ_{0} \Delta^{\prime}\right)\right] \Rightarrow \mathrm{t}: \mathrm{C}}{\Gamma\left[\left\langle\left(\Delta \circ_{0} \Delta^{\prime}\right)\right\rangle\right] \Rightarrow \mathrm{t}: \mathrm{C}}\left[\mathrm{K} 1\left(\bullet_{0}\right)\right]
$$

d. $\mathrm{K}\left(\bullet_{2}\right): \diamond\left(\mathrm{A} \bullet_{2} \mathrm{~B}\right) \rightarrow \diamond \mathrm{A} \bullet_{2} \diamond \mathrm{B}$

$$
\frac{\Gamma\left[\left(\langle\Delta\rangle \circ_{2}\left\langle\Delta^{\prime}\right\rangle\right)\right] \Rightarrow \mathrm{t}: \mathrm{C}}{\Gamma\left[\left\langle\left(\Delta \circ_{2} \Delta^{\prime}\right)\right\rangle\right] \Rightarrow \mathrm{t}: \mathrm{C}}\left[\mathrm{K}\left(\bullet_{2}\right)\right]
$$

e. $\mathrm{K}(\mathrm{l} / \mathrm{rd}): \mathrm{A} \bullet_{1 l} \mathrm{~B} \rightarrow \mathrm{A} \bullet_{r d} \mathrm{~B}$

$$
\frac{\Gamma\left[\left(\Delta \circ_{r d} \Delta^{\prime}\right)\right] \Rightarrow \mathrm{t}: \mathrm{C}}{\Gamma\left[\left(\Delta \circ_{1 l} \Delta^{\prime}\right)\right] \Rightarrow \mathrm{t}: \mathrm{C}}[\mathrm{K}(\mathrm{l} / \mathrm{rd})]
$$

f. $\mathrm{K}^{*}\left(\bullet_{1 l}\right): \diamond\left(\left(\diamond \mathrm{A} \bullet_{r d} \mathrm{~B}\right) \bullet_{1 l} \mathrm{C}\right) \rightarrow \diamond\left(\diamond \mathrm{A} \bullet_{r d} \mathrm{~B}\right) \bullet_{1 l} \diamond \mathrm{C}$

$$
\frac{\Gamma\left[\left(\left\langle\langle\Delta\rangle \circ_{r d} \Delta^{\prime}\right\rangle \circ_{1 l}\left\langle\Delta^{\prime \prime}\right\rangle\right)\right] \Rightarrow \mathrm{t}: \mathrm{C}}{\Gamma\left[\left\langle\left(\langle\Delta\rangle \circ_{r d} \Delta^{\prime}\right) \circ_{1 l} \Delta^{\prime \prime}\right\rangle\right] \Rightarrow \mathrm{t}: \mathrm{C}}\left[\mathrm{K}^{*}\left(\bullet_{1 l}\right)\right]
$$

g. $\mathrm{K} * 2\left(\bullet_{r d}\right): \diamond\left(\diamond \mathrm{A} \bullet_{r d} \mathrm{~B}\right) \rightarrow \diamond \mathrm{A} \bullet_{r d} \diamond \mathrm{B}$

$$
\frac{\Gamma\left[\left(\langle\Delta\rangle \circ_{r d}\left\langle\Delta^{\prime}\right\rangle\right)\right] \Rightarrow \mathrm{t}: \mathrm{C}}{\Gamma\left[\left\langle\left(\langle\Delta\rangle \circ_{r d} \Delta^{\prime}\right)\right\rangle\right] \Rightarrow \mathrm{t}: \mathrm{C}}\left[\mathrm{K} * 2\left(\bullet_{r d}\right)\right]
$$

h. $\mathrm{K}^{*}\left(\bullet_{0}\right): \diamond\left(\mathrm{A} \bullet_{0}\left(\diamond \mathrm{B} \bullet_{r d} \mathrm{C}\right)\right) \rightarrow \diamond \mathrm{A} \bullet_{0} \diamond\left(\diamond \mathrm{B} \bullet_{r d} \mathrm{C}\right)$

$$
\frac{\Gamma\left[\left(\langle\Delta\rangle \circ_{0}\left\langle\left\langle\Delta^{\prime}\right\rangle \circ_{r d} \Delta^{\prime \prime}\right\rangle\right)\right] \Rightarrow \mathrm{t}: \mathrm{C}}{\Gamma\left[\left\langle\Delta \circ_{0}\left(\left\langle\Delta^{\prime}\right\rangle \circ_{r d} \Delta^{\prime \prime}\right)\right\rangle\right] \Rightarrow \mathrm{t}: \mathrm{C}}\left[\mathrm{K}^{*}\left(\bullet_{0}\right)\right]
$$

Mixed Permutation Rules:

a. MP1: $\left(\mathrm{A} \bullet{ }_{1 l} \diamond \mathrm{B}\right) \bullet_{i} \mathrm{C} \rightarrow\left(\mathrm{A} \bullet \bullet_{i} \mathrm{C}\right) \bullet_{1 l} \diamond \mathrm{B} \quad i=0$ or $i=2$

$$
\frac{\Gamma\left[\left(\left(\Delta \circ_{i} \Delta^{\prime \prime}\right) \circ_{1 l}\left\langle\Delta^{\prime}\right\rangle\right)\right] \Rightarrow \mathrm{t}: \mathrm{C}}{\Gamma\left[\left(\left(\Delta \circ_{1 l}\left\langle\Delta^{\prime}\right\rangle\right) \circ_{i} \Delta^{\prime \prime}\right)\right] \Rightarrow \mathrm{t}: \mathrm{C}}[\mathrm{MP} 1]
$$

b. MP2: $\left(\mathrm{A} \bullet_{r d} \mathrm{~B}\right) \bullet_{1 l} \mathrm{C} \rightarrow\left(\mathrm{A} \bullet_{1 l} \mathrm{C}\right) \bullet_{r d} \mathrm{~B}$

$$
\frac{\Gamma\left[\left(\left(\Delta \circ_{1 l} \Delta^{\prime \prime}\right) \circ_{r d} \Delta^{\prime}\right)\right] \Rightarrow \mathrm{t}: \mathrm{C}}{\Gamma\left[\left(\left(\Delta \circ_{r d} \Delta^{\prime}\right) \circ_{1 l} \Delta^{\prime \prime}\right)\right] \Rightarrow \mathrm{t}: \mathrm{C}}[\mathrm{MP} 2]
$$

c. MP3: $\left(\mathrm{A} \bullet_{r d} \mathrm{~B}\right) \bullet_{0} \mathrm{C} \rightarrow\left(\mathrm{A} \bullet{ }_{0} \mathrm{C}\right) \bullet_{r d} \mathrm{~B}$

$$
\frac{\Gamma\left[\left(\left(\Delta \circ_{0} \Delta^{\prime \prime}\right) \circ_{r d} \Delta^{\prime}\right)\right] \Rightarrow \mathrm{t}: \mathrm{C}}{\Gamma\left[\left(\left(\Delta \circ_{r d} \Delta^{\prime}\right) \circ_{0} \Delta^{\prime \prime}\right)\right] \Rightarrow \mathrm{t}: \mathrm{C}}[\mathrm{MP} 3]
$$


Mixed Contraction Rule:

a. $\mathrm{MC}:\left(\mathrm{A} \bullet \bullet_{0} \mathrm{~B}\right) \bullet_{1 l} \diamond \mathrm{C} \rightarrow\left(\mathrm{A} \bullet_{1 l} \diamond \mathrm{C}\right) \bullet_{0}\left(\mathrm{~B} \bullet \bullet_{1 l} \diamond \mathrm{C}\right)$

$$
\frac{\Gamma\left[\left(\left(\Delta_{1} \circ_{1 l}\left\langle x: \Delta_{3}\right\rangle\right) \circ_{0}\left(\Delta_{2} \circ_{1 l}\left\langle y: \Delta_{3}\right\rangle\right)\right)\right] \Rightarrow \mathrm{t}: \mathrm{C}}{\Gamma\left[\left(\left(\Delta_{1} \circ_{0} \Delta_{2}\right) \circ_{1 l}\left\langle x: \Delta_{3}\right\rangle\right)\right] \Rightarrow \mathrm{t}[y \leftarrow x]: \mathrm{C}}[\mathrm{MC}]
$$

The types vp and tv are defined in the usual way.
a. $\quad \mathrm{vp}={ }_{\text {def. }} \mathrm{np} \backslash_{1 r} \mathrm{~s}$
b. $\quad \mathrm{tv}={ }_{\text {def. }} \mathrm{vp} /{ }_{1 l} \mathrm{np}$

Let $\Psi$ be the set of structural rules given above. The logic to be used in the sections to follow is NL( $\diamond)$ plus the structural rules in $\Psi$. This logic will be referred to as $\mathrm{NL}(\diamond)+\Psi$. The notion of Lambek Grammar is defined as follows. ${ }^{29}$

DEFINITION 4 Lambek Grammar Let $\Theta$ be an alphabet. A Lambek grammar $G$ is a triple $(\Omega, L E X, S)$, where $\Omega$ is a finite set (i.e. the set of basic categorial formulas), LEX is a finite subrelation of $\Theta^{+} \times \operatorname{CAT}_{I}(\Omega)$ (with an index set I), and $S$ is a finite subset of $C_{A} A T_{I}(\Omega)$ (the designated categorial formulas).

For Edo, the designated categorial formula is $\square$ s. This is empirically motivated in Section 5.1. In the presence of a semantic component, one gets a term-labeled lexicon. LEX $\subseteq \Theta^{+} \times\left(\operatorname{CAT}_{I}(\Omega) \times\right.$ Term $)$. One has: if $\langle w,\langle A, t\rangle\rangle \in \operatorname{LEX}$ then $t \in \lambda$-term $\tau(A)$.

A Lambek grammar $\mathbf{G}$ determines a language over $\Theta$ in the following way. ${ }^{30}$

DEFINITION 5 Language determined by a Lambek Grammar Let $\boldsymbol{G}=\langle\Omega, L E X, S\rangle$ be a Lambek grammar over the alphabet $\Theta$. Then $\alpha \in L(G)$ iff there are $a_{1}, \ldots, a_{n} \in \Theta^{+},\left(A_{1}, \ldots, A_{n}\right) \in \operatorname{CAT}_{I}(\Omega)$, and $S \in S$ such that

(i) $\alpha=a_{1}, \ldots, a_{n}$

(ii) for all $i$ such that $1 \leq i \leq n:\left\langle a_{i}, A_{i}\right\rangle \in L E X$, and

(iii) $N L(\diamond)+\Psi \vdash\left(A_{1}, \ldots, A_{n}\right) \Rightarrow S$.

${ }^{29}$ See Jäger (2005) for details from which the following definitions are adapted.

${ }^{30}$ Note that the lexicon is defined without reference to the Curry-Howard correspondence. The adaption of the definition to labeled sequents is straightforward. 
In Definition $5, \vdash$ is the relation of derivability relative to $\mathrm{NL}(\diamond)+\Psi .\left(\mathrm{A}_{1}, \ldots, \mathrm{A}_{n}\right)$ is a binary bracketed structure. If for a sequent $\left(\mathrm{A}_{1}, \ldots, \mathrm{A}_{n}\right) \Rightarrow \mathrm{S}$ such that $\mathrm{NL}(\diamond)+\Psi \vdash\left(\mathrm{A}_{1}, \ldots, \mathrm{A}_{n}\right) \Rightarrow \mathrm{S} \in \mathrm{S}$ there is a sequence $\alpha=\mathrm{a}_{1}, \ldots, \mathrm{a}_{n}$ such that for all $i$ with $1 \leq i \leq n$ : $\left\langle\mathrm{a}_{i}, \mathrm{~A}_{i}\right\rangle \in \mathrm{LEX}$, the sequent $\left(\mathrm{A}_{1}, \ldots, \mathrm{A}_{n}\right) \Rightarrow \mathrm{S}$ is said to admit of a lexical substitution, meaning that the sequent is an element of $L(G)$, i.e. the language determined by G. Basing the definition of terms (or structures) $\Sigma$ not only on the set $\Omega$ of categorial formulas but also on the subset of $\Theta^{+}$consisting of those elements occurring in the domain of $\operatorname{LEX}$ (i.e. the set $\left\{\mathrm{a} \in \Theta^{+} \mid\right.$there is an $\mathrm{A}$ in $\operatorname{CAT}_{I}(\Omega)$ s.t. $\left.\langle\mathrm{a}, \mathrm{A}\rangle \in \mathrm{LEX}\right\}=$ $\operatorname{dom}(\mathrm{LEX})$ ), an element $\langle\mathrm{a}, \mathrm{A}\rangle \in \mathrm{LEX}$ can be taken as a lexical axiom, written a $\Rightarrow$ A.

The way modalities are used in this article was first introduced in Moortgat (1996) and extended in Moortgat (1997) and Kurtonina (1995). Kurtonina and Moortgat (1997) develop a theory of communication between categorial type logics. It is shown how one can recover the structural discrimination of a weaker logic from within a stronger one (structural inhibition) and how one can reintroduce structural relaxation of stronger logics within weaker ones.

Monomodal NL is sound and complete with respect to the interpretation of unary and binary connectives given in (96) (see Moot and Retoré 2012 for a proof and details). For the multimodal variant, the situation is more complicated (see again Moot and Retoré 2012 for details and references cited therein). NL is strictly context-free and has a polynomial recognition problem. The move to a multimodal variant without structural rules does not lead beyond context-free recognition. The relation between multimodality, structural rules and unary modalities is more complicated. If no copying and deletion are allowed for structural rules and if the unary modalities are non-expanding, one obtains the full expressivity of context-sensitive grammars, and the PSPACE complexity that goes with it. If no restrictions are imposed on structural rules (specifically, if one allows copying and deletion operations), one obtains the expressivity of unrestricted rewriting systems. 


\section{AGKNOWLEDGEMENTS}

This work was supported by the CRC991 "The Structure of Representations in Language, Cognition, and Science" funded by the German Research Foundation (DFG). We are grateful to the reviewers of this paper for their valuable comments and suggestions.

\section{REFERENGES}

Rebecca AGHEYISI (1986), Edo-English dictionary, Ethiope Publishers, Benin City.

Alexandra AikhenVAld (2006), Serial verb constructions, in Alexandra AIKHENVALD and Robert Malcolm Ward DiXON, editors, Serial verb constructions in typological perspective, pp. 1-68, Oxford University Press.

Nicholas ASHER and Alex LASCARIDES (2001), Logics of conversation, Cambridge University Press.

Mark BAKER and Osamuyimen Thompson STEWART (1999), On double headedness and the anatomy of the clause, ms. Rutgers University.

Mark BAKER and Osamuyimen Thompson STEWART (2001), A serial verb construction without constructions, ms. Rutgers University.

Jürgen BoHNEMEYER, Nicholas J. ENFIELD, James ESSEgBEY, Iraide IBARRETXE-ANTUÑANO, Sotaro KitA, Friederike LÜPKE, and Felix K. AMEKA (2007), Principles of event segmentation in language: The case of motion events, Language, 83(3):495-532.

Oliver BotT and Wolfgang STERNEFELD (2017), An event semantics with continuations for incremental interpretation, Journal of Semantics, 34(2):201-236.

Lucas CHAMPOLLION (2015), The interaction of compositional semantics and event semantics, Linguistics and Philosophy, 38(1):31-66.

Robert Malcolm Ward DiXON (2006), Serial verb constructions: conspectus and coda, in Alexandra AIKHENVALD and Robert Malcolm Ward Dixon, editors, Serial verb constructions - a cross-linguistic typology, pp. 338-350, Oxford University Press.

William FOLEY (1991), The Yimas language of New Guinea, Stanford University Press. 
William A. FOLEY (2010), Events and serial verb constructions, in Mengistu AMBERBER, Brett BAKER, and Mark HARVEY, editors, Complex predicates: cross-linguistic perspectives on event structure, pp. 79-109, Cambridge University Press.

Thomas GAMERSCHLAG (2005), Komposition und Argumentstruktur komplexer Verben. Eine lexikalische Analyse von Verb-Verb-Komposita und Serialverbkonstruktionen, volume 61 of Studia grammatica, Akademie Verlag. Jane GRIMSHAW (1990), Argument structure, MIT Press.

Ken HALE and Samuel J. KEYSER (1993), On argument structure and the lexical expression of syntactic relations, in Ken HALE and Samuel J. KEYSER, editors, The view from building 20, pp. 53-109, MIT Press.

Lars Hellan, Dorothee BeERMANN, and Eli SÆTHERØ ANDENES (2003), Towards a typology of serial verb constructions in Akan, in Mary Esther KROPP DAKUBU and Kweku E. OSAM, editors, Proceedings of the annual colloquium of the Legon-Trondheim linguistics project, Studies in the languages of the Volta basin, pp. 61-86.

Gerhard JÄGER (2005), Anaphora and Type Logical Grammar, Trends in Logic 24, Springer.

Angelika KRATZER (1996), Severing the external argument from its verb, in Johan ROORYCK and Laurie ZARING, editors, Phrase Structure and the Lexicon, pp. 109-138, Kluwer.

Natasha KuRTONINA (1995), Frames and labels, Phd., OTS, University of Utrecht \& ILLC, University of Amsterdam.

Natasha KurtoninA and Michael Moortgat (1997), Structural control, in Patrick BLACKBURN and Maarten DE RIJKE, editors, Specifying syntactic structures, Studies in Language, Logic and Information, pp. 75-114, CSLI Press. Godehard LINK (1998), Algebraic Semantics in Language and Philosophy, CSLI Publications, Stanford.

Michael Moortgat (1996), Multimodal linguistic inference, Journal of Logic, Language and Information, 5(3):349-385.

Michael Moortgat (1997), Categorial type logics, in Johan van BENTHEM and Alice ter MEULEN, editors, Handbook of logic and language, pp. 93-177, North-Holland.

Michael Moortgat and Richard Oerhle (1993), Adjacency, dependency and order, in Proceedings of the 9th Amsterdam Colloquium, pp. 447-466.

Richard MOOT and Christian RETORÉ (2012), The logic of categorial grammars: a deductive account of natural language syntax and semantics, Springer.

Glyn MORRILL (1994), Type Logical Grammar, Kluwer. 
Glyn MORRILL (1995), Discontinuity in categorial grammar, Linguistics and Philosophy, 18(2):175-219.

Glyn MORRILL (2011), Categorial grammar: logical syntax, semantics, and processing, Oxford University Press.

Ralf NAUMANN and Wiebke PETERSEN (2019), Bridging inferences in a dynamic frame theory, in Alexandra Silva, Sam Staton, Peter Sutton, and Carla UMBACH, editors, Language, logic, and computation, pp. 228-252, Springer. Ota OGIE (2010), Multi-verb constructions in Edo, VDM Verlag.

Osamuyimen Thompson STEWART (1996), Adverb placement and the structure of the serial verb construction, in Proceedings of the North East Linguistic Society 26, pp. 409-423.

Osamuyimen Thompson STEWART (2001), The serial verb construction parameter, Garland.

Yoad WINTER and Joost ZWARTs (2011), Event semantics and abstract categorial grammar, in Makoto KANAZAWA, András KoRNAI, Marcus KRACHT, and Hiroyuki SEKI, editors, The mathematics of language, pp. 174-191, Springer.

\section{Ralf Naumann}

(iD) $0000-0002-0222-5540$

naumann@phil-fak.uni-duesseldorf.de

\section{Thomas Gamerschlag}

(iD) $0000-0 \odot \odot 1-7996-9137$

gamer@phil-fak.uni-duesseldorf.de

Heinrich-Heine-Universität Düsseldorf

Düsseldorf, Germany

Ralf Naumann and Thomas Gamerschlag (2020), Serial verb constructions and covert coordinations in Edo - an analysis in Type Logical Grammar, Journal of Language Modelling, 8(2):337-413

(dii) https://dx.doi.org/10.15398/jlm.v8i2.221

This work is licensed under the Creative Commons Attribution 4.0 Public License. (c) (i) http://creativecommons.org/licenses/by/4.0/ 